UNIVERSIDADE DE SÃO PAULO

I N S T I T U T O DE QUÍM I C A

\title{
ESTUDO DAS MODIFICAÇÕES ESTRUTURAIS INDUZIDAS PELA RADIAÇÃO DE ALTA ENERGIA SOBRE O COPOLÍMERO P(VDF-TrFE)
}

\section{Hector Alexandre Chaves Gil Tese de Doutoramento}

Prof. Dr. Yoshio Kawano

Orientador

1998

São Paulo 
"Estudo das Modificaçōes Estruturais Induzidas Pela Radiação de Alta Energia Sobre 0 Copolímero P(VDF-TrFE)".

\section{HECTOR ALEXANDRE CHAVES GIL}

Tese de Doutorado submetida ao Instituto de Química da Universidade de São Paulo como parte dos requisitos necessários à obtenção do grau de Doutor em Ciências - Área: Físico-Química.

Aprovada por:

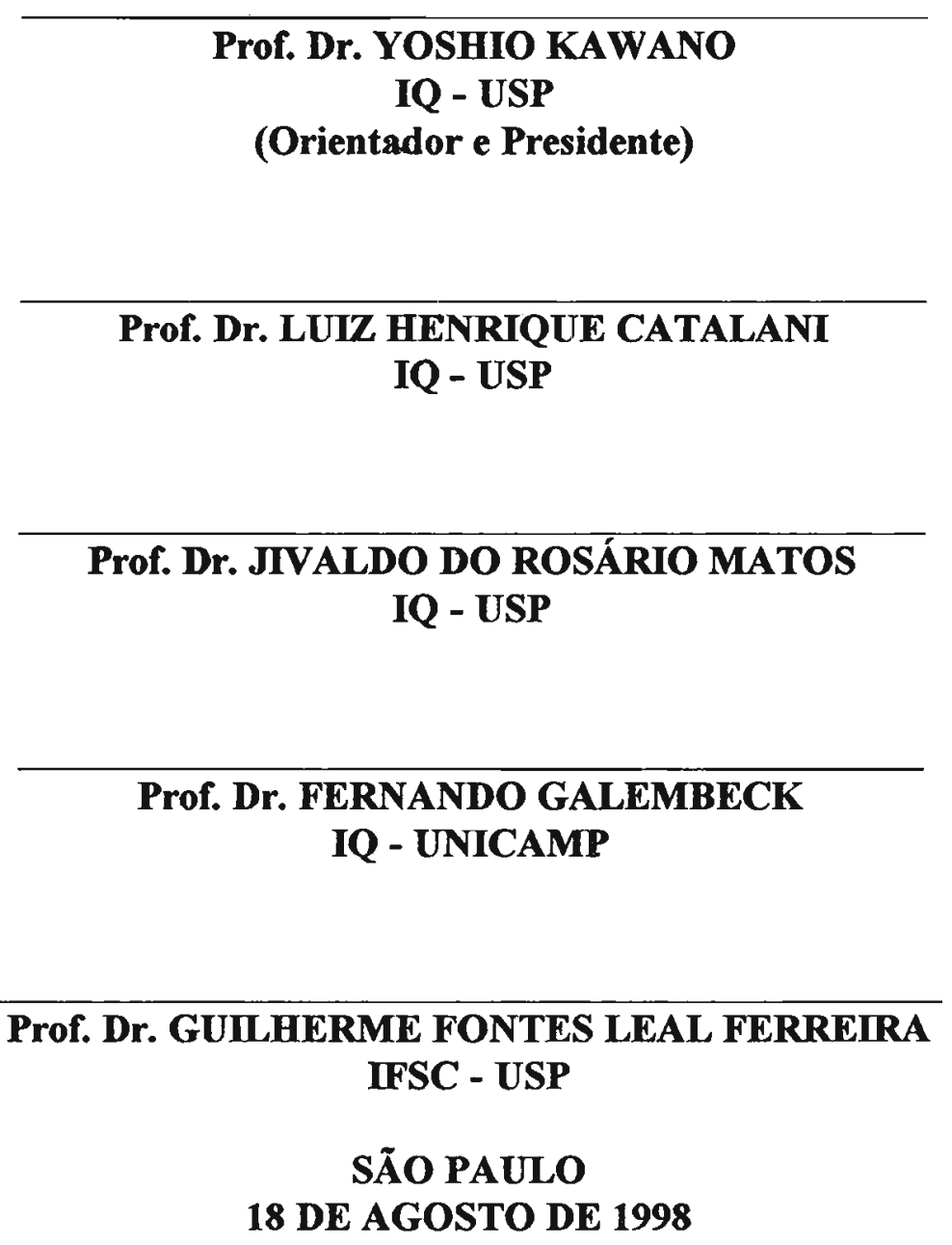


Nós não conhecemos.

Nós só podemos fazer palpites.

E os nossos palpites são guiados pela

fé

não cientifica,

metafisica

em leis e regularidades que podemos

descobrir,

des-cobrir.

$O$ velho ideal cientifico de episteme,

Conhecimento certo,

demonstrável,

provou ser um ídolo.

A exigência de objetividade, em ciência,

exige que cada declaração científica permaneça,

para sempre,

tentativa

Karl Popper 
“O corpo diz para o seu eu: 'Sinta dor aqui!' Então o eu sofre e pensa em como parar de sofrer - e é isso que o faz pensar. O corpo diz para o seu eu: 'Sinta prazer aqui!' Então o eu sente prazer e pensa no que fazer para ter de novo o prazer - e é isso que o faz pensar..."

Nietzsche 


\section{Agradecimentos}

Àqueles que, como eu, ainda tentam crer na humanidade... apesar de alguns.

A todos aqueles que, como eu, se sentem indignados com a injustiça.

À Fátima, companheira de sempre, incansável e forte.

Ao meu melhor amigo, e filho, Otávio.

Aos meus pais e meus irmãos.

Ao Prof. Yoshio Kawano, uma vez mais...

Ao Prof. Sala, pela presença exemplar.

Ao Prof. Machado, com quem reaprendi muito do que acreditava já saber.

À Prof. - Dalva Lúcia, sempre amiga.

Ao Prof. Álvaro, pelo incentivo.

Aos amigos:

Luís Geraldo e Elena, Paola e Paulo, Norba e Lúcia, Rosana e Pimenta, Marcinha e Henrique, Brolo e familia, Alfredo e familia, Yoshinori, Guarabira. André e Rute, Henrique (pp) e familia, Mauro, Luiz Carlos, Edu, Ricardo, Mônica, Lucidalva, Sílvia Helena, Sérgio, Laércio, Valdir, Terezinha, Márcia, Joel,Beth, Marina, Suzana, Elzita, Paulinho, Nivaldo, Vitor, Michael, Fejfar, Rodrigo, Jailson, Pedro Kaloubek, Mesquita, Rangel, Bertevello, Cristina, Rubens Gedraite, Newton Libânio e Ana, Nilson, Rosana Bretas, Sandra, Luís Roberto, Gerald, Rosilene, Perci, Edenailton, Antônia, Chrisitian, Melina, Adriana, Solange, André, Adelino, e a todos aqueles de quem não me recordo nesse momento de digitação, mas que considero igualmente.

A todos aqueles que foram, são, ou serão meus alunos, e com quem tive, tenho ou terei oportunidade de compartilhar e re-aprender.

Ao Prof. Jivaldo pelas facilidades concedidas para a utilização do Bomem Michelson MB-102.

Ao CNPq pela bolsa.

Enfim... 


\section{Índice}

Lista de Abreviaturas $\quad$ i

Resumo ii

Abstract iv

1 Capítulo 1: Considerações Gerais 1

1.1 A Busca do Modelo Macromolecular 1

1.2 Objetivos 2

1.3 Modificações de Sistemas Poliméricos 3

1.3.1 Modificações Através de Radiações de Alta Energia 4

1.3.2 Modificações de Superfícies por Enxertia 11

1.3.3 Modificações de Superfícies por Tratamento de Plasma $\quad 12$

1.3.4 Tratamentos Térmicos e Deformações Mecânicas 15

1.4 Principais Técnicas de Caracterização de Sistemas Poliméricos 17

1.5 Sobre as Características dos Sistemas Estudados 20

2 Capítulo 2: Parte Experimental 28

$\begin{array}{lll}2.1 & \text { Materiais Utilizados } & 28\end{array}$

2.1.1 Filmes do Copolímero P(VDF-TrFE) na Razão molar 70:30 28

2.1.2 Filmes do Copolímero P(VDF-TrFE) na Razão molar 60:40 29

2.1.3 Outras Razões Molares do Copolímero P(VDF-TrFE) 30

2.2 Técnicas Experimentais 30

2.2.1 Irradiação das Amostras com Raios-X

2.2.2 Difração de Raios-X $X 1$

2.2.3 Espectros Vibracionais na Região do Infravermelho 32

2.2.4 Espectros Vibracionais Raman 32

2.2.5 Espectroscopia de Absorção Eletrônica 33 
2.2.6 Calorimetria Exploratória Diferencial (DSC)

2.2.7 Termogravimetria (TG)

3 Capítulo 3: Resultados e Discussão 35

3.1 Difração de Raios-X 35

3.2 Espectros Vibracionais na Região do Infravermelho 49

3.2.1 Espectros Fotoacústicos na Região do Infravermelho 49

3.2.2 Espectros de Transmitância na Região do Infravermelho $\quad 60$

$\begin{array}{lll}3.3 & \text { Espectros Vibracionais Raman } & 67\end{array}$

3.4 Espectroscopia de Absorção Eletrônica 77

3.5 Calorimetria Exploratória Diferencial (DSC) 81

3.6 Termogravimetria (TGA) 89

4 Capítulo 4: Conclusões 91

5 Bibliografia 95

6 Curriculum Vitae 103 


\section{Lista de Abreviaturas}

VDF

TrFE

P(VDF-TrFE)

$\mathrm{T}_{\mathrm{C}}$

IR

FT

PAS

DSC

TG

UV

$\mathrm{T}_{\mathrm{g}}$

$T_{m}$

PTFE

PVC

XPS

ESCA

ATR

NMR

EPR

FEP

PFA

PVDF

PVF

$\mathrm{k}_{\mathrm{t}}$

P(VDF-VF)

FA

$F \beta$

FP

$\mathrm{d}_{\mathrm{ij}}$

I

$\Delta \mathrm{H}_{\mathrm{m}}$

$\Delta S_{\mathrm{m}}$
Fluoreto de vinilideno

Trifluoretileno

Poli(fluoreto de vinilideno-co-trifluoretileno)

Temperatura de Curie

Infravermelho

Transformada de Fourier

Espectroscopia Fotoacústica

Calorimetria Exploratória Diferencial

Termogravimetria

Ultravioleta

Temperatura de Transição Vítrea

Temperatura de Fusão

Politetrafluoretileno

Poli(cloreto de vinila)

Espectroscopia Fotoeletrônica de Raios-X

Espectroscopia Eletrônica para Análise Química

Reflexão Total Atenuada

Ressonância Magnética Nuclear

Ressonância Paramagnética Eletrônica

Hexafluorpropileno

Perfluorpropilviniléter

Poli(fluoreto de vinilideno)

Poli(fluoreto de vinila)

Fator de acoplamento eletromecânico

Poli(fluoreto de vinilideno-co-fluoreto de vinila)

Fase A

Fase $\beta$

Fase Paraelétrica

Constante Piezoelétrica

Intensidade

Variação da Entalpia de Fusão

Variação da Entropia de Fusão 


\section{Resumo}

Filmes de poli(fluoreto de vinilideno-co-trifluoretileno), $\mathrm{P}(\mathrm{VDF}-\mathrm{TrFE})$, com uma razão molar 70/30 de VDF e TrFE, respectivamente, foram expostos à radiação-X sob vácuo em uma ampla faixa de doses de irradiação. Este é um copolímero estatístico e semi-cristalino que possui a especial característica de cristalizar espontaneamente numa estrutura ferroelétrica. Ele também possui uma transição de fase ferro-paraelétrica detectável, definida como a temperatura de Curie $\left(\mathrm{T}_{\mathrm{c}}\right)$. Devido a estas características tem despertado considerável interesse, em especial na área da eletrônica como elemento transdutor.

As modificações induzidas foram investigadas por espectroscopia fotoacústica no infravermelho (FT-IR/PAS), assim como FT-IR por transmitância, calorimetria exploratória diferencial (DSC), termogravimetria (TG), difração de raios-X, UV/Visível e espectroscopia Raman.

As técnicas espectroscópicas vibracionais (fotoacústica no IR, Raman e absorção no IR) foram utilizadas na identificação de bandas relacionadas às regiões cristalinas e amorfas, formação e rompimento de ligações e presença de novos grupos funcionais.

Nos espectros IR e Raman são observadas duas bandas que estão relacionadas às regiões cristalinas e sofrem mudanças nas suas intensidades relativas de acordo com a dose de radiação. Essas mudanças podem ser interpretadas como aumento ou diminuição do grau de cristalinidade, e também em termos de modificações de arranjos cristalinos.

A difração de raio-X mostrou o aparecimento de um pico, próximo àquele da fase ferroelétrica, sob aumento da dose de radiação, devido a um processo de modificação do arranjo cristalino acima da dose de $480 \mathrm{kGy}$. 
Foi observado um aumento de intensidade no referido pico de difração, correspondendo a um aumento do grau de cristalinidade da amostra.

As curvas de DSC mostraram picos endotérmicos correspondentes a fusão e transições de fases que, através de suas variações, possibilitam avaliar os efeitos da irradiação com raios- $X$.

Os espectros UV/Visível mostraram absorções dos cromóforos cujas intensidades de banda aumentam com a dose de radiação e diminuem durante o envelhecimento da amostra.

Os dados indicam que a radiação- $\mathrm{X}$ induz uma modificação no arranjo cristalino do $\mathrm{P}(\mathrm{VDF}-\mathrm{TrFE})$. Tal modificação, é provavelmente uma mudança de estrutura ferroelétrica para outra, paraelétrica. 


\begin{abstract}
Poly(vinylidene fluoride-co-trifluoroethylene) films, P(VDF-TrFE),
\end{abstract} with a molar ratio 70/30 of VDF and TrFE units, respectively, were exposed to $\mathrm{X}$-ray radiation under vacuum in a wide range of irradiation doses. This is a statistic semi-crystalline copolymer and displays the unique feature of a spontaneous crystallization into a ferroelectric structure. It also possesses a detectable ferro-paraelectric transition, the Curie temperature $\left(T_{c}\right)$. Due to these characteristics considerable interest in such copolymer has been generated, specially in electronics as a transducer element.

The induced modifications were investigated by Fourier transform infrared photoacoustic spectroscopy (FT-IR/PAS) as well as transmittance FT-IR, differential scanning calorimetry (DSC), thermogravimetry (TG), X-ray diffraction, UV/Visible and Raman spectroscopies.

The spectroscopic vibrational techniques (FT-IR/PAS, FT-IR and Raman) were used to identify bands related to crystalline and amorphous regions, bond formation, bond scission and presence of new functional groups.

In both IR and Raman spectra were observed a couple of bands related to the crystalline regions that undergo changes of relative intensities with the radiation dose. These changes may be interpreted as an increase or decrease of the crystallinity degree, and also modifications of crystal structure.

X-ray diffraction showed a new peak, close to that of the ferroelectric phase, under increasing radiation doses, due to a modification of crystal structure process above $480 \mathrm{kGy}$ dose. An increase in the intensity of the 
former diffraction peak was observed, corresponding to an increase in the crystallinity degree.

The DSC curves showed the endothermic peaks corresponding to the melting and the phase transitions, whose variations allow an evaluation of the effects of X-ray radiation.

UV/Visible spectra showed chromophores absorptions whose band intensities increase by radiation dose and decrease during sample's aging.

The data indicate that $\mathrm{P}(\mathrm{VDF}-\mathrm{TrFE})$ under $\mathrm{X}$-ray radiation exposition undergoes a crystal structure modification, probably a change of a ferroelectric structure to another one, paraelectric. 


\section{Capítulo 1: Considerações Gerais}

\section{1- A Busca do Modelo Macromolecular}

Em dias remotos, quase perdidos na memória do homem de ciência, o então filósofo clamava pela ordem na natureza. A matéria, algo tão variado quanto misterioso, haveria de possuir uma estrutura, uma composição, propriedades que de ambas dependessem, logicamente. A busca pelo modelo lógico foi longa, e tão antiga quanto a história da civilização.

Em dias mais recentes, mas ainda distantes em nossas memórias, a busca pela ordem, por leis bem definidas na natureza nos leva a Proust e às composições constantes. Berthollet e bertholitos foram, momentaneamente, esquecidos.

Apesar da ordem atômica simples, mas não simplória, de Dalton, Avogadro clamou por algo maior, molecular. A molécula, provavelmente, não era o que a ciência esperava da natureza. Ela pode assumir muitas formas, variadas estruturas moleculares, e portanto desordens intrínsecas. Quase sessenta anos separam o modelo de Avogadro de sua aceitação pela ciência, e este não mais estava lá para ver. Cannizzaro estava. Não fosse ele, talvez cem anos se passassem.

Repete-se a história ao final do século XIX e início do século XX, agora com relação à extensão de algumas moléculas. Que tamanho as moléculas poderiam assumir? Kekulé e Fischer já acreditavam que as biomoléculas pudessem ser na verdade macromoléculas, pensando na relação entre estrutura e propriedades, mas somente em 1920 Hermann Staudinger propõe a estrutura macromolecular dos polímeros [1]. 
$\mathrm{Na}$ busca pela ordem, pela hipótese mais simples, o modelo de Staudinger sofreu resistências por parte de muitos. Contudo, ao contrário de Avogadro, Staudinger viu seu modelo estrutural triunfar, sendo laureado com o prêmio Nobel de Química em 1953, por suas descobertas no campo de química macromolecular.

$\mathrm{O}$ século $\mathrm{XX}$ viu avanços nunca antes imaginados na ciência, dentre eles a elucidação de estruturas moleculares, macromoleculares e supramoleculares, arranjos cristalinos e amorfos, por meio de novas técnicas de investigação estrutural. Através de tais técnicas melhores sínteses puderam ser realizadas, e os polímeros sintéticos tornaram-se, então, uma das mais importantes classes de materiais envolvendo homopolímeros, copolímeros, terpolímeros, ionômeros, compósitos e blendas poliméricas dentre outros. Os sistemas macromoleculares consagram-se então dentre aqueles em que existe uma importante relação entre estrutura e propriedades, impressionantes e variadas organizações intra e intermolecular, macro e microestrutural, originando surpreendentes propriedades, muitas das quais ainda não estudadas ou mesmo percebidas.

\section{2- Objetivos}

O trabalho apresentado nesta tese usa as técnicas de investigação estrutural para discutir e propor um modelo sobre a interação e os efeitos da radiação com a matéria, filmes do copolímero poli(fluoreto de vinilideno-cotrifluoretileno), $\mathrm{P}(\mathrm{VDF}-\mathrm{TrFE})$. É uma pequena contribuição, mas é parte dessa história. 


\section{3- Modificações de Sistemas Poliméricos}

Modificações induzidas em polímeros sintéticos vêm despertando crescente atenção de pesquisadores envolvidos na área das ciências dos materiais nos últimos anos, haja visto suas importantes aplicações científicotecnológicas que envolvem desde alterações da cristalinidade e das propriedades mecânicas, elétricas e ópticas do material, até estudos sobre adsorção, adesão, catálise, reatividade e biocompatibilidade. O interesse e desenvolvimento nesse campo foi contemplado pelo avanço das técnicas instrumentais para a caracterização dos materiais modificados, as quais permitem a compreensão dos mecanismos e, desta forma, o planejamento dos processos de modificação e suas aplicações nos mais diferentes campos do conhecimento.

De forma geral, pode-se classificar as modificações sobre polímeros como internas e de superfície. Assim, modificações internas, ou de "bulk", são aquelas que alteram propriedades intrínsecas do material, como: massa molar, conformação, estrutura ou fase cristalina, que, conseqüentemente, alteram as propriedades mecânicas $\mathrm{e}$ as temperaturas de transição caracteristicas, $T_{g}$ (transição vítrea) e $T_{m}$ (fusão). Por outro lado, modificações de superfície alteram propriedades típicas da interface polímero-meio, como: potenciais de superficie, polaridade, hidrofilicidade, funcionalidade da superficie, reatividade, caráter ácido-base de Lewis e propriedades adesivas em geral. De fato, as técnicas de modificação permitem melhorar a performance de um polímero sintético comercial, através da combinação das propriedades estruturais internas e de superfície deste material. 
São várias as formas de alteração de polímeros sintéticos, conforme mostra a Figura 1, classificando-se as deformações mecânicas, tratamentos térmicos e exposições às radiações de alta energia (X e $\gamma$ ), como agentes de modificação interna, e, além destas, os feixes de íons e neutrons, radiações $\alpha$ e $\beta$, plasma e interação com substâncias reativas, como agentes de modificação de superfícies.

A seguir são discutidas algumas das principais técnicas de modificações e seus efeitos sobre os materiais poliméricos.

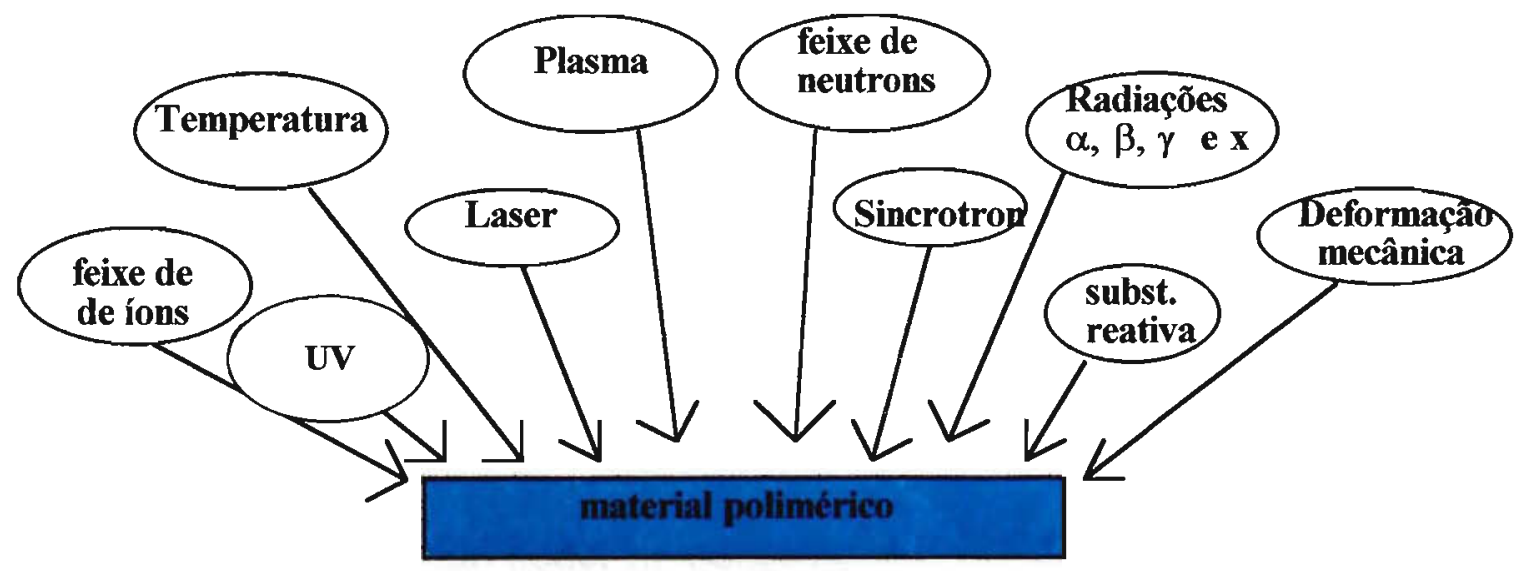

Figura 1: Possiveis agentes de modificação sobre um material polimérico.

\subsection{1- Modificações Através de Radiações de Alta Energia ( $\alpha, \beta, \gamma$ e X)}

Dentre as radiações ionizantes mais relevantes nos estudos de modificações de polímeros encontram-se:

- Partículas $\alpha$ : produzidas por aceleradores de íons positivos, possuem grande massa e energia (MeV) mas pequeno poder de penetração, interagindo de forma intensa com a superficie. 
- Radiação $\beta$ : radiação eletromagnética obtida a partir de radioisótopos como o ${ }^{90}$ Sr. Possui energia da ordem de MeV.

- Feixes de elétrons: são elétrons gerados a partir de aceleradores, possui energia da ordem de $\mathrm{MeV}$ com poder de penetração de alguns milímetros ( $<10 \mathrm{~mm}$ ). É utilizada em microlitografia e para a formação de ligações cruzadas em revestimentos de superfície.

- Radiação $\gamma$ : radiação eletromagnética obtida a partir de radioisótopos como o ${ }^{60} \mathrm{Co}$, também da ordem de $\mathrm{MeV}$ porém com grande poder de penetração $(>300 \mathrm{~mm})$. Tal radiação, mesmo em baixas doses, pode produzir mudanças estruturais no polímero.[2].

- Raios-X: radiação eletromagnética produzida pela desaceleração de elétrons de grande velocidade quando estes atingem um alvo metálico apropriado. Raios-X podem ser obtidos por uma lâmpada de raios-X ou através de um sincrotron, possuindo energia da ordem de algumas dezenas de $\mathrm{keV}$ e determinado poder de penetração.

- Feixes de neutrons e íons pesados: são produzidos por reatores nucleares, possuindo energia de alguns $\mathrm{MeV}$ e baixo poder de penetração. Interagem de forma intensa com a superfície sendo utilizados nos processos de gravação ou "etching" sobre superfícies poliméricas.

As radiações de alta energia são importantes agentes de modificação de materiais poliméricos, uma vez que são capazes de originar espécies reativas iônicas e/ou radicalares em tais materiais. Desta forma permitem a reatividade da superfície pelo contato com substâncias reativas (líquidas ou gasosas). A enxertia, por exemplo, utiliza este princípio como forma de inserção de cadeias (poliméricas ou oligoméricas) sobre a superfície. Muitas vezes, 
contudo, a simples irradiação do material na presença de ar o leva à oxidação com a formação de radicais oxil e peroxil, resultando finalmente em grupos carboxilatos, ou carbonilas, efeitos esses observados em polímeros perfluorados como o PTFE, conhecidos pela resistência química à oxidação e redução [3]. Na ausência de ar, as radiações de alta energia, por si só, são capazes de produzir modificações das características do polímero, seja na estrutura, como faz a radiação $\gamma$, seja na superfície, como fazem os feixes de ínns pesados e neutrons nos processos de "etching". Assim, são bem conhecidos os efeitos da interação das radiações de alta energia com os materiais poliméricos $[4,5,6]$ conforme ilustrado na Figura 2.
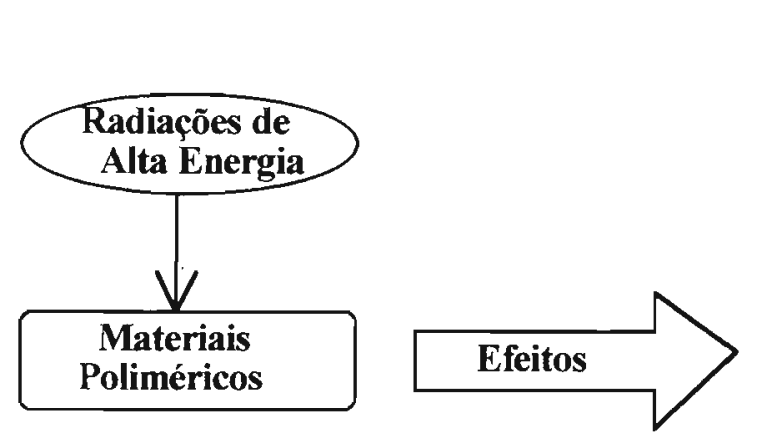

Figura 2: Efeitos das radiações de alta energia sobre os materiais poliméricos.

Alguns dos efeitos acima relacionados podem ser facilmente observados por técnicas convencionais como a espectroscopia eletrônica de absorção na 
região do ultravioleta-visível $[\mathbf{7 , 8}]$ (alternativamente à técnica de absorção pode-se utilizar a reflectância [7]). É o caso da formação de ligações duplas conjugadas formando polienos (dienos, trienos e tetraenos) [9-11], grupos cromóforos responsáveis por intensas absorções na região do ultravioleta. $\mathrm{O}$ efeito é geralmente acompanhado pela liberação de gases como pode ser observado no exemplo abaixo para o PVC (Figura 3):

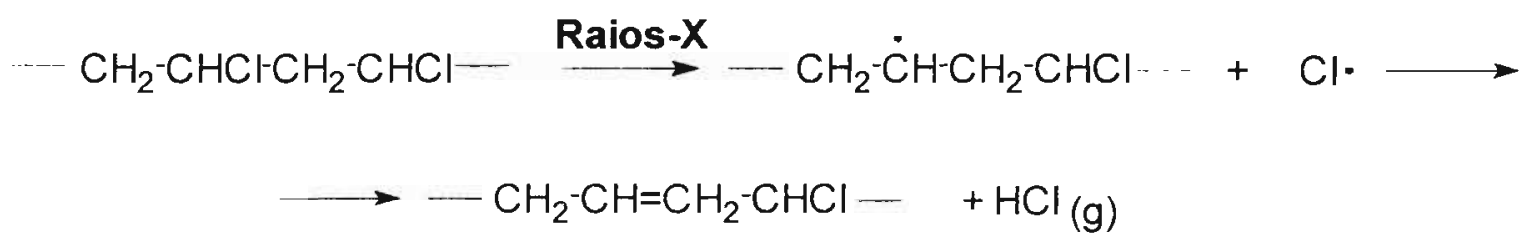

Figura 3: Efeito da radiação-X sobre o PVC.

Os efeitos de cisão de cadeia com formação de radicais e recombinação dos mesmos, podem produzir um aumento na cristalinidade do material, pelo reparo de "defeitos" nas regiões amorfas, conforme ilustrado na Figura 4 através de um modelo lamelar [12]. 


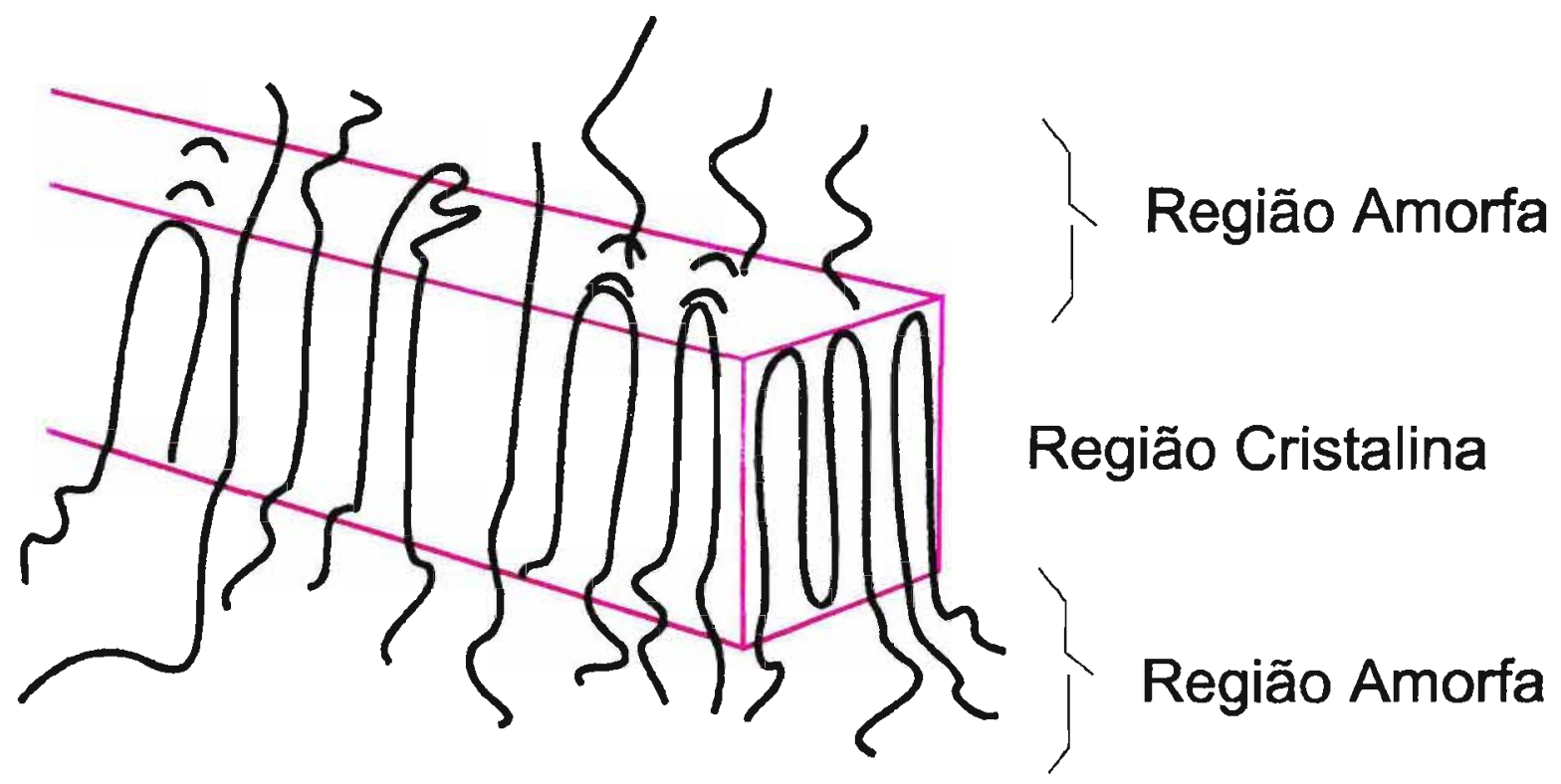

Raios - X

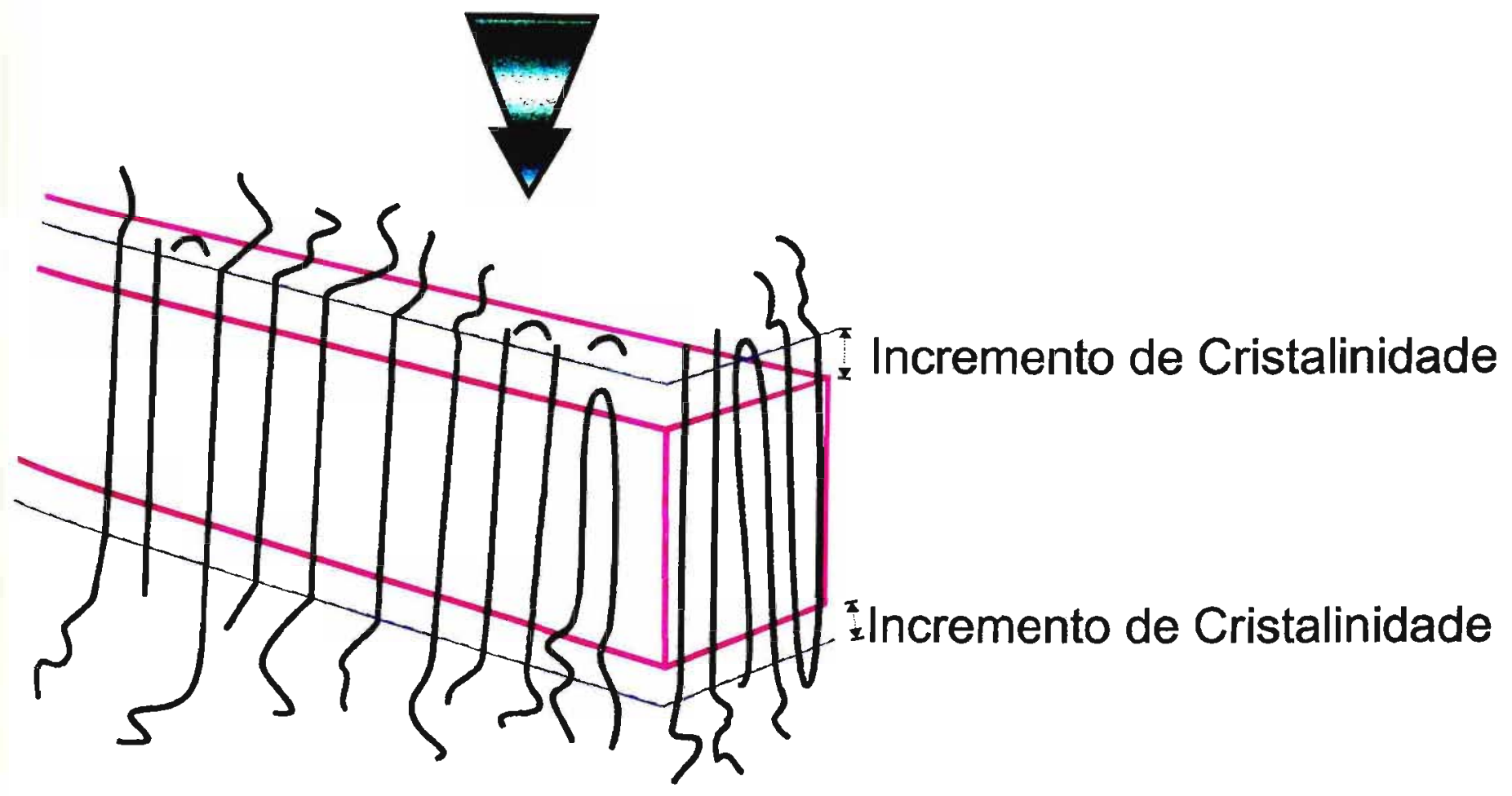

Figura 4: Aumento da cristalinidade de um material polimérico submetido à radiação de alta energia. 
De modo semelhante, um aumento da massa molecular de algumas cadeias do material pode ser verificado em materiais irradiados até uma determinada dose, tendo origem nos processos de recombinação de radicais formados durante a irradiação, produzindo cadeias de maior massa devido às ligações cruzadas, conforme ilustra a Figura 5.

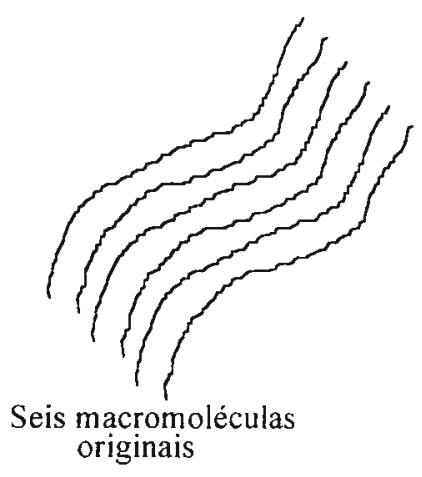

originais

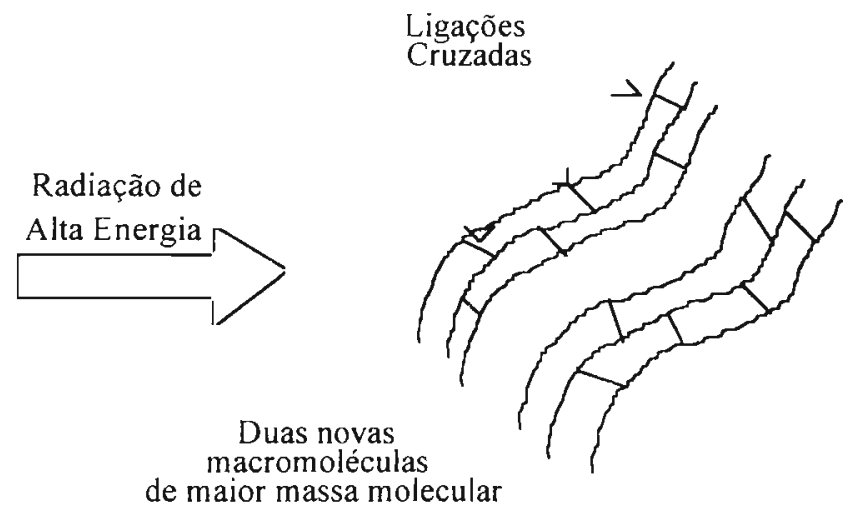

Figura 5: Aumento da massa molecular de cadeias poliméricas, devido à formação de ligações cruzadas após exposição à radiação de alta energia

[13].

É interessante também, considerar os efeitos das radiações de alta energia, em particular as eletromagnéticas $(\gamma$ e X), sobre os materiais que apresentam polimorfismo. Em tais casos são por vezes detectáveis modificações de arranjo cristalino induzidas pela radiação [11], que têm origem no reordenamento de cadeias adjacentes em regiões cristalinas, conforme ilustrado na Figura 6. Esse reordenamento está, provavelmente, relacionado com a ação da radiação promovendo a formação de insaturações e consequente mudanças das conformações de cadeia. Esses eventos podem 
ser convenientemente estudados através da técnica de difração de raios-X, ou mesmo por calorimetria exploratória diferencial (DSC).

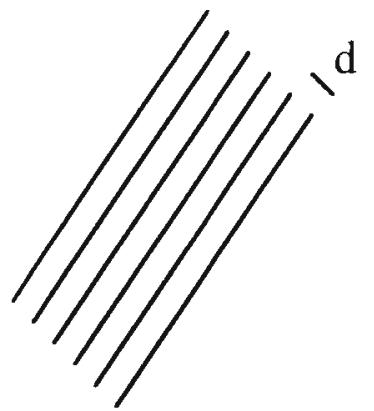

Fase 1

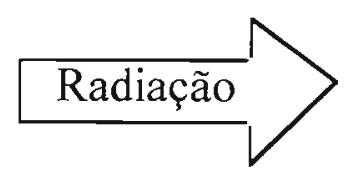

Fase 2

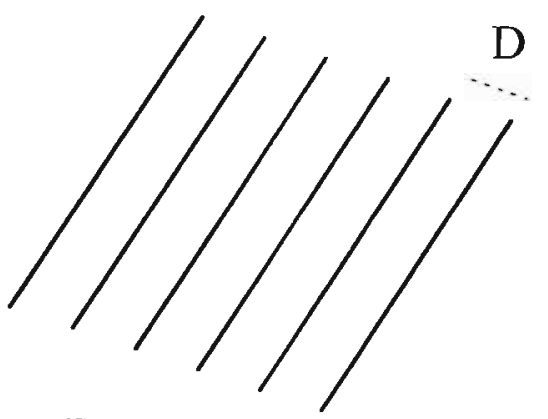

Figura 6: Mudança de estrutura cristalina induzida pela radiação de alta energia (aumento da distância interplanar: $D>d$ ).

Os processos de modificação de polímeros que envolvem radiações oferecem, de modo geral, uma série de vantagens em relação aos processos puramente químicos. Assim, são processos limpos, pois dependem somente do polímero e da radiação, possuem grande poder de penetração no caso de radiações eletromagnéticas, permitem amplo controle das condições de reação (energia, dose, temperatura, pressão, meio e etc.), a iniciação dos processos ocorrem a baixa temperatura e, além de tudo, são processos que combinam alta eficiência com alta qualidade. 


\subsection{2- Modificação de Superfícies por Enxertia ("Grafting")}

A enxertia é uma importante técnica de modificação de materiais poliméricos, que permite a conjugação das propriedades estruturais de um polímero base com um caráter específico (físico ou químico), oferecido por outro polímero de enxerto. A técnica possui importantes aplicações nas alterações do caráter de superfícies hidrofilica/hidrofóbica, neutra/iônica ou inerte/reativa, através de sua funcionalização, com importante papel, por exemplo, na tecnologia de biomateriais em substituição a tecidos, artérias e órgãos naturais $[\mathbf{1 4 , 1 5}]$. O processo mais eficiente para a realização da enxertia é aquele que faz uso das radiações de alta energia, como a radiação $\gamma$ por exemplo, como um agente gerador de radicais, em especial na superficie, para então reagirem com monômeros colocados em contato com o material, após ou durante a irradiação. A Figura 7 ilustra o processo simultâneo e de pré-irradiação para a enxertia com radiações de alta energia. No primeiro, é realizada a irradiação simultânea do polímero base em uma solução do monômero M, devidamente acompanhado de um inibidor de homopolimerização para evitar a simples polimerização de $\mathrm{M}$ em detrimento do processo de enxertia. No segundo processo, é realizada uma préirradiação do polímero base contido em uma ampola à vácuo, inserindo-se, a seguir uma solução do monômero de enxertia. 

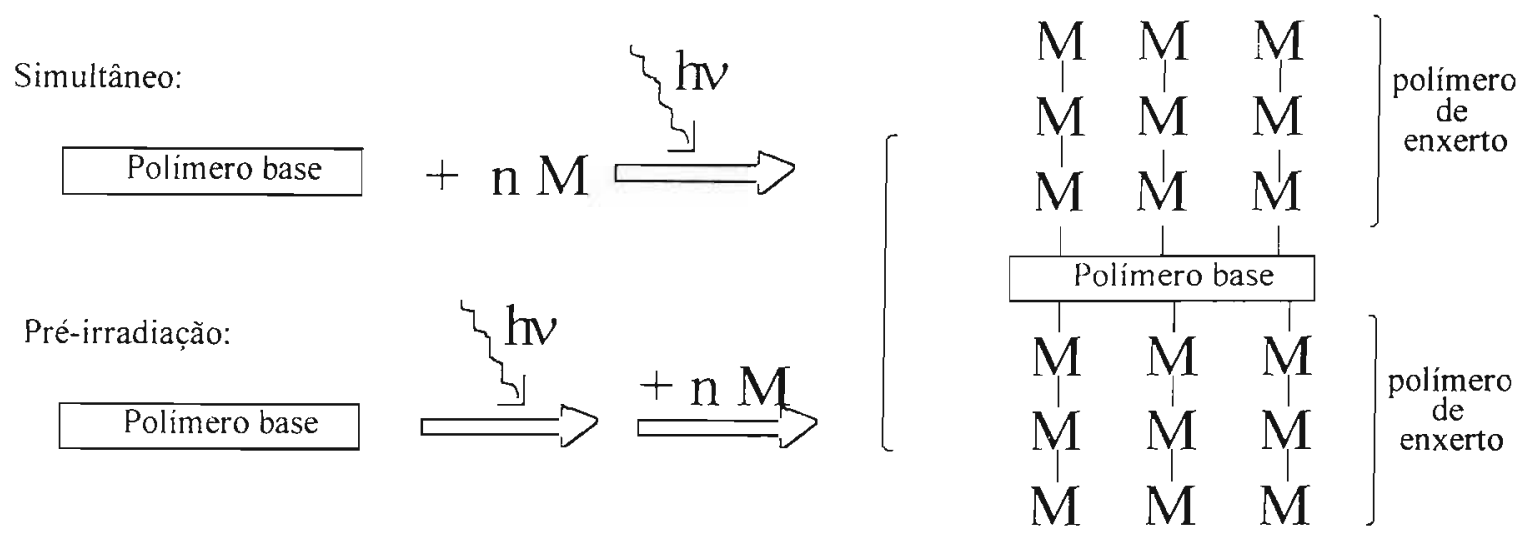

Figura 7: Métodos Simultâneo e de Pré-irradiação para processos de enxertia (hv = radiação e $\mathrm{M}=$ monômero) .

Os processos envolvendo radiações de alta energia conduzem, geralmente, a altas taxas de enxertia, com espessuras de camadas da ordem de alguns centimetros. Contudo, modificações com radiações de menor energia, como a radiação ultravioleta por exemplo, podem resultar em modificações mais específicas, uma vez que o comprimento de onda de tais radiações pode ser selecionado por meio de filtros de interferência, de forma a interagir com uma ligação específica (cromóforo) das moléculas da superficie. Embora com maior especificidade na modificação, tais processos conduzem, de forma geral, a baixas taxas de modificação.

\subsection{3- Modificações de Superfícies por Tratamento de Plasma.}

O tratamento de plasma tem sido utilizado como uma técnica atrativa na modificação de superfícies, em geral "etching" [16], funcionalização [17] ou modificação do caráter hidrofilico/hidrofóbico de muitos polímeros, como poliolefinas, poliésteres, poliamidas, poliuretanas e fluoroelastômeros 
[18-21]. Além disso, o recente desenvolvimento de técnicas de caracterização de superfícies tem permitido maior compreensão sobre a química do tratamento de plasma, uma vez que, por muito tempo, houve pouca clareza à respeito dos processos que ocorrem neste evento [22].

Um plasma, no sentido ao qual nos referimos ("plasma frio"), consiste em uma descarga elétrica em determinada freqüência através de um gás rarefeito, efetuada no interior de um reator de plasma. Tal descarga pode produzir a formação de íons, radicais, fótons, elétrons e novas espécies em estado fundamental e excitado.

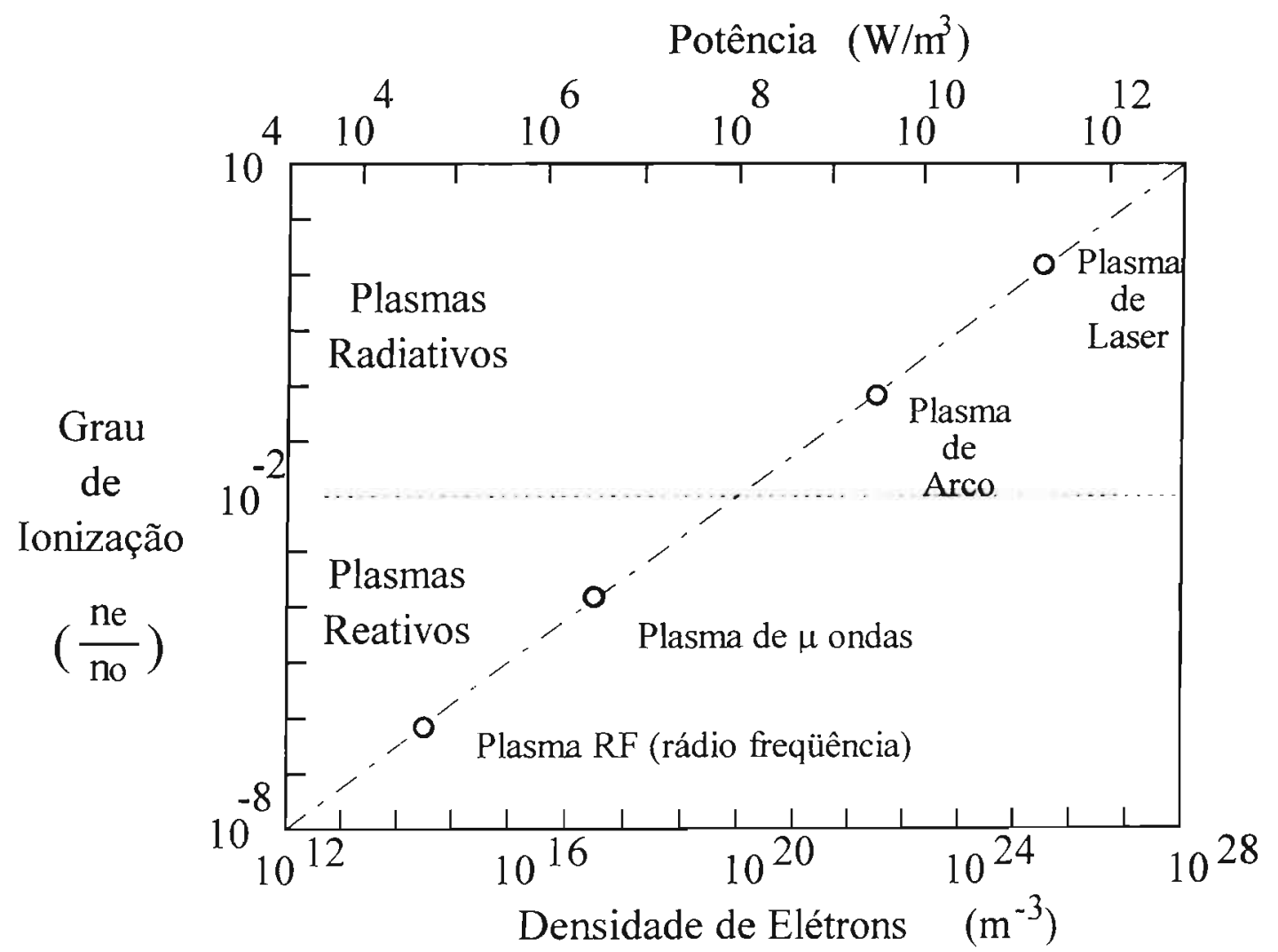

Figura 8: Dependência da radiação de plasma quanto a densidade de elétrons, potência e grau de ionização, onde $n_{e}=$ densidade de elétrons e $n_{0}$ $=$ densidade neutra $[\mathbf{2 3}]$ 
Os plasmas podem ser caracterizados segundo a densidade de elétrons, a temperatura e o grau de ionização, conforme ilustrado na Figura 8, podendo-se classifica-los em plasmas reativos e plasmas radioativos.

Modificações de superfícies de polímeros podem ser convenientemente realizadas pela exposição do material a um plasma reativo em rádio freqüência (plasma RF), selecionando-se adequadamente o tipo de gás ao qual se aplica a descarga, de forma a obter-se o efeito desejado. Desta forma, as modificações por plasma podem variar desde o "etching" [16] à inserção de grupos ou simples ativação da superfície (resultante da ação do plasma sobre o material, gerando radicais sobre a superficie).

Os tratamentos de plasma conduzem, em geral, a pequenas profundidades de penetração (menor que $100 \AA$ ) sendo em geral utilizada, para a caracterização dos materiais assim modificados, as técnicas de: espectroscopia fotoeletrônica de Raios-X (XPS ou ESCA) [20,24], espectroscopia na região do infravermelho por reflexão total atenuada (ATR) [17], e medidas de ângulo de contato.

Uma questão importante à cerca dos tratamentos de plasma diz respeito à reprodutibilidade e especificidade da modificação. Sabe-se que durante a ação do plasma não se obtém apenas uma única funcionalidade dentre os grupos que se inserem na superficie, e, portanto, este não se trata de um método altamente específico. No que diz respeito à reprodutibilidade, esta pode ser alcançada, em boa extensão, através do controle dos parâmetros de reação (corrente, frequência, temperatura e etc.).

Alguns autores têm vislumbrado interessantes estratégias na modificação superficial de filmes poliméricos como meio de aumentar as propriedades de contato sanguíneo necessárias a um biomaterial. Assim, 
Giroux e Cooper [17], por exemplo, desenvolveram duas formas de modificação de filmes de poliuretano utilizando o tratamento de plasma, com o objetivo de introduzir grupos sulfonatos na superfície. Na primeira, a superficie do material é exposta a um plasma de $\mathrm{SO}_{2}$, ocorrendo contudo um elevado grau de "etching" sobre o filme. Numa segunda forma, o filme é tratado com plasma de $\mathrm{NH}_{3}$, com o objetivo de formar agentes reativos na superficie, sendo a seguir colocado em contato com um agente de funcionalização (líquido ou gás), como o $\mathrm{SO}_{2}$ gasoso por exemplo. Esta é a técnica de tratamento pós-plasma que se apresenta como uma boa forma de inserir uma funcionalidade específica no substrato.

\subsection{4- Tratamentos Térmicos e Deformações Mecânicas}

Materiais poliméricos, são em geral submetidos a tratamentos térmicos e deformações mecânicas durante as operações de processamento, ou quando submetidos a condições extremas de esforço e temperatura. Os efeitos mais comuns, relacionados à temperatura, são as modificações internas no material, como a modificação de seu grau de cristalinidade devido à sua fusão e recristalização, o que pode ser facilmente verificado através da análise térmica, mais especificamente por calorimetria exploratória diferencial (DSC). É comum, contudo, a observação de indícios de oxidação através da investigação da superfície dos materiais termicamente processados. Para tanto pode ser útil a técnica ATR-FT/IR (reflexão total atenuada) ou FT/IRPA (fotoacústica), ambas na região do infravermelho. 
O tratamento térmico pode ser também responsável por perda de massa e liberação de gases do material, efeito este tipicamente degradativo que ocorre mesmo nas classes de materiais de grande estabilidade térmica como os polímeros fluorados e seus copolímeros [25].

Esforços mecânicos sobre materiais poliméricos, são também conhecidos por provocarem modificações na estrutura cristalina e mesmo na composição da superficie. Assim, materiais poliméricos, filmes ou mesmo corpos de prova, submetidos a estiramentos apresentam, em geral, aumento de cristalinidade resultante da orientação das cadeias nas regiões amorfas do material conforme mostra a Figura 9 para um polímero semicristalino, através do modelo abaixo.

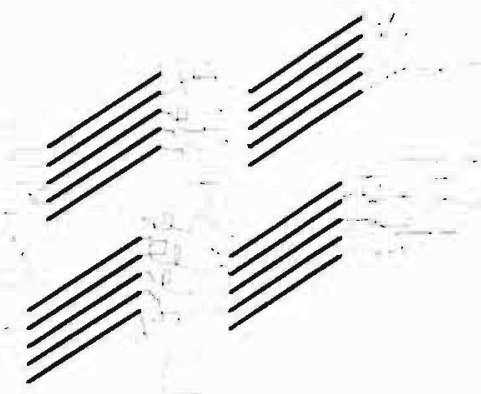

Cadeias desordenadas entre os cristalitos.

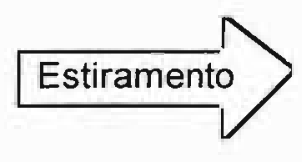

Figura 9: Efeito de aumento da cristalinidade devido ao estiramento de um polímero semicristalino.

Os efeitos de estiramento de materiais poliméricos levam, por vezes, à oxidação do polímero. Tal oxidação tem origem na reação entre os radicais formados no polímero, devido a cisão de cadeias durante o estiramento, e o oxigênio do ar [4]. 


\section{4- Principais Técnicas Espectroscópicas de Caracterização de Sistemas} Poliméricos

As modificações induzidas sobre materiais poliméricos podem ser avaliadas através de diversas técnicas instrumentais, espectroscópicas ou não, fornecendo uma variedade de informações qualitativas e quantitativas.

As técnicas espectroscópicas correspondem àquelas em que se estuda a interação da radiação com a matéria e têm sido de especial interesse, já há muito tempo, na elucidação da estrutura da matéria. Assim, de acordo com a faixa de comprimentos de onda da radiação eletromagnética utilizada, a espectroscopia pode fornecer informações rotacionais, vibracionais e eletrônicas a respeito das moléculas componentes da amostra, sendo que apenas as duas últimas têm relevância no estudo de sistemas poliméricos.

A utilização de campos magnéticos que interagem com a matéria, geram também duas importantes técnicas espectroscópicas na investigação de sistemas poliméricos, a saber: Ressonância Magnética Nuclear (NMR) e Ressonância Paramagnética Eletrônica (EPR) [12,26-28]. A primeira, através da interação do campo magnético com o movimento de spin nuclear $\left({ }^{1} \mathrm{H},{ }^{13} \mathrm{C}\right.$, ${ }^{19} \mathrm{~F}$ e outros) permite a determinação da estrutura molecular. A segunda, devido à interação do campo com o spin de elétrons desemparelhados, permite a detecção de espécies radicalares formadas.

Para a obtenção de informações sobre as vibrações moleculares (movimento vibracional dos núcleos), a espectroscopia vibracional se utiliza da radiação infravermelha, IR, na espectroscopia de absorção no IR [29-31]. Por um mecanismo de espalhamento inelástico de radiação visível, UV, ou 
mesmo no infravermelho próximo, distinto do processo de absorção no IR, é possível também, a obtenção de informações vibracionais. Isto ocorre devido ao efeito Raman, em homenagem ao físico indiano C. V. Raman, que em 1928 descobriu experimentalmente o fenômeno, e que dá nome à técnica da espectroscopia Raman [32]. A aplicação da espectroscopia Raman ao estudo de polímeros e polimerizações, vem em ritmo crescente desde a introdução da excitação das amostras no infravermelho próximo e da instrumentação Raman por transformada de Fourier [33], contudo, ainda assim, as duas técnicas, IR e Raman, fornecem informações vibracionais complementares, devendo ser utilizadas em conjunto para uma caracterização vibracional completa dos sistemas poliméricos [34].

A espectroscopia eletrônica fornece informações sobre transições de elétrons de valência quando a radiação empregada é ultravioleta (UV) ou visível (vis), e sobre transições de elétrons internos quando se utiliza raios-X. Assim o emprego das radiações UV e vis, dá origem à espectroscopia eletrônica de absorção, quando se detecta a luz transmitida pela amostra, espectroscopia eletrônica de reflectância, quando se detecta a luz refletida, espectroscopia eletrônica de emissão ou fluorescência, quando se mede a radiação emitida pela amostra após a absorção de determinada radiação, e espectroscopia fotoeletrônica de raios-X (XPS) ou espectroscopia eletrônica para análise química (ESCA), onde se mede a energia do elétron interno emitido quando a amostra interage com a radiação-X [26-35].

A técnica de difração de raios-X para polímeros semi-cristalinos é importante na elucidação estrutural de macromoléculas, podendo fornecer um mapeamento de densidade eletrônica. A maior dificuldade na obtenção de tais informações consiste na obtenção de monocristais para a determinação 
estrutural através da difração. Contudo, especialmente no caso do estudo de polímeros sintéticos, modificados ou não, a análise unidimensional de filmes destes materiais fornece importantes informações sobre sua porcentagem de cristalinidade, distâncias interplanares, fases cristalinas, presença de impurezas e etc $[36,37,38]$. 


\section{5- Sobre os Sistemas Estudados: Copolímeros de VDF com TrFE}

Polímeros fluorados são conhecidos desde 1938, com a descoberta do politetrafluoretileno, PTFE [39]. A combinação entre carbono e flúor com uma elevada entalpia de ligação, $484 \mathrm{~kJ} \cdot \mathrm{mol}^{-1}$ [35], somada à grande eletronegatividade do flúor $\mathrm{e}$ ao alto valor do momento dipolar da ligação C-F, igual a $6,4 \times 10^{-30}$ C.m [40], conferem às cadeias carbônicas fluoradas propriedades singulares. Acrescente-se a isso o fato de que o flúor é um átomo pequeno o suficiente para substituir os átomos de hidrogênio de uma cadeia carbônica, sem causar grandes efeitos estéricos. Contudo, é maior do que o hidrogênio, protegendo, de certa forma, o esqueleto carbônico.

Resulta assim o fluoroplástico introduzido comercialmente em 1950 pela DuPont com o nome de Teflon ${ }^{\circledR}$, possuindo as propriedades de inércia química, alta estabilidade térmica, baixa inflamabilidade e baixa constante dielétrica dentre outras, cada uma delas, isoladamente ou em conjunto, resultando nas aplicações desse material [39].

Após o PTFE, surge uma extensa classe de polímeros fluorados com destaque para os perfluoroplásticos, copolímeros do tetrafluoretileno com hexafluorpropileno (Teflon ${ }^{\circledR}$ FEP) ou perfluor-propil-viniléter (Teflon ${ }^{\circledR}$ PFA), amplamente utilizados em eletro-eletrônica, especialmente na isolação de cabos elétricos. Segue-se o desenvolvimento comercial de plásticos parcialmente fluorados como o poli(fluoreto de vinila) ou PVF, poli(fluoreto de vinilideno) ou PVDF, e seus copolímeros com trifluoretileno e clorotrifluoretileno [39].

A despeito das conhecidas propriedades isolantes dos fluoroplásticos, ao final da década de sessenta, foram pela primeira vez atribuidas ao PVDF 
intensas propriedades piezoelétricas [41]. Tal propriedade corresponde à conversão bilateral de energia eletromecânica (mecânica em elétrica e viceversa). Nasce portanto uma classe de polímeros transdutores (eletretos), materiais que possuem polarização elétrica permanente, propriedade essa que, até então, encontrava-se restrita a alguns cristais iônicos como o sal de Rochelle (tetraidrato do tartarato de potássio e sódio 99,98\%), além do quartzo [42].

A Figura 10 ilustra o efeito piezoelétrico para uma determinada distribuição de cargas em um cristal.
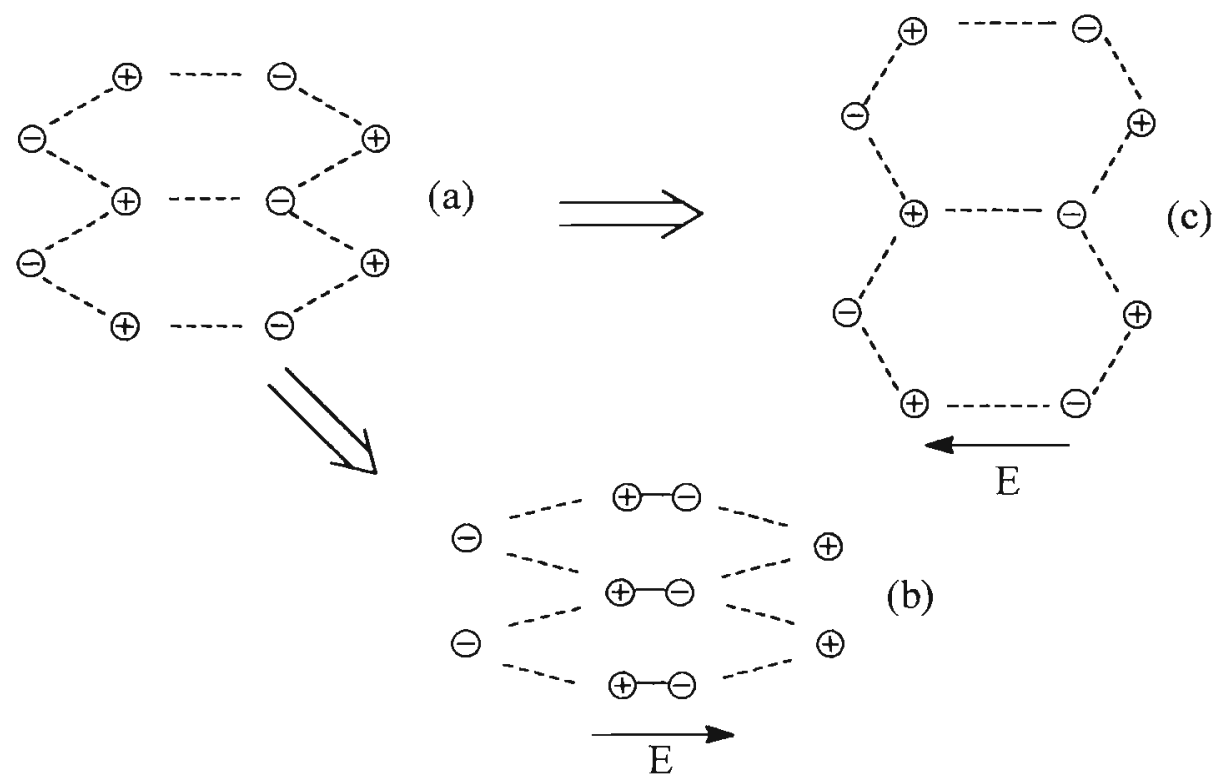

(b)

Figura 10: Efeito piezoelétrico: variação das dimensões do cristal(a) devido a aplicação de um campo elétrico: (b) redução da altura e aumento da largura, e (c) redução da largura e aumento da altura com o campo invertido.

Dessa forma, a aplicação de um campo elétrico num determinado sentido, ou no sentido oposto, causa a deformação do cristal devido a 
orientação das cargas positivas no sentido do campo, e as negativas no sentido inverso, causando a contração do cristal em uma direção e distensão na direção ortogonal.

Cristais piezoelétricos quando apresentam polarização permanente, respondem também a mudanças na temperatura e são ditos então piroelétricos, propriedade esta que também foi observada para o PVDF [40]. Cristais como esses, com um único eixo polar, cuja direção possa ser reorientada pela aplicação de um campo elétrico, são conhecidos como cristais ferroelétricos.

O PVDF, poli(fluoreto de vinilideno), é um elastômero semicristalino com unidade de repetição constitucional $-\mathrm{CH}_{2}-\mathrm{CF}_{2^{-}}$, podendo, contudo, apresentar alguns defeitos na configuração da cadeia, do tipo cauda-cauda ($\mathrm{CF}_{2}-\mathrm{CH}_{2}-\mathrm{CH}_{2}-\mathrm{CF}_{2}$-), e cabeça-cabeça $\left(-\mathrm{CH}_{2}-\mathrm{CF}_{2}-\mathrm{CF}_{2}-\mathrm{CH}_{2}-\right)$, porém em pequena extensão, tipicamente inferior a $5 \%[\mathbf{4 0}]$.

O PVDF apresenta polimorfismo, sendo conhecidas pelo menos cinco formas cristalinas [43], a saber: $\alpha, \beta, \gamma, \delta$ e $\varepsilon$. A forma mais comum é a fase $\alpha$, que se obtém espontaneamente por cristalização a partir do material fundido ou mesmo em solução [44]. Nesta, as cadeias encontram-se em uma conformação do tipo tgtg (trans-gauche-trans-gauche), conforme a Figura 11, possuindo momento de dipolo resultante na cadeia. 


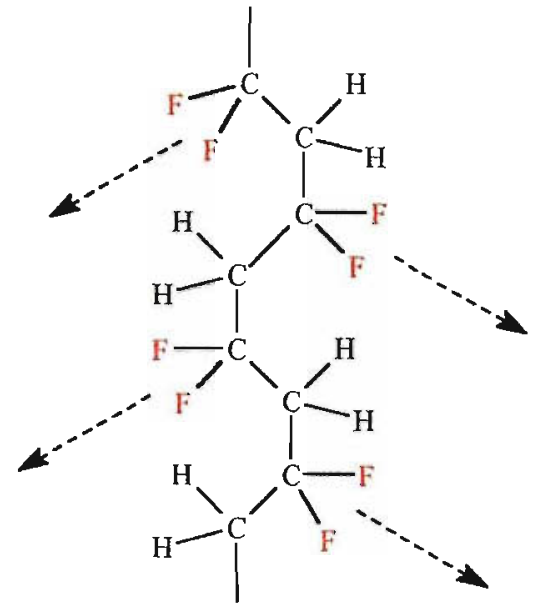

Figura 11: conformação de cadeia do tipo tgtg da forma $\alpha$ do PVDF. As setas indicam os vetores momento de dipolo.

Ocorre, contudo, que quando se considera a cela unitária da forma $\alpha$, os momentos de dipolo das cadeias se cancelam dois a dois, conforme a Figura 12.
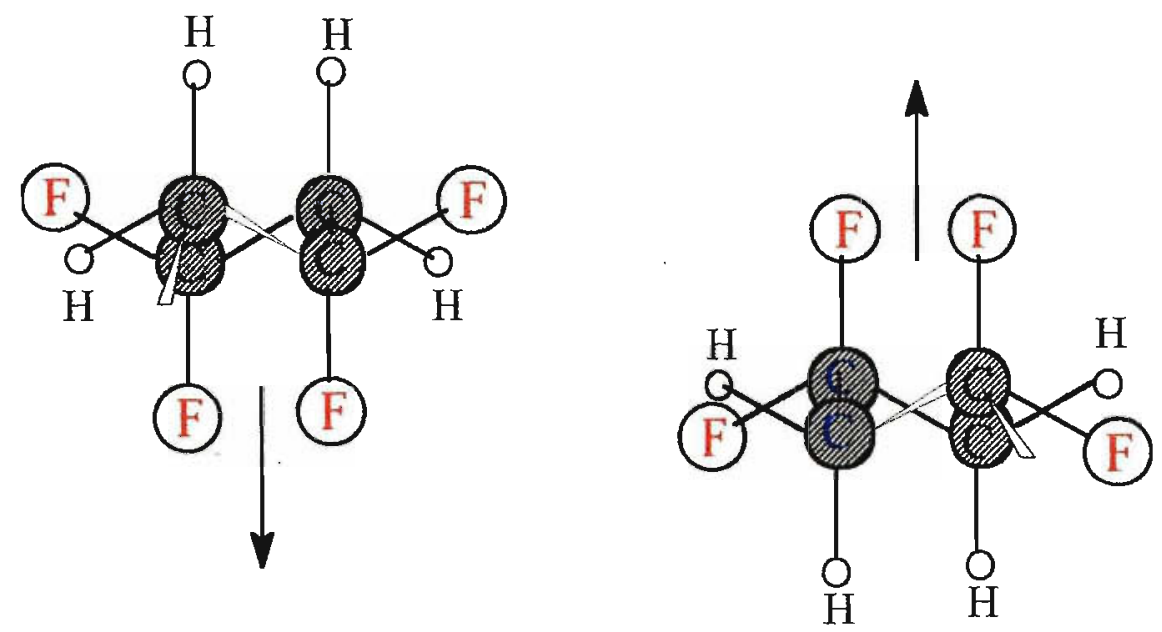

Figura 12: Cela unitária da fase $\alpha$ do PVDF: ocorre cancelamento do vetor momento de dipolo. 
A piezoeletricidade do PVDF aparece na fase polar $\beta$, onde a conformação totalmente trans das cadeias (Figura 13) possibilita a construção de uma cela unitária com elevado momento de dipolo (Figura 14).

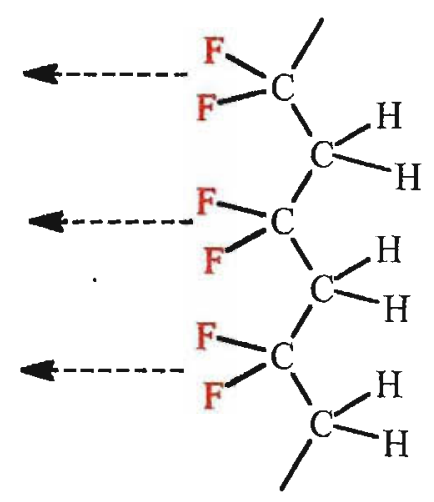

Figura 13: conformação de cadeia totalmente trans da forma $\beta$ do PVDF. As setas indicam os vetores momento de dipolo
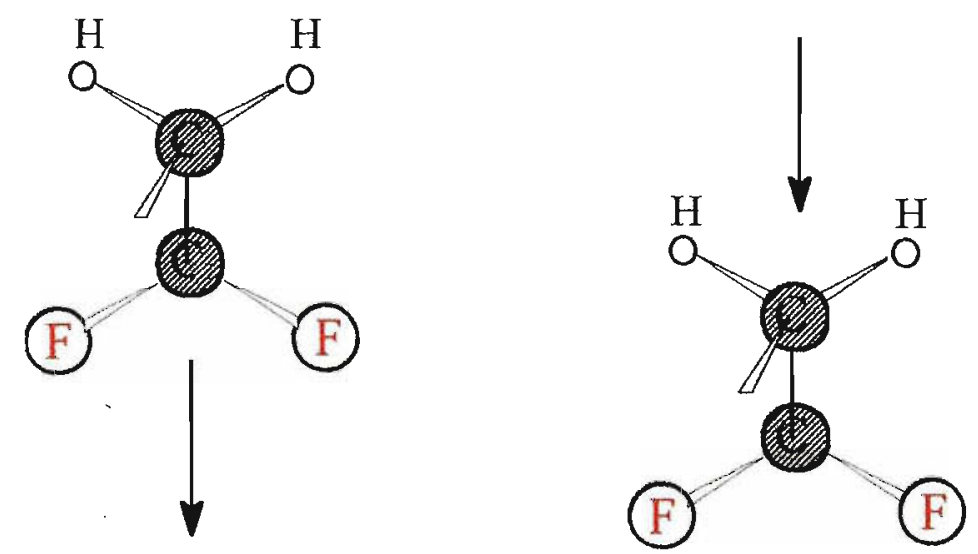

Figura 14: Cela unitária da fase $\beta$ do PVDF. Existe uma resultante do vetor momento de dipolo. 
A fase $\beta$ do PVDF, contudo, só é obtida por estiramento uniaxial do material na fase $\alpha$, ou por cristalização epitaxial (sobre $\mathrm{KBr}$ ) [44].

A combinação das propriedades típicas de um elastômero com as propriedades elétricas, mecânicas e acústicas da fase $\beta$ do PVDF, permitem a aplicação desse material em diversas áreas. Assim, podemos encontrá-lo como componentes de auto-falantes, microfones, sensores de pressão, detectores, dentre outros dispositivos [44].

Apesar do grande interesse científico e tecnológico no PVDF ao longo de quase três décadas, do ponto de vista tecnológico a atividade piezoelétrica de filmes do material mecânicamente estirado não é satisfatoriamente intensa, e nem o é a sua estabilidade térmica [45]. De fato, a constante de acoplamento eletromecânico, $\mathrm{k}_{\mathrm{t}}$, que reflete a capacidade transdutora (conversão) de um material, é da ordem de 0,2 (20\%), quando muito, para o PVDF, e se torna zero, irreversivelmente, a temperaturas próximas de $130{ }^{\circ} \mathrm{C}$ [45]. Assim, polímeros piezoelétricos mais ativos e termoestáveis seriam desejáveis para as aplicações práticas.

Devido às possibilidades estruturais para apresentar propriedades piezoelétricas, copolímeros do fluoreto de vinilideno foram estudados ao longo da década de setenta, como o P(VDF-VF), com fluoreto de vinila, e o $\mathrm{P}$ (VDF-TFE), com tetrafluoretileno, dentre outros. O copolímero de VDF com trifluoretileno, TrFE, dentre todos, apresenta a singular característica de cristalização espontânea, a partir do material fundido ou em solução, diretamente na fase ferrroelétrica (fase $\beta$ ). Isto ocorre quando o conteúdo de VDF encontra-se entre $55 \%$ e $80 \%$ [44]. Assim, ao contrário do PVDF, não necessita de estiramento para passar à fase cristalina piezoelétrica. Para o 
copolímero 60/40, por exemplo, foi também observado o surpreendente fato de que a fase amorfa do material pode apresentar comportamento ferroelétrico [46]. Recentemente uma nova classe de polímeros ferroelétricos, os Nylons impares (11,9,7 e 5), foi sintetizada e tem merecido atenção dos pesquisadores $[47,48]$.

O interesse pelo copolímero P(VDF-TrFE) começa a aumentar quando se verifica que este apresenta uma temperatura de transição de primeira ordem [49], anterior à fusão, para conteúdos de VDF entre $50 \%$ a $80 \%$. Tal temperatura foi, a seguir, atribuída à transição da fase ferroelétrica para a fase paraelétrica, conhecida como temperatura de Curie $\left(\mathrm{T}_{\mathrm{C}}\right)$ [50-52]. Em analogia com os ferromagnetos, incluem-se dentre as propriedades características dos ferroelétricos, a polarização elétrica espontânea, a polarização reversa e o desaparecimento da polarização abaixo da temperatura de Curie [53]. A Figura 15, adaptada da literatura $[\mathbf{5 4 , 5 5}]$ é ilustrativa para transições no copolímero.

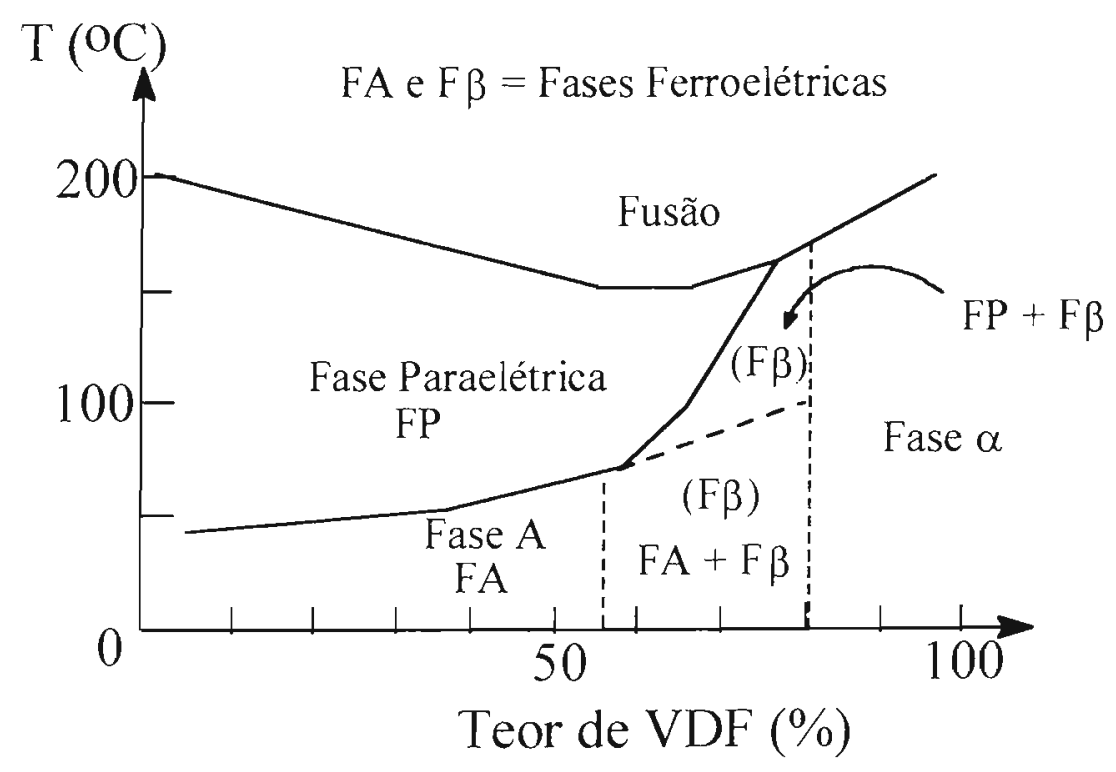

Figura 15: Diagrama de fases $T$ vs.\% de VDF. 
A temperatura de Curie e as transições de fases associadas ao copolímero $\mathrm{P}(\mathrm{VDF}-\mathrm{TrFE})$ despertam, ainda hoje, intenso interesse dos pesquisadores por motivos teóricos [56] e experimentais [57-60].

Em 1981, Higashihata et al. [61] reportaram pela primeira vez um estudo sobre as propriedades piezoelétricas do P(VDF-TrFE). Estes mostraram que o referido material pode apresentar constantes piezoelétricas, $\mathrm{d}_{\mathrm{ij}}$ (onde os índices $\mathrm{i}$ e $\mathrm{j}$ indicam, convencionalmente, a direção de estiramento e da polarização), com a mesma magnitude daquela para o PVDF. Tal constante para o copolímero varia com a composição, sendo maior para o material com $55 \%$ de VDF. Contudo, o fator de acoplamento eletromecânico, $k_{t}$, é quem melhor caracteriza um material como um conversor de energia. Assim, medidas realizadas para o copolímero P(VDF$\mathrm{TrFE}$ ), indicaram maiores valores de $\mathrm{k}_{\mathrm{t}}$ para os materiais com conteúdo de VDF entre $70 \%$ e $80 \%$ [62]. Tipicamente, os copolímeros nessa faixa de composição atingem $\mathrm{k}_{\mathrm{t}} \cong 0,3$ [45] cerca de $30 \%$ a mais do que o PVDF que tenha sido previamente estirado.

Recentemente, foram reportadas variações dos fatores de acoplamento eletromecânico de filmes de $\mathrm{P}(\mathrm{VDF}-\mathrm{TrFE})$ monocristalinos, como função da temperatura, bem como das constantes piezoelétricas [63]. Materiais desse tipo, monocristalinos, com elevada atividade piezoelétrica em uma ampla faixa de temperaturas abaixo da $\mathrm{T}_{C}$, além de elevados valores do módulo de Young (constante elástica), são adequados para a construção de dispositivos eletromecânicos e sensores piezoelétricos. Aplicações como sensores piroelétricos também têm sido reportadas recentemente [64]. 


\section{Capítulo 2 : Parte Experimental}

\section{1- Materiais Utilizados}

\subsection{1- Filmes do Copolímero P(VDF-TrFE) na Razão molar 70:30}

Filmes circulares do copolímero P(VDF-TrFE) com espessura média de $60 \mu \mathrm{m}$, e na razão molar 70:30, respectivamente em VDF e TrFE, foram obtidos por prensagem a quente sob temperatura superior àquela de fusão $\left(154^{\circ} \mathrm{C}\right)$, a partir do material comercial na forma de grãos da Atochem Co.

Filmes mais finos, com espessura média de $20 \mu \mathrm{m}$ foram obtidos pela dissolução do material acima em quantidade suficiente de acetona (Merck), colocando-se a solução sobre uma superfície de vidro delimitada, e posicionando-a no interior de uma placa de Petri. A placa foi tampada com uma placa menor, de forma a cobrir a superfície da solução, mas permitindo a saída do vapor do solvente. Após cerca de 4 horas de evaporação na capela, obteve-se um filme transparente e bastante homogêneo. Uma secagem por cerca de 4 horas em estufa a vácuo a $60{ }^{\circ} \mathrm{C}$ foi necessária para a eliminação do solvente, conforme observado no espectro eletrônico de absorção.

Em uma nova tentativa de obtenção de filmes finos de $\mathrm{P}(\mathrm{VDF}-\mathrm{TrFE})$, verificou-se que a presença da umidade do ar parece desempenhar papel crítico na formação de superfícies opacas, uma vez que a observação do mesmo procedimento anterior conduziu à formação de filmes com essa característica em um dia de alta umidade relativa do ar. 
A verificação acima indicou a necessidade de procurar manter o filme em formação sob uma atmosfera de vapor do solvente. Desta forma, cerca de $5 \mathrm{~mL}$ de acetona foram colocados dentro da placa de Petri, posicionando-se sobre a camada de acetona a placa de vidro sobre a qual evaporava a solução do copolímero. Sobre o sistema é então colocada uma tampa (uma placa de petri menor). O conjunto foi colocado dentro de um dessecador com a válvula aberta. Após cerca de 8 horas verificou-se a formação de um filme totalmente transparente e homogêneo.

Espectros vibracionais na região do Infravermelho e espectros eletrônicos no ultravioleta, do material preparado, apresentaram bandas características do solvente (acetona), indicando a presença deste no filme. A secagem deste material em estufa a vácuo a $60{ }^{\circ} \mathrm{C}$ por 4 horas foi suficiente para eliminação dos traços do solvente, conforme confirmação espectroscópica.

\subsection{2- Filmes do Copolímero P(VDF-TrFE) na Razão molar 60:40}

Foram também utilizados para irradiação filmes de $\mathrm{P}(\mathrm{VDF}-\mathrm{TrFE})$ na razão molar 60:40, respectivamente em VDF e TrFE. Os filmes circulares com cerca de $60 \mu \mathrm{m}$ desse material foram preparados conforme os anteriores, sendo também de mesma procedência. 


\subsection{3- Outras Razões Molares do Copolímero P(VDF-TrFE)}

Outras razões molares do copolímero (VDF/TrFE), a saber: 85:15, 80:20 e 75:25, foram usadas apenas para comparações espectrais. Possuem a mesma procedência dos demais e foram utilizados na forma de filmes circulares de cerca de $60 \mu \mathrm{m}$ preparados por prensagem a quente, no Laboratório de Polímeros da USP de São Carlos.

\section{2- Técnicas Experimentais}

\subsection{1 - Irradiação das Amostras com Raios-X}

Os filmes de P(VDF-TrFE) foram fixados em um porta amostra de alumínio, com uma área de exposição de $10 \mathrm{~mm}$ por $15 \mathrm{~mm}$. A irradiação desses filmes foi realizada sob vácuo, com a amostra em rotação para permitir homogeneidade de incidência do feixe. Utilizou-se um espectrômetro de fluorescência de raios-X da Philips, modelo PW 1410, munido de um tubo com alvo de tungstênio sob corrente de filamento de $20 \mathrm{~mA}$ e tensão de aceleração de $40 \mathrm{kV}$. A radiação produzida em tais condições corresponde a um espectro contínuo de raios-X com comprimentos de onda variando de 400 a $32 \mathrm{pm}\left(1 \mathrm{pm}=10^{-12} \mathrm{~m}\right)$.

A taxa de dose foi determinada através do método da termoluminescência [65], utilizando-se dosímetros de cristais nas mesmas condições da amostra, os quais foram analisados pelo Laboratório de Dosimetria Termoluminescente do IPEN/CNEN-SP, obtendo-se um resultado de $160 \mathrm{kGy} / \mathrm{h}$ para a taxa de exposição. 
As amostras foram irradiadas em doses que variaram de 0 e $1280 \mathrm{kGy}$ (0 a 8 horas de exposição).

\subsection{2- Difração de Raios-X}

Os difratogramas de raios- $\mathrm{X}$ foram obtidos a partir de um difratômetro Philips modelo PW 1370, interfaceado a um osciloscópio Nicolet-310. Os dados foram coletados em formato ASC II, sendo então analisados pelo programa Grams 386.

Como fonte de radiação foi utilizada um tubo com alvo de $\mathrm{Cu}$, sob corrente de fillamento de $20 \mathrm{~mA}$ e tensão de aceleração do feixe de elétrons de $30 \mathrm{kV}$. Um filtro de $\mathrm{Ni}$ acoplado, permitiu a seleção da radiação de comprimento de onda $\lambda=154,1 \mathrm{pm}$ (linha $\mathrm{K}_{\alpha}$ do $\mathrm{Cu}$ ).

As amostras foram fixadas em um porta amostra de alumínio, mantendo-se uma área retangular constante para exposição, de 10 por $15 \mathrm{~mm}$, e os difratogramas foram obtidos para a região de ângulos de Bragg variando entre $5^{\circ}>2 \theta>30^{\circ}$ e $5^{\circ}>2 \theta>60^{\circ}$.

As medidas dos ângulos foram determinadas em relação a um padrão de Si, para o qual são conhecidos os ângulos $2 \theta$ com valores iguais a $28,44^{\circ}$, $47,38^{\circ}$ e $56,12^{\circ}$.

Estimativas da porcentagem de cristalinidade e uma análise de bandas superpostas foi realizada a partir dos dados de difração de raios-X. Para tanto foi utilizada a expressão:

$\%$ cristalinidade $=100 \times$ área cristalina $/$ (área amorfa + área cristalina $),$ onde procurou-se ajustar, para delimitação das áreas, curvas de Lorentz às regiões cristalinas e curvas Gaussianas às regiões amorfas [66]. 


\subsection{3- Espectros Vibracionais na Região do Infravermelho}

Os espectros vibracionais fotoacústicos na região do infravermelho médio, foram obtidos por meio do espectrômetro FT-IR da Bomem, modelo DA 3.02, utilizando-se um beamsplitter de $\mathrm{KBr}$ e detecção através de um acessório fotoacústico da MTEC, modelo 200. Foi utilizado carvão ativo como referência e todas as medidas foram realizadas após uma purga de gás He (Oxigênio do Brasil) através do compartimento de amostras, por cerca de 1 minuto.

Os espectros vibracionais de transmitância na região do infravermelho médio, foram obtidos fixando-se os filmes do copolímero em um porta amostras metálico adequado, e fazendo-se as medidas por meio do espectrômetro FT-IR da Bomem, modelo Michelson MB-102.

\subsection{4- Espectros Vibracionais Raman}

Os espectros de espalhamento Raman para os filmes de P(VDF-TrFE) foram obtidos através de um espectrômetro de microscopia Raman da Renishaw modelo 3000, com sistema de detecção por CCD, acoplado a um laser de He-Ne da Spectra Physics, modelo 127, utilizando-se a linha de excitação em $\lambda=632,8 \mathrm{~nm}$. Foram focalizadas regiões da amostra através de um microscópio Olympus BH2-UMA, com uma objetiva com aumento de 80 vezes, acoplado a uma câmara da Sony. Os espectros varreram uma região de números de onda de 100 a $1800 \mathrm{~cm}^{-1}$ (deslocamento Raman).

Tentativas para a obtenção de espectros Raman dos filmes irradiados foram também realizadas por meio dos espectrômetros: 
- Jobin Yvon modelo U-1000, com detecção através de um tubo fotomultiplicador, utilizando-se como linha de excitação a radiação 514,5 $\mathrm{nm}$, proveniente de um laser de íons $\mathrm{Ar}^{+}$da Coherent, modelo Innova 90.

- FT-Raman da Bomem, modelo DA 3.02 com beamsplitter de quartzo e deteç̧ão por meio de pastilha semicondutora de InGaAs, refrigerada com $\mathrm{N}_{2}$ (1), acoplado a um laser contínuo de Nd-YAG $\left(\mathrm{YAG}=\mathrm{Y}_{3} \mathrm{Al}_{5} \mathrm{O}_{12}\right)$ da Quantronix com linha de excitação em $\lambda=1064,0 \mathrm{~nm}$.

\subsection{5- Espectroscopia Eletrônica de Absorção}

Os espectros eletrônicos de absorção, na região do ultravioleta-visível, para os filmes do copolímero foram obtidos através de um espectrofotômetro da BECKMAN modelo DU-70, dentro de uma faixa de comprimentos de onda de 190 a $400 \mathrm{~nm}$. Foi utilizado um suporte metálico para irradiações e leituras sucessivas de uma mesma amostra.

\subsection{6- Calorimetria Exploratória Diferencial (DSC)}

As medidas de DSC foram realizadas através de um módulo DSC-10 da TA Instruments, gerenciado pelo programa Thermal Analyst 2000. Foram utilizadas amostras na forma de filmes em celas semi-herméticas de alumínio.

$\mathrm{O}$ aparelho foi calibrado com um padrão de índio $\left(\mathrm{T}_{\mathrm{m}}=156,6{ }^{\circ} \mathrm{C}\right)$ e $\mathrm{Zn}$ ( $H=28,59 \mathrm{~J} / \mathrm{g}$ ) nas mesmas condições da amostra.

As medidas de fusão e cristalização para cada amostra foram efetuadas conforme o procedimento descrito através da norma correspondente [67]. 
Assim, a massa das amostras variou entre 5 e $10 \mathrm{mg}$, sendo submetida ao seguinte método, em atmosfera de $\mathrm{N}_{2}$ a um fluxo de $30 \mathrm{~mL}$ por minuto:

1 - estabilização a $25^{\circ} \mathrm{C}$ por 10 min.;

2- razão de aquecimento a $10^{\circ} \mathrm{C} / \min$ até $190^{\circ} \mathrm{C}$;

3- isoterma por $10 \mathrm{~min}$;

4- razão de resfriamento a $10^{\circ} \mathrm{C} / \mathrm{min}$ até $20^{\circ} \mathrm{C}\left(\right.$ com $\mathrm{H}_{2} \mathrm{O}$ gelada);

5- estabilização a $25^{\circ} \mathrm{C}$;

6- razão de aquecimento a $10{ }^{\circ} \mathrm{C} / \min$ até $190^{\circ} \mathrm{C}$.

\subsection{7- Termogravimetria (TG)}

Amostras de filmes de $\mathrm{P}(\mathrm{VDF}-\mathrm{TrFE})$, irradiados e não-irradiados, na razão molar 70:30, foram submetidas a análise termogravimétrica em um equipamento Hi-Res TGA 2950 Thermogravimetric Analyzer da TA Instruments.

As amostras foram submetidas ao aquecimento numa faixa de temperaturas de 20 a $600{ }^{\circ} \mathrm{C}$, sob atmosfera dinâmica de $\mathrm{N}_{2}$, através de uma razão de aquecimento de $20{ }^{\circ} \mathrm{C}$ por minuto. Foram utilizados para os experimentos um suporte de cerâmica (prato da balança) e uma cápsula de platina, sobre a qual se posicionavam as amostras (1,5 a 2,0 mg). Os dados foram coletados e analisados pelo programa Thermal Analyst 2000 da TA Instruments. 


\section{Capítulo 3: Resultados e Discussão}

\section{1- Difração de Raios-X}

Os difratogramas de raios- $\mathrm{X}$ para o $\mathrm{P}(\mathrm{VDF}-\mathrm{TrFE})$ na razão molar 70:30 foram registrados para doses de irradiação variando entre 0 e 1280 kGy em intervalos de $160 \mathrm{kGy}(0$ a 8 h de exposição à radiação-X). A região analisada para todas as amostras foi de $2 \theta=5^{\circ}$ até $30^{\circ}$, embora tenham sido registrados difratogramas até $60^{\circ}$.

A Figura 16 mostra o difratograma de raios- $X$ para um filme do copolímero não irradiado com cerca de $60 \mu \mathrm{m}$ de espessura, onde observa-se um pico principal intenso e estreito centrado em $2 \theta=18,9^{\circ}$ correspondente à Fase $\beta[4 \mathbf{4 5 , 6 2 , 3 7 , 6 8 ]}$. Tal pico está relacionado às reflexões dos planos (110) e (200) [36,37,69-71], conforme os índices de Miller (h,k,l). Observa-se também, associada a esse pico, uma ligeira assimetria para o lado de ângulos de Bragg menores, provável resultado de sobreposição. A existência de tal assimetria está de acordo com a presença de um pico de pequena intensidade correspondente a uma das fases cristalinas ferroelétricas, provavelmente a fase menos ordenada (FA, na Figura 15), em pequena porção no material de partida. Essa assimetria foi anteriormente verificada $[45,50,62,69,72]$, e tem sido atribuída também à presença de uma fase paraelétrica $P$ [60]. Outros picos, de pequena intensidade, foram observados em $2 \theta=34,9^{\circ}$, associado aos planos (310) e (020), e $2 \theta=40,9^{\circ}$, associado aos planos (400) e (220) $[45,36]$. 
Foi possivel estimar, a partir dos difratogramas de raios- $\mathrm{X}$ das amostras, uma parcela cristalina de cerca de $62 \%$ para a amostra não irradiada, e $20 \%$ após a dose de $1280 \mathrm{kGy}$, por deconvolução de picos, conforme descrito no item 2.2.2.

A Figura 17 mostra a diminuição da intensidade e pequeno alargamento do pico atribuído à fase ferroelétrica mais ordenada, para a amostra submetida à dose de $160 \mathrm{kGy}$. Nota-se que apesar da diminuição da cristalinidade, o mesmo continua centrado em $18,9^{\circ}$, não havendo, portanto, a predominância de uma nova fase.

A Figura 18, para uma amostra irradiada por $320 \mathrm{kGy}$, apresenta novamente uma diminuição da intensidade do pico, e portanto do grau de cristalinidade, juntamente com um aparente deslocamento do mesmo para $18,3^{\circ}$, o que, na verdade, deve corresponder ao aparecimento de um novo pico (nova fase) com valor de ângulo inferior a $18,3^{\circ}$, e diminuição do pico inicial. Tal fato sugere uma mudança de estrutura cristalina induzida pela radiação, da fase ferroelétrica mais ordenada (fase $\beta$ ) para uma fase paraelétrica (FP), de forma semellhante ao observado anteriormente por irradiação do material com elétrons [69] radiação $\gamma$ [71]e íons pesados $[70,73]$.

Pela Figura 19 nota-se um novo pico e diminuição do pico principal no difratograma de raios- $\mathrm{X}$ da amostra irradiada por uma dose de $480 \mathrm{kGy}$. O pico centrado em $17,6^{\circ}$ deve corresponder à predominância de uma fase cristalina paraelétrica $[\mathbf{7 0 , 6 0}$. Além disso, é possível notar também pela Figura 19, a forma de um pico assimétrico para o lado de ângulos de Bragg 
maiores, assimetria esta que deve ocorrer devido às reflexões residuais das fases ferroelétricas ainda existentes no copolímero.

$\mathrm{Na}$ Figura 20, para a amostra irradiada por $640 \mathrm{kGy}$, é notável a intensificação do pico centrado em 17,6", indicando assim um sensível aumento da cristalinidade da fase paraelétrica correspondente. Efeito semelhante foi anteriormente observado para o PVDF [10], tendo origem, provavelmente, no reparo de defeitos das regiões cristalinas do material.

As Figuras 21, 22, 23 e 24 apresentam os difratogramas de raios-X para as amostras do copolímero submetidas às irradiações de 800, 960, 1120 e 1280 kGy. Observa-se para todos eles a tendência de diminuição do pico correspondente à fase paraelétrica, e portanto diminuição do grau de cristalinidade, constituindo-se em um efeito típico de degradação da amostra.

A Figura 25 procura sumarizar os resultados obtidos, mostrando os efeitos de mudança estrutural, aumento de cristalinidade e degradação induzidos pela radiação-X.

Para copolímeros de mesma composição submetidos a feixes de elétrons [69], foram observados efeitos semelhantes de deslocamentos do pico da fase ferroelétrica. Krüger et al. [37] observaram também a transição de fase ferroelétrica-paraelétrica, para doses de irradiação entre 100 e 200 Mrad para o material irradiado com feixe de elétrons. 


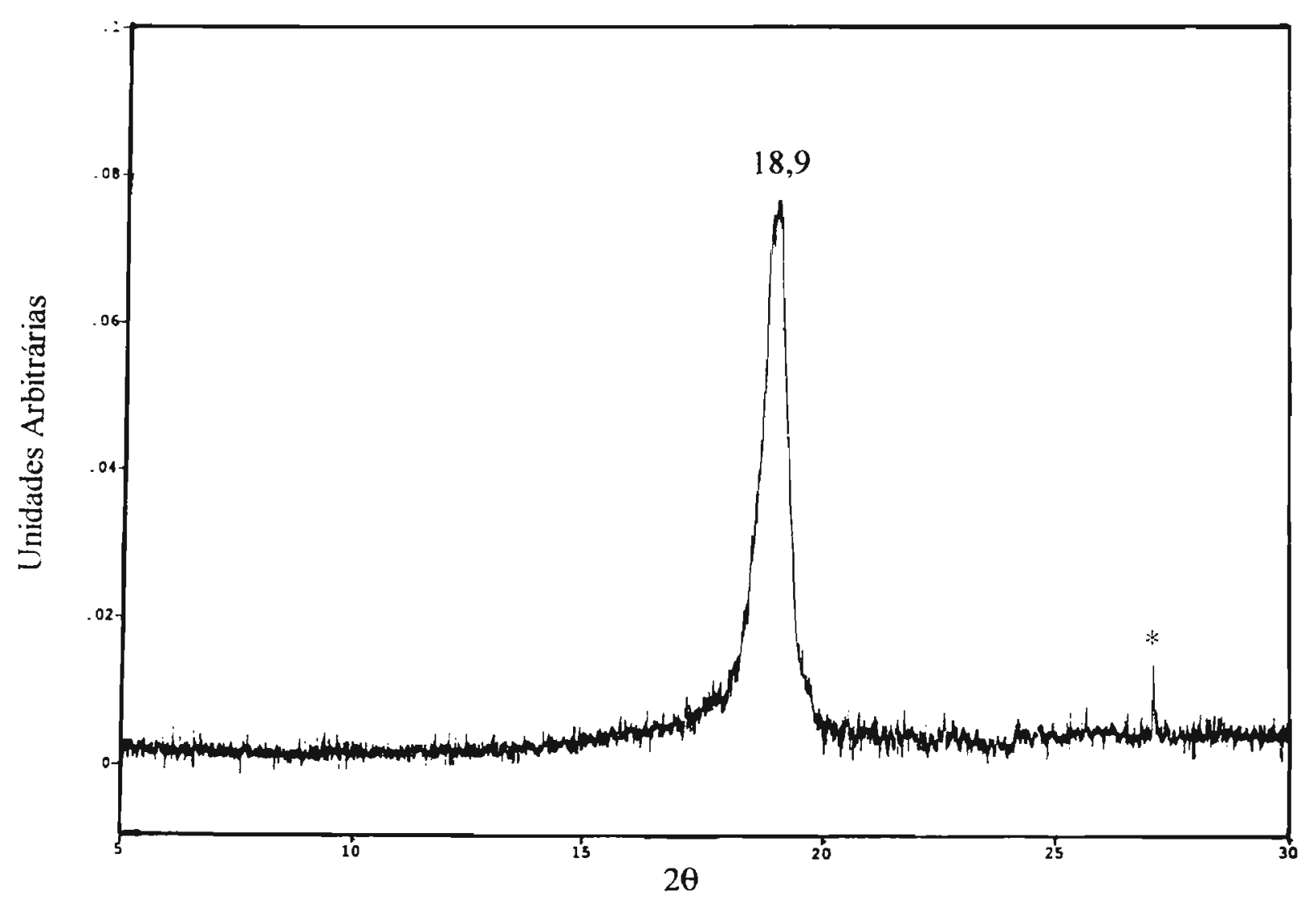

Figura 16: Difratograma de raios-X para o $P(V D F-T r F E)$ não irradiado

Obs: * indica picos espúrios resultantes da flutuação da rede elétrica ou radiação cósmica incidente sobre o detector. 


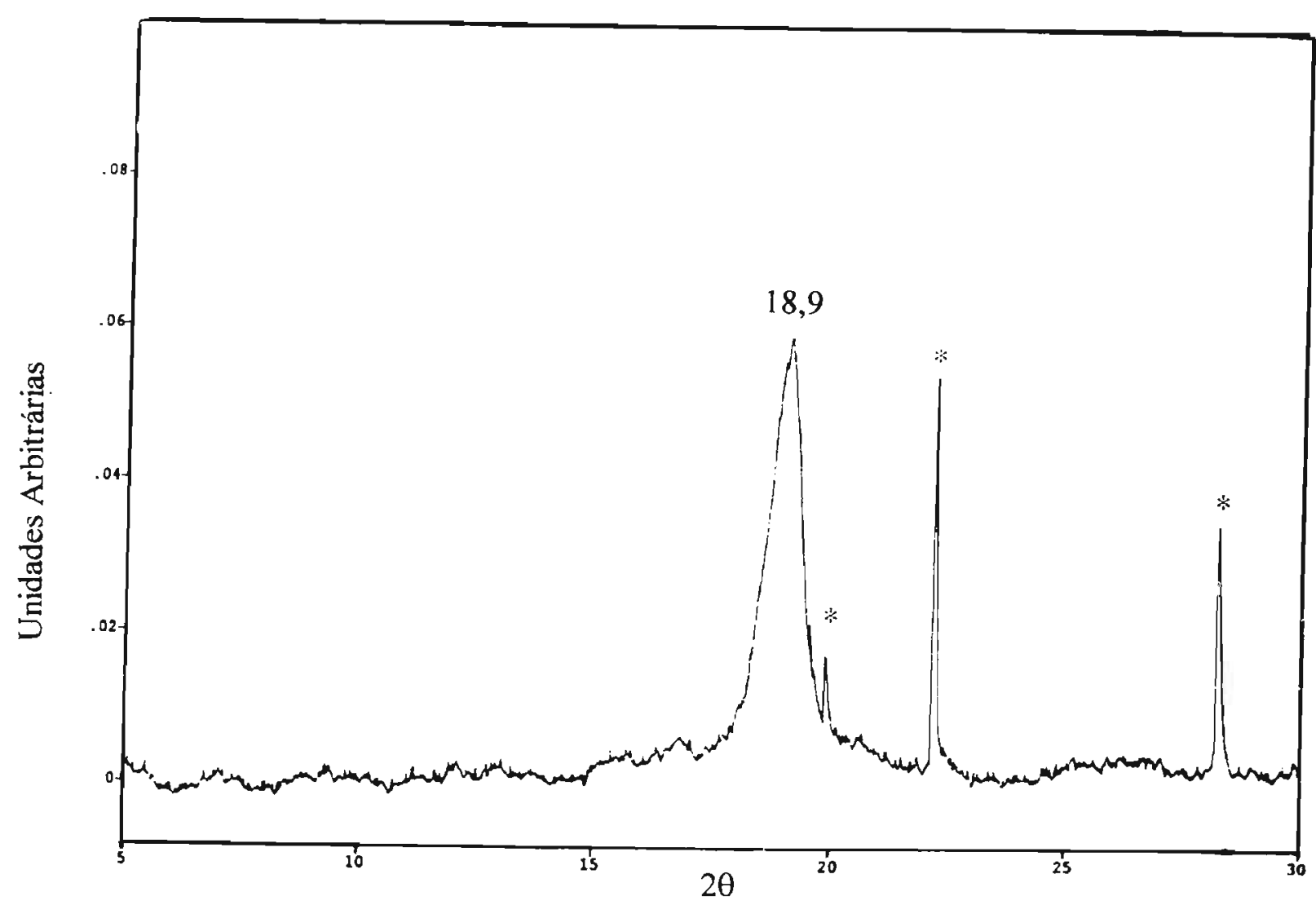

Figura 17: Difratograma de raios-X para o P(VDF-TrFE) irradiado por uma dose de $160 k G y$.

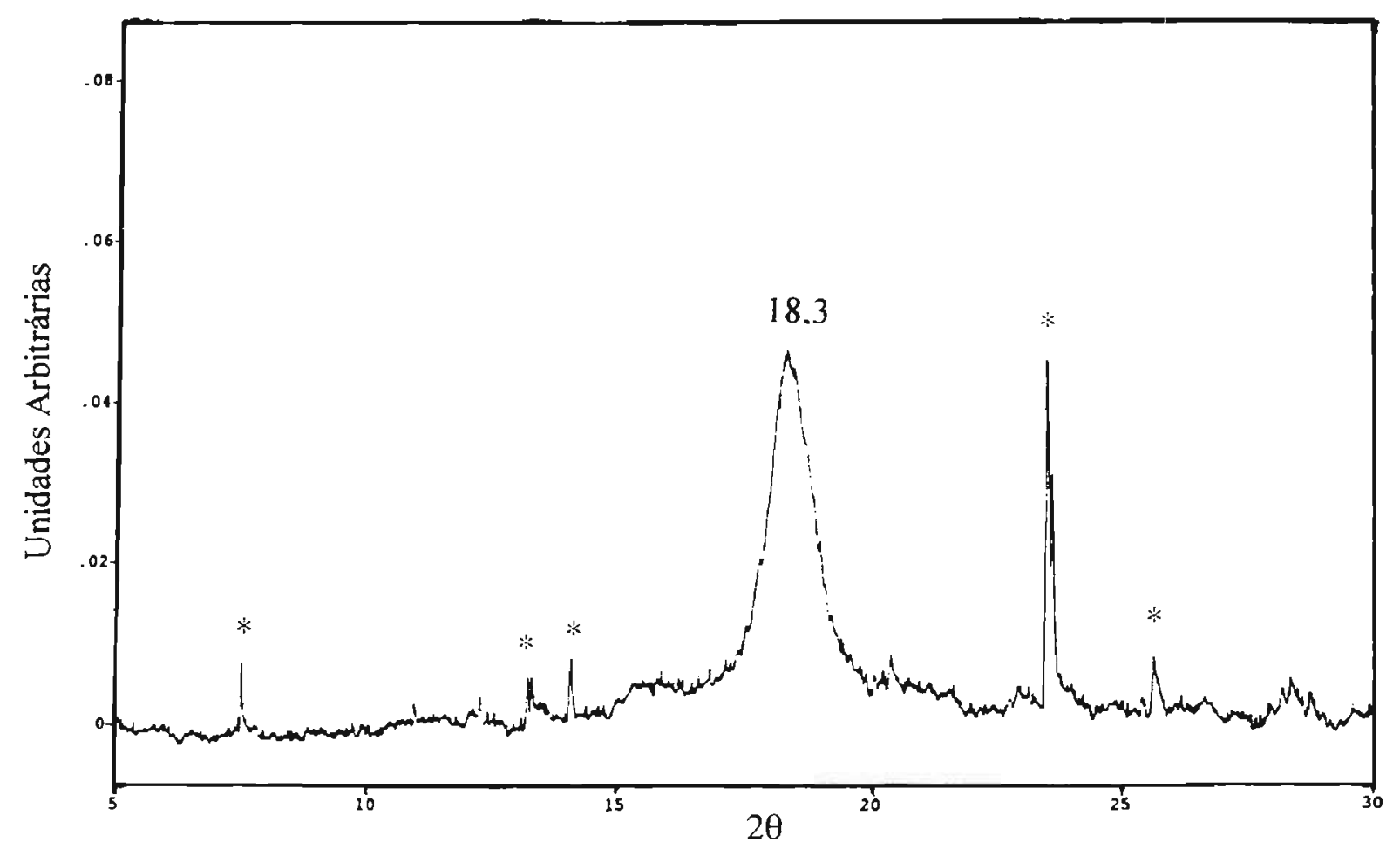

Figura 18: Difratograma de raios-X para o $P(V D F-T r F E)$ irradiado por uma dose de $320 k G y$. 


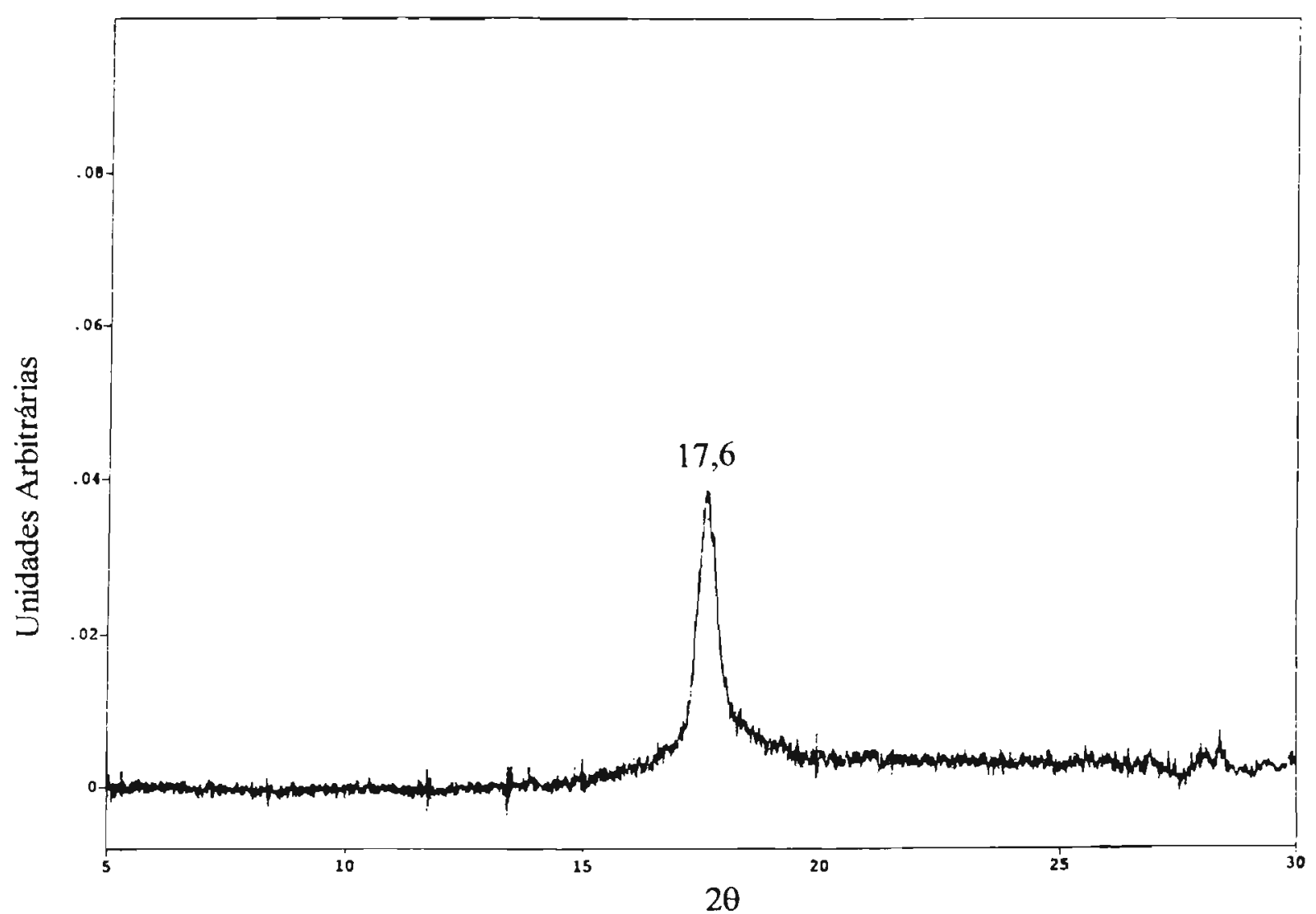

Figura 19: Difratograma de raios-X para o $P(V D F-T r F E)$ irradiado por uma dose de $480 k G y$.

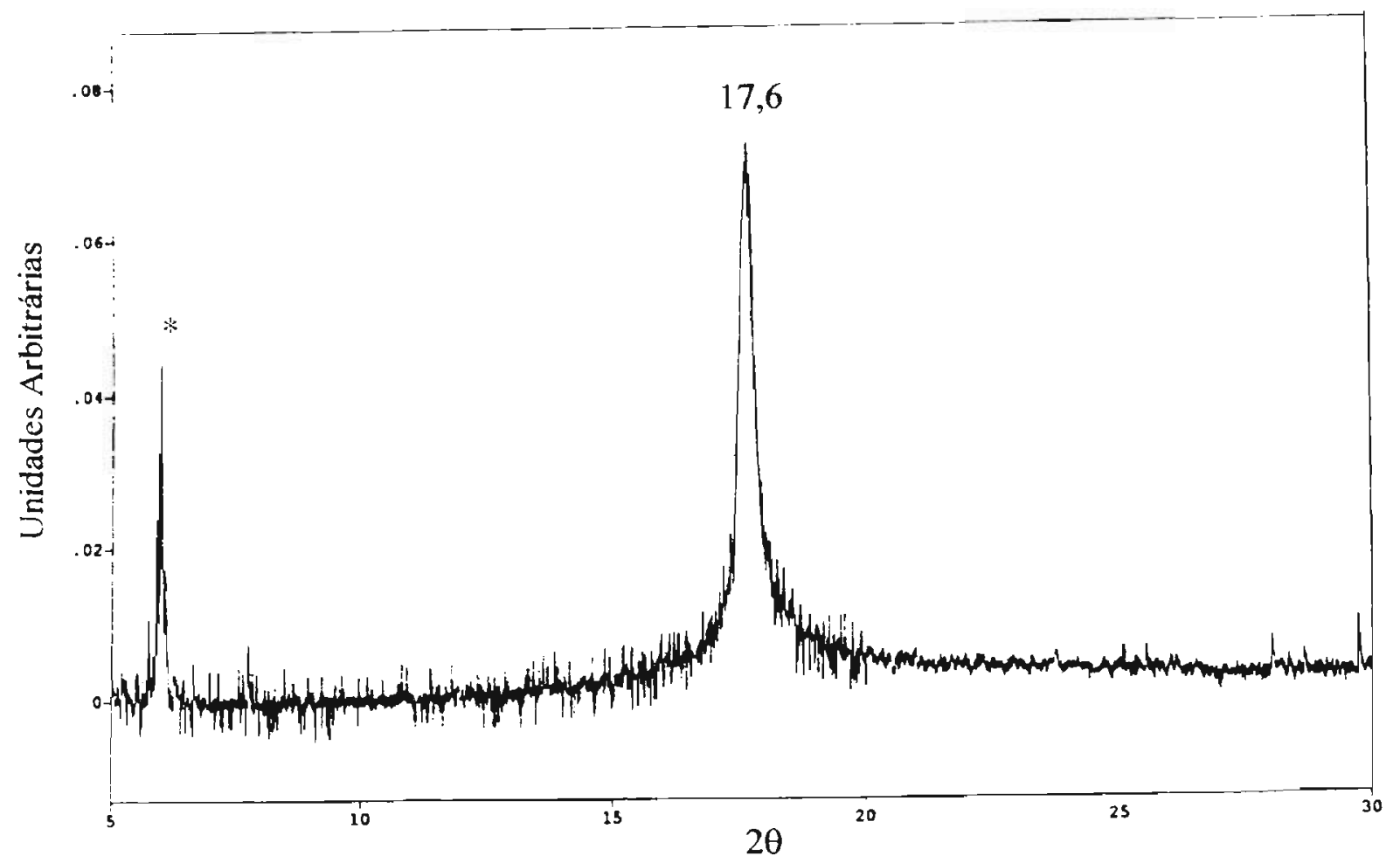

Figura 20: Difratograma de raios-X para o $P(V D F-T r F E)$ irradiado por uma dose de $640 k G y$. 


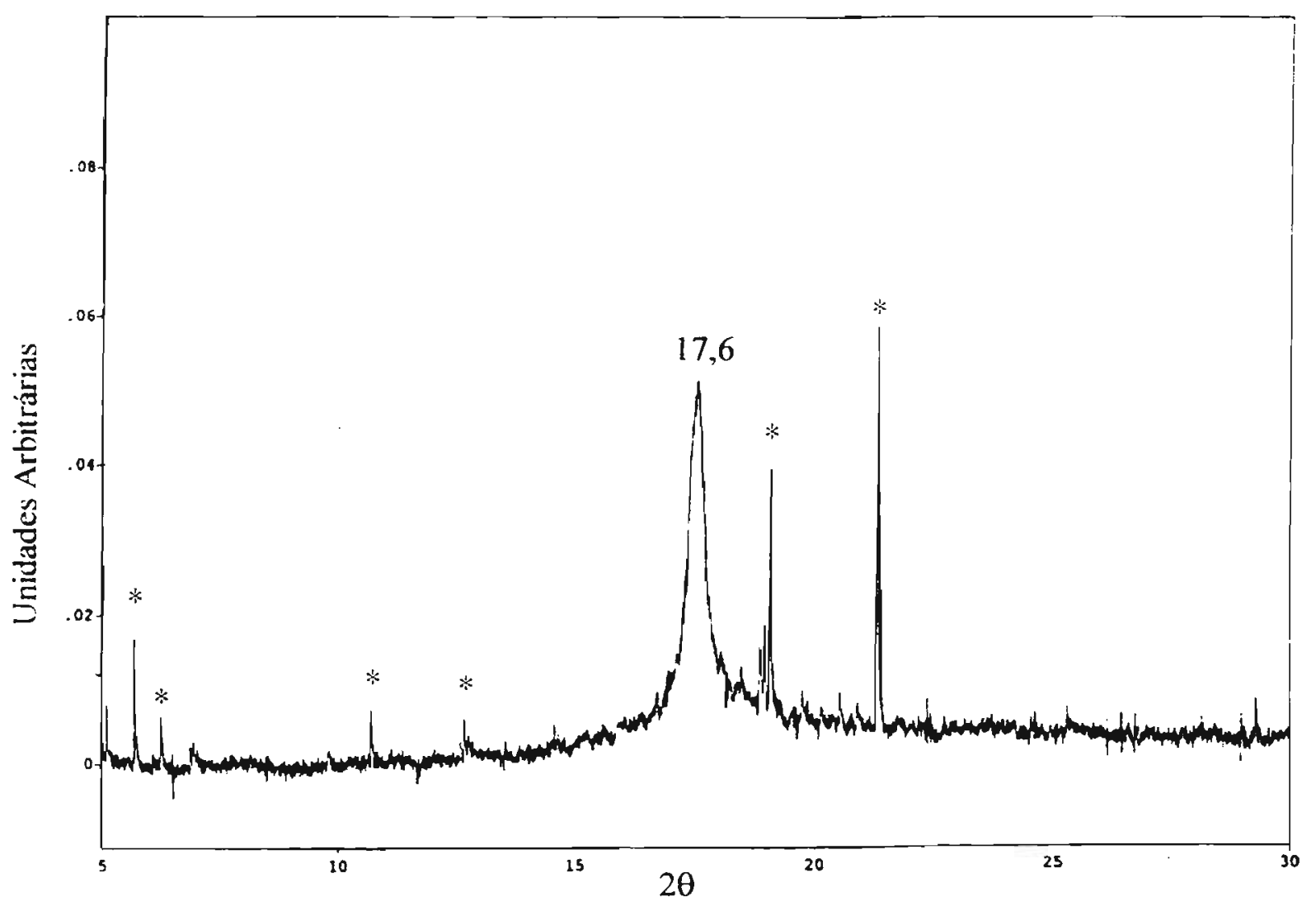

Figura 21: Difratograma de raios-X para o $P(V D F-T r F E)$ irradiado por uma dose de $800 k G y$.

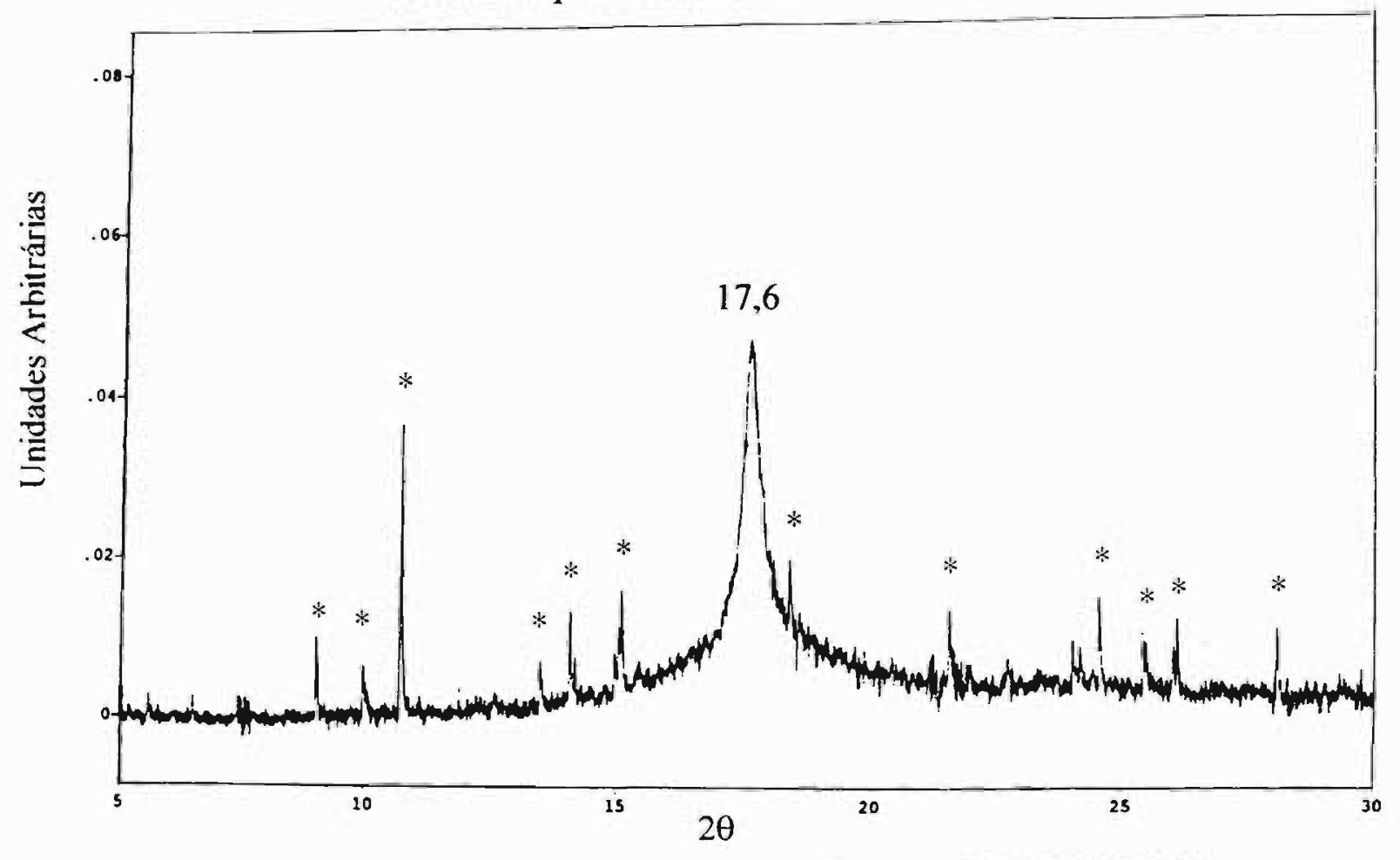

Figura 22: Difratograma de raios-X para o $P(V D F-T r F E)$ irradiado por uma dose de $960 k G y$. 


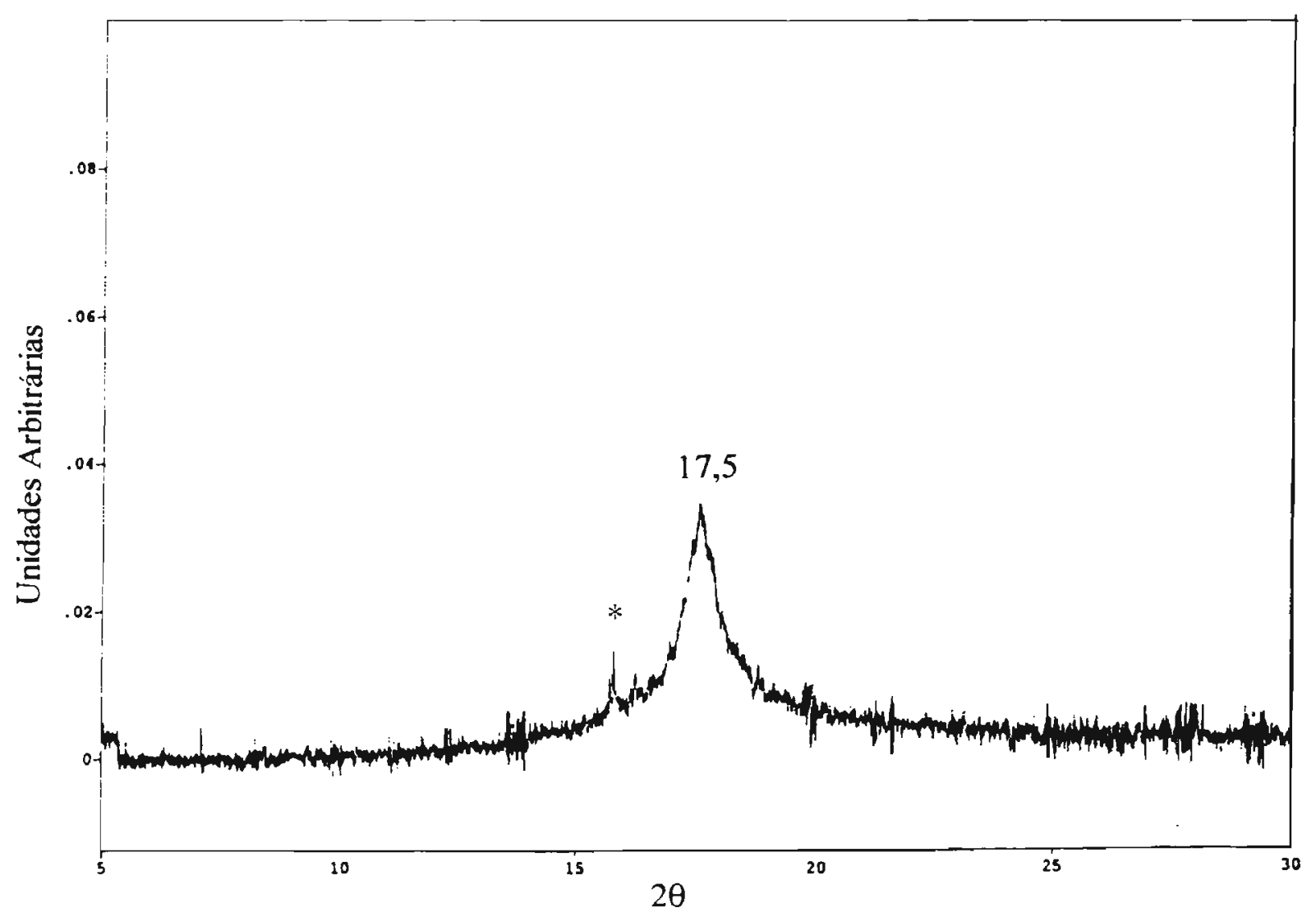

Figura 23: Difratograma de raios-X para o $P(V D F-T r F E)$ irradiado por uma dose de $1120 k G y$.

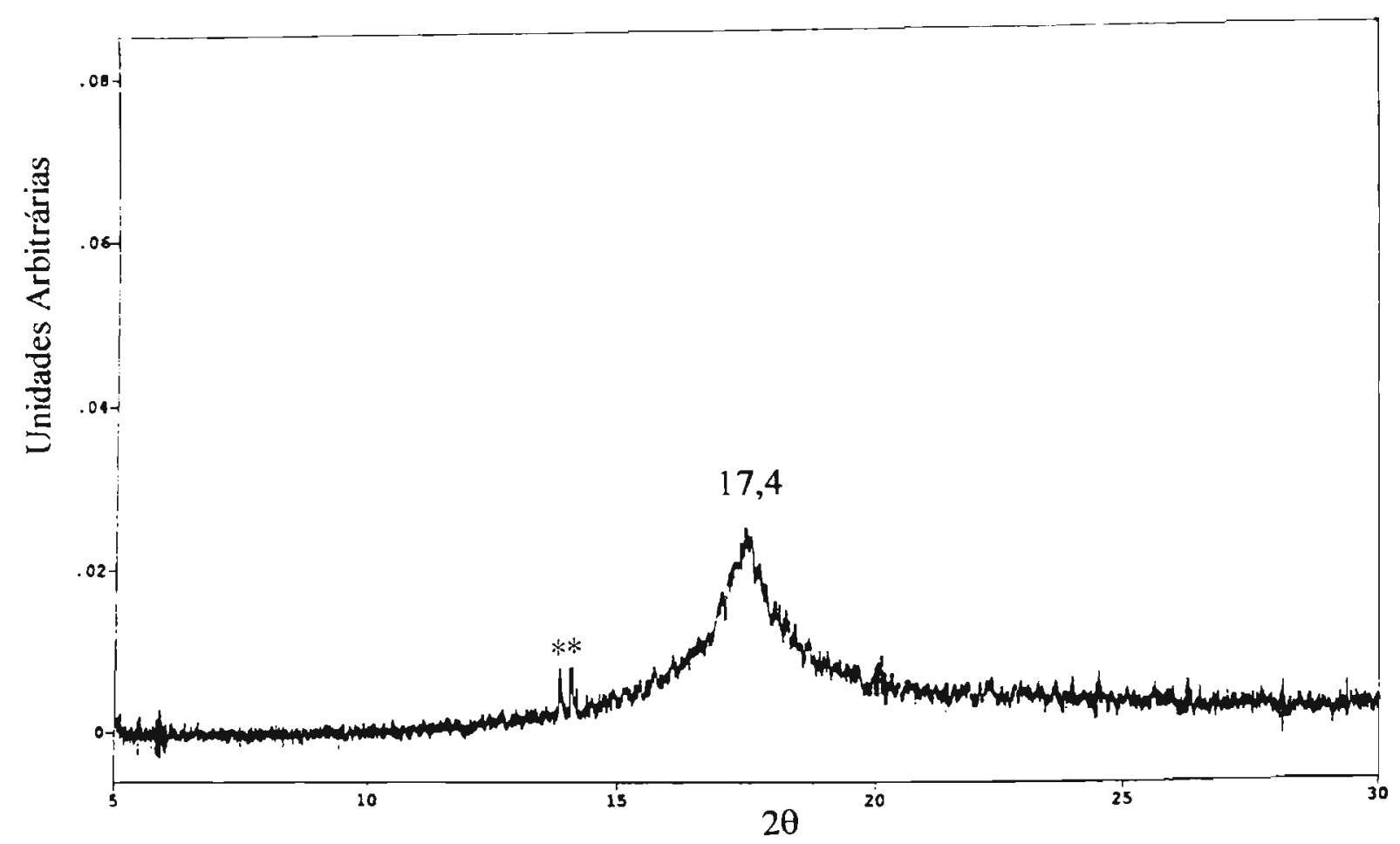

Figura 24: Difratograma de raios-X para o $P(V D F-T r F E)$ irradiado por uma dose de $1280 k G y$. 


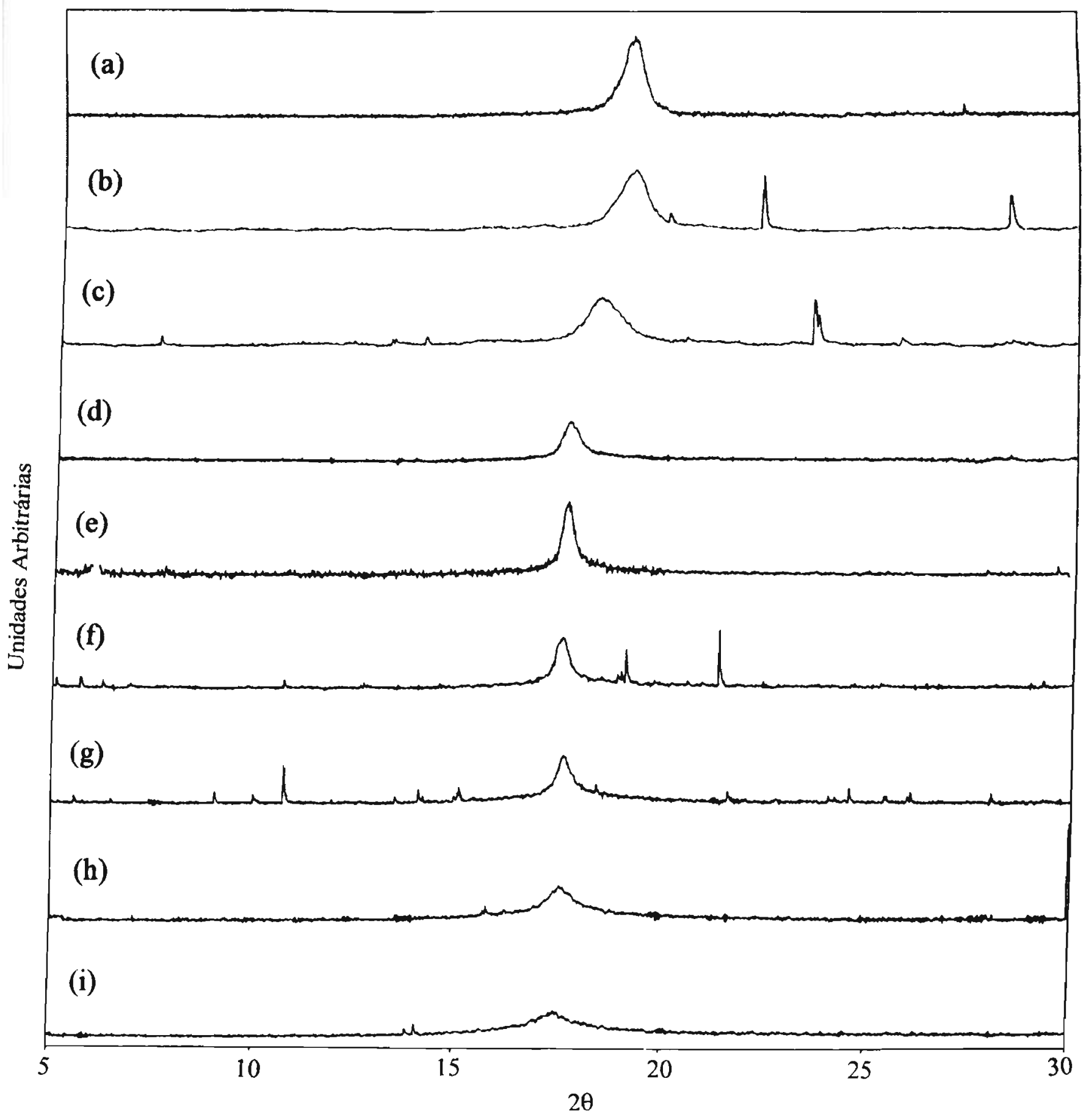

Figura 25: Difratogramas de raios-X para as doses de: (a) não irradiado,

(b) $160 k G y$, (c) $320 k G y$, (d) $480 k G y$, (e) $640 k G y$, (f) $800 k G y$, (g) 960 $k G y$, (h) $1120 k G y e$ (i) $1280 k G y$. 
A Figura 26 mostra a evolução do espaçamento "d", interplanar, obtido a partir dos ângulos de difração, em função da dose aplicada à amostra do copolímero $\mathrm{P}(\mathrm{VDF}-\mathrm{TrFE})$ na razão molar 70:30. Verifica-se que ocorre um aumento da distância interplanar nos cristalitos (região cristalina), como uma das principais informações obtidas pela difração de raios-X.

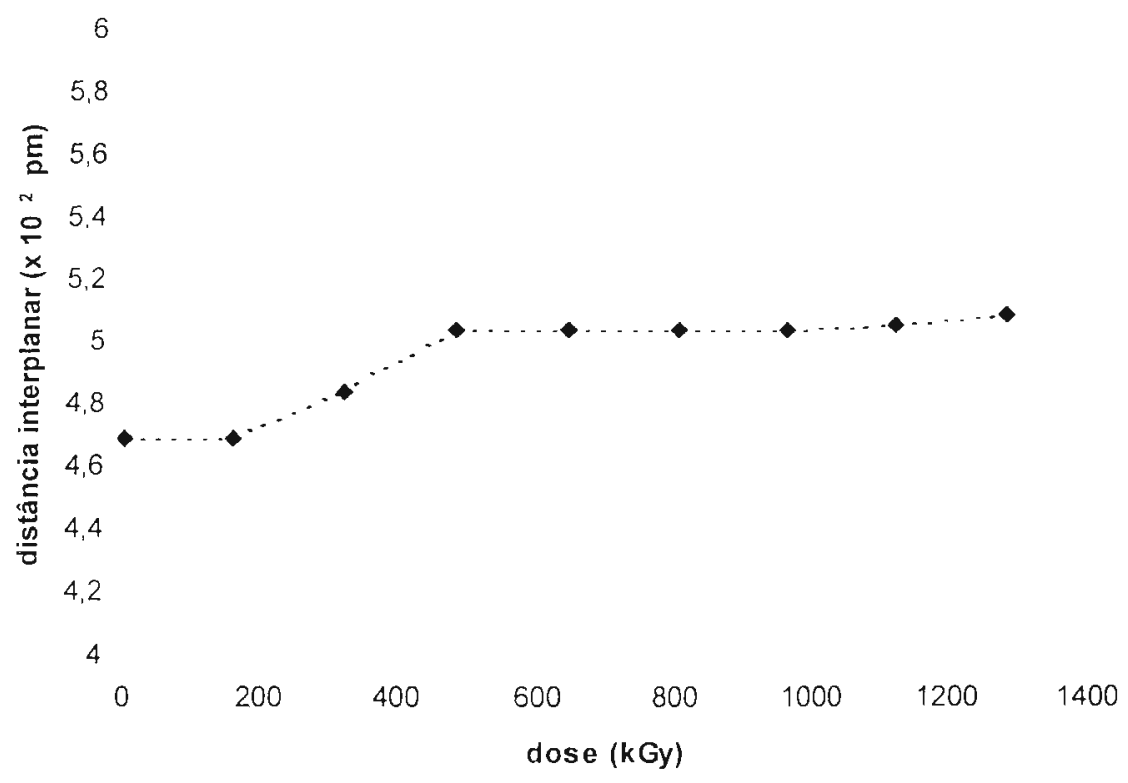

Figura 26: variação da distância interplanar em função da dose aplicada a amostra de P(VDF-TrFE) 70:30.

Os difratogramas de raios-X para os filmes de $\mathrm{P}(\mathrm{VDF}-\mathrm{TrFE})$, na razão molar 60:40, encontram-se representados nas Figuras 27, 28 e 29, respectivamente para a amostra não irradiada e irradiada por 160 e 320 kGy.

Observa-se para a amostra $60: 40$ um pico estreito em $2 \theta=18,6^{\circ}$ quando não irradiado, o qual passa a $2 \theta=18,7^{\circ}$ para a amostra irradiada por 160 kGy com sensível intensificação do pico. A seguir o ângulo desloca 
para $2 \theta=18,3^{\circ}$ quando submetida a uma dose de $320 \mathrm{kGy}$, com nítida diminuição de intensidade.

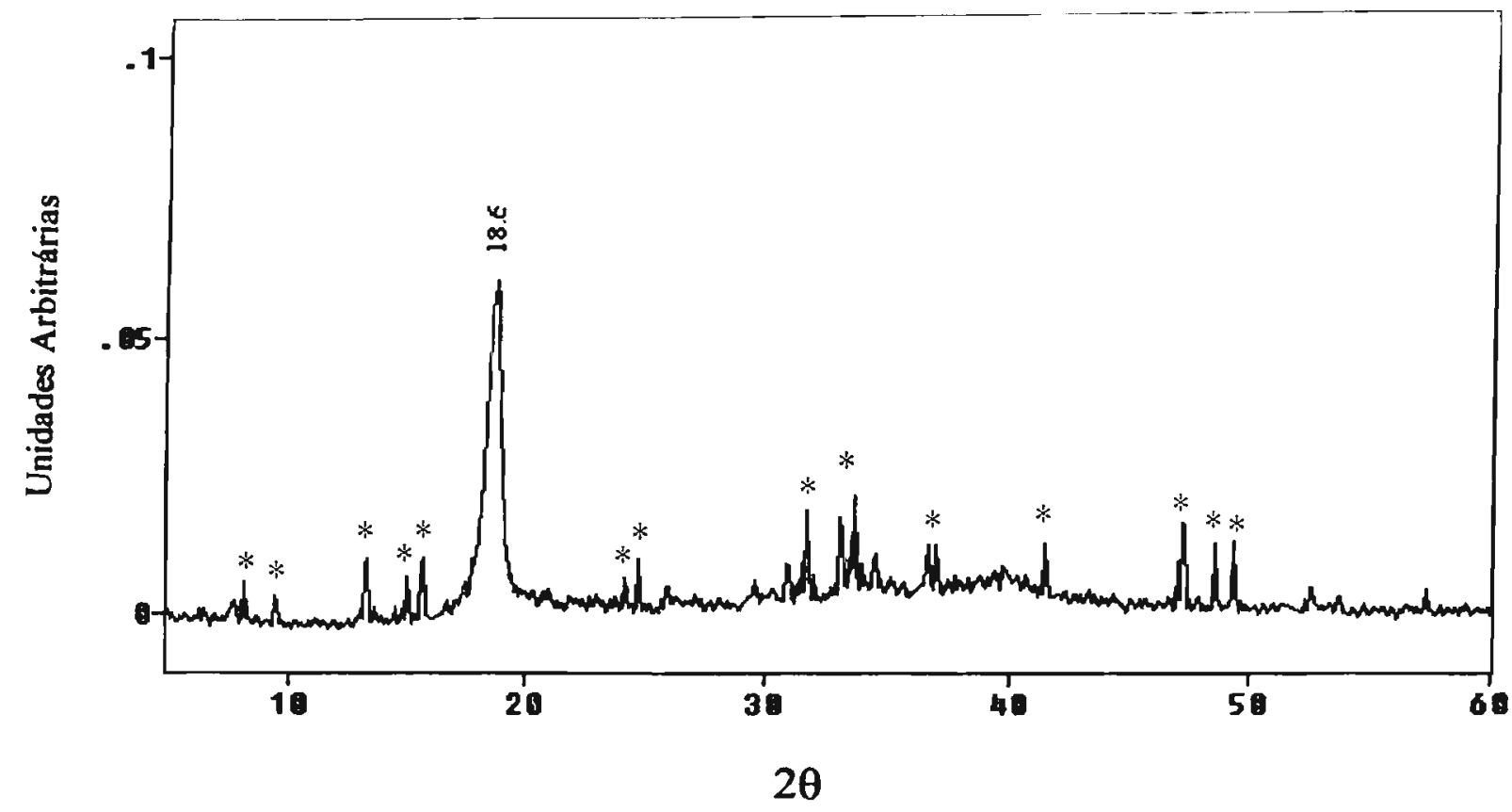

Figura 27: Difratograma de raios-X para o $P(V D F-T r F E)$ 60:40 não irradiado.

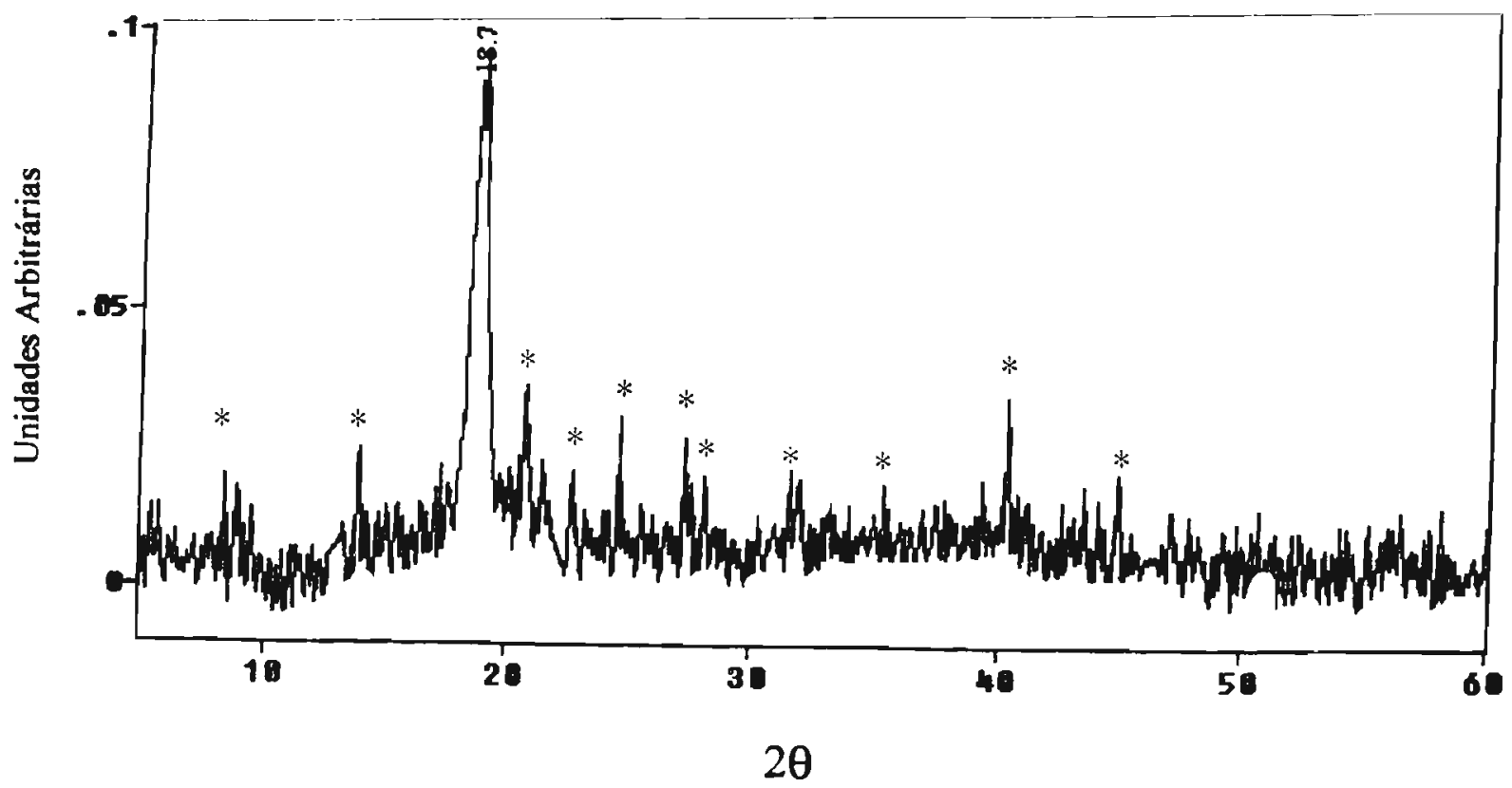

Figura 28: Difratograma de raios-X para o $P(V D F-T r F E)$ 60:40 irradiado por uma dose de $160 k G y$. 


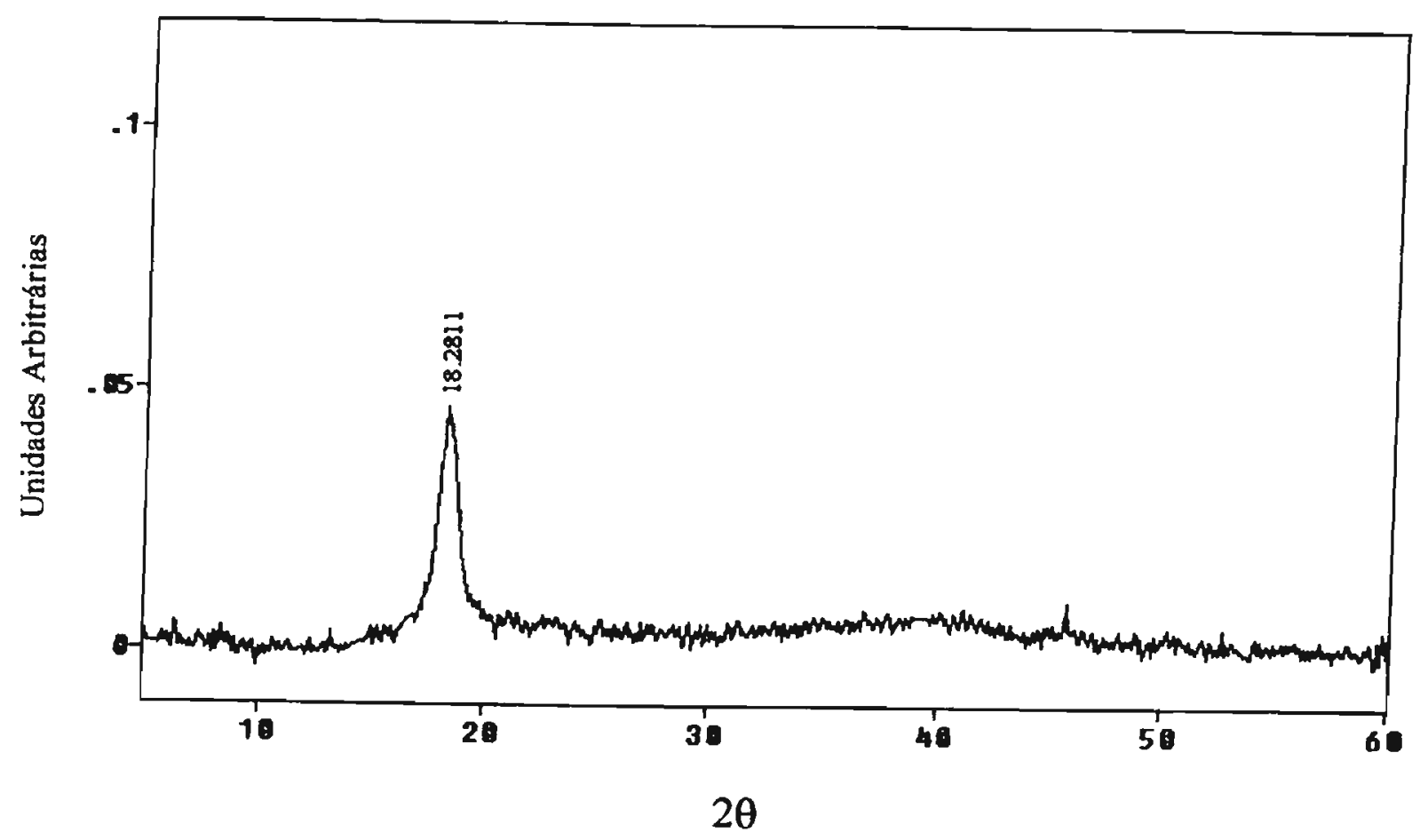

Figura 29: Difratograma de raios-X para o $P(V D F-T r F E)$ 60:40 irradiado por uma dose de $320 \mathrm{kGy}$.

Ao que tudo parece indicar, deve ocorrer, já na dose de 160 kGy, um aumento da intensidade do pico, de forma semelhante à razão molar 70:30. Isso significa que na razão 60:40 o copolímero é mais sensivel à radiação. Segue-se o aumento da intensidade do pico em $18,3^{\circ}$, indicando um processo de mudança de estrutura cristalina, possivelmente, de uma fase ferroelétrica para uma fase paraelétrica.

Estudos do copolímero 60:40 submetidos a radiação-X foram anteriormente realizados [74], contudo não foram discutidos esses aspectos.

A Figura 30 apresenta os difratogramas das amostras 60:40, irradiadas e não irradiadas, de forma a mostrar a semelhança com os eventos observados para o material na razão molar 70:30. 
As Figuras 31 e 32 destacam a região do pico cristalino para as amostras de composição 60:40. É possivel notar que tais picos encontram-se desdobrados, o que foi anteriormente verificado para copolímeros na razão 51:49. respectivamente em VDF e TrFE [72| e também 70:30. 64:36 [49]. Tal fato poderá estar ligado à coexistencia de duas fases ferroelétricas (FA e $F \beta)$.

\section{Unidades Arbitrárias}

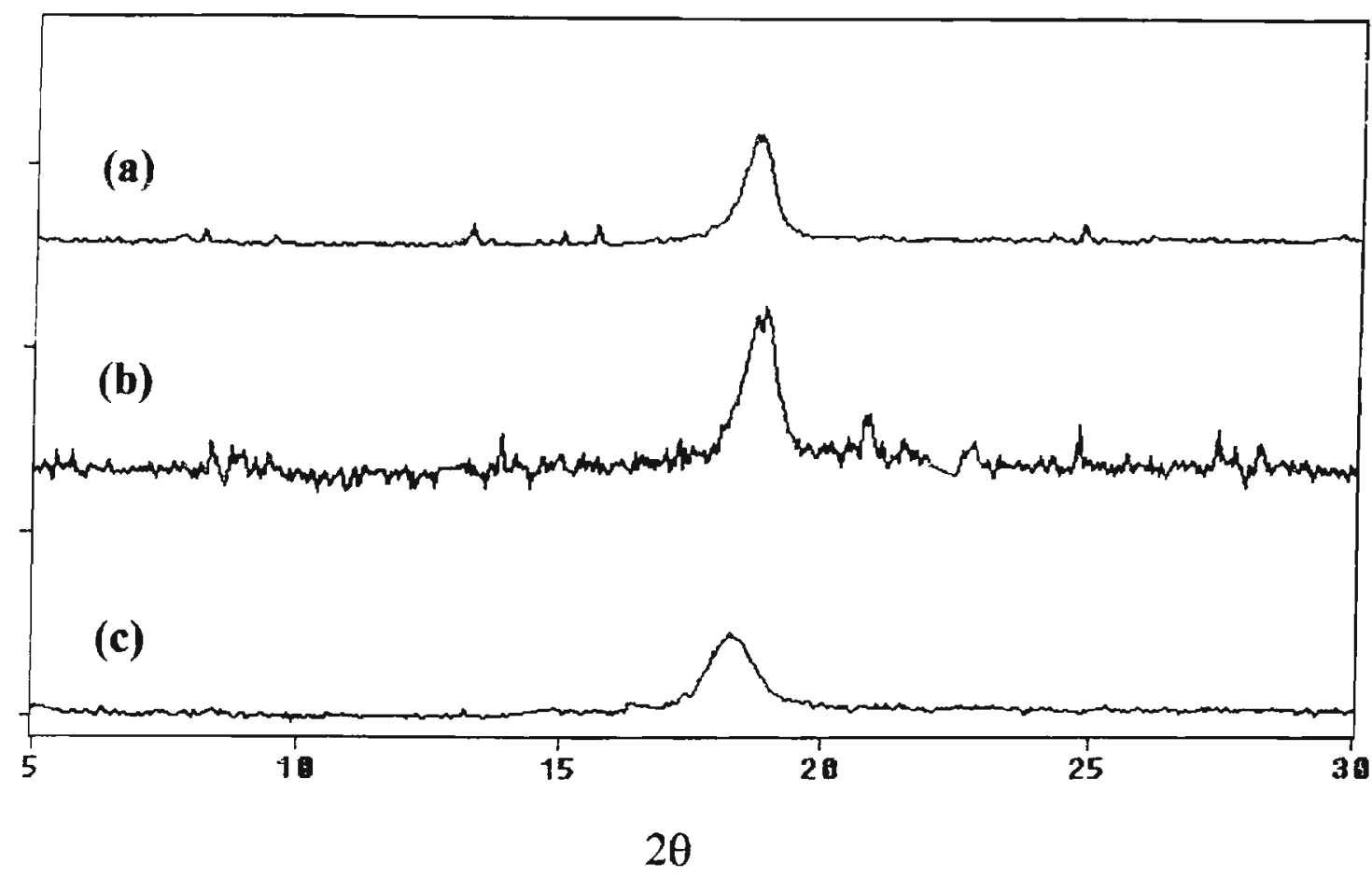

Figura 30: Difratogramas de raios-X para o P(VDF-TrFE) 60:40

(a) não ir radiado. (b) irradiado a uma dose de $160 \mathrm{kGy}$

e (c) irradiado a $320 k G y$. 


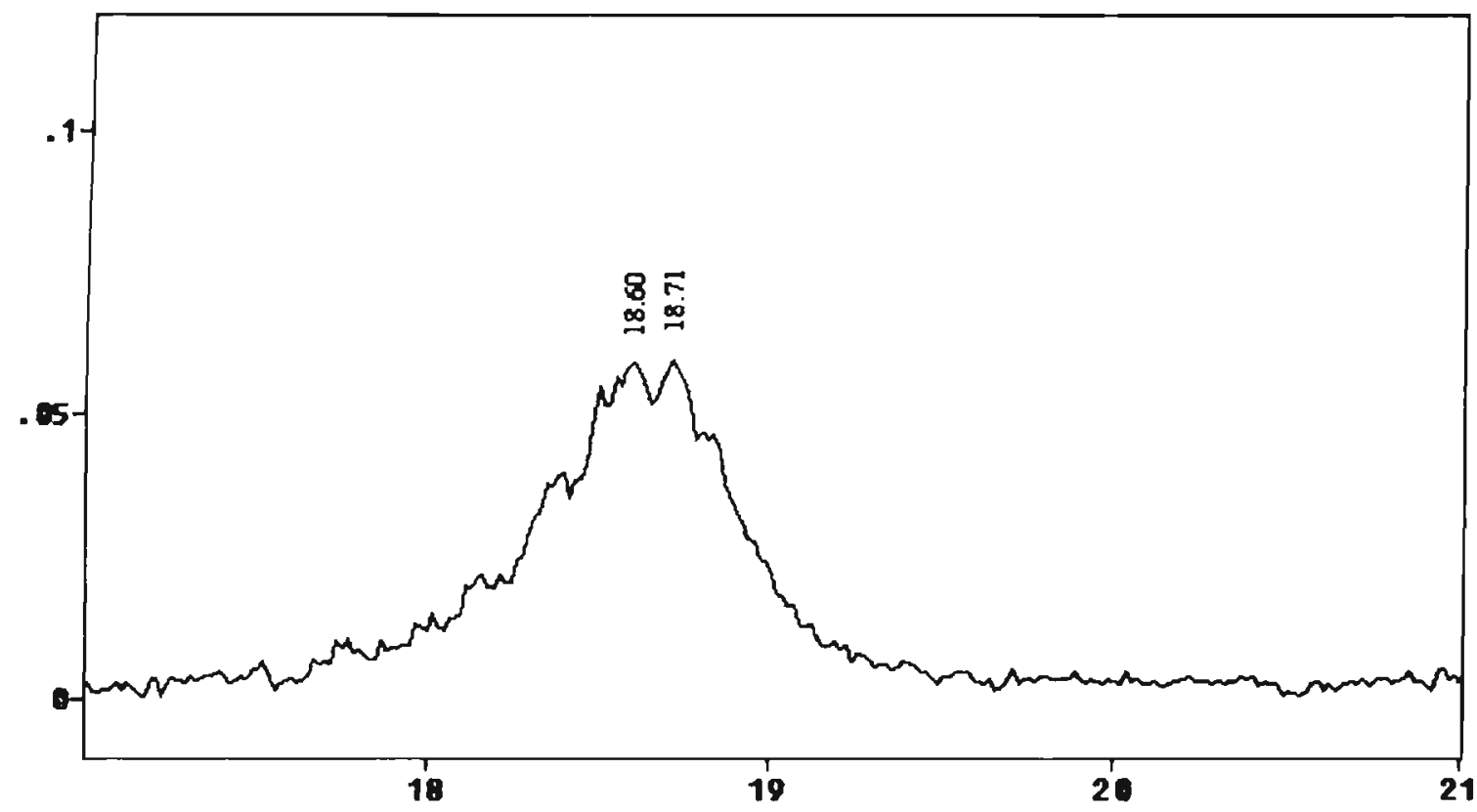

Figura 31: Difratograma de raios-X para o $P(V D F-T r F E)$ 60:40 não irradiado.

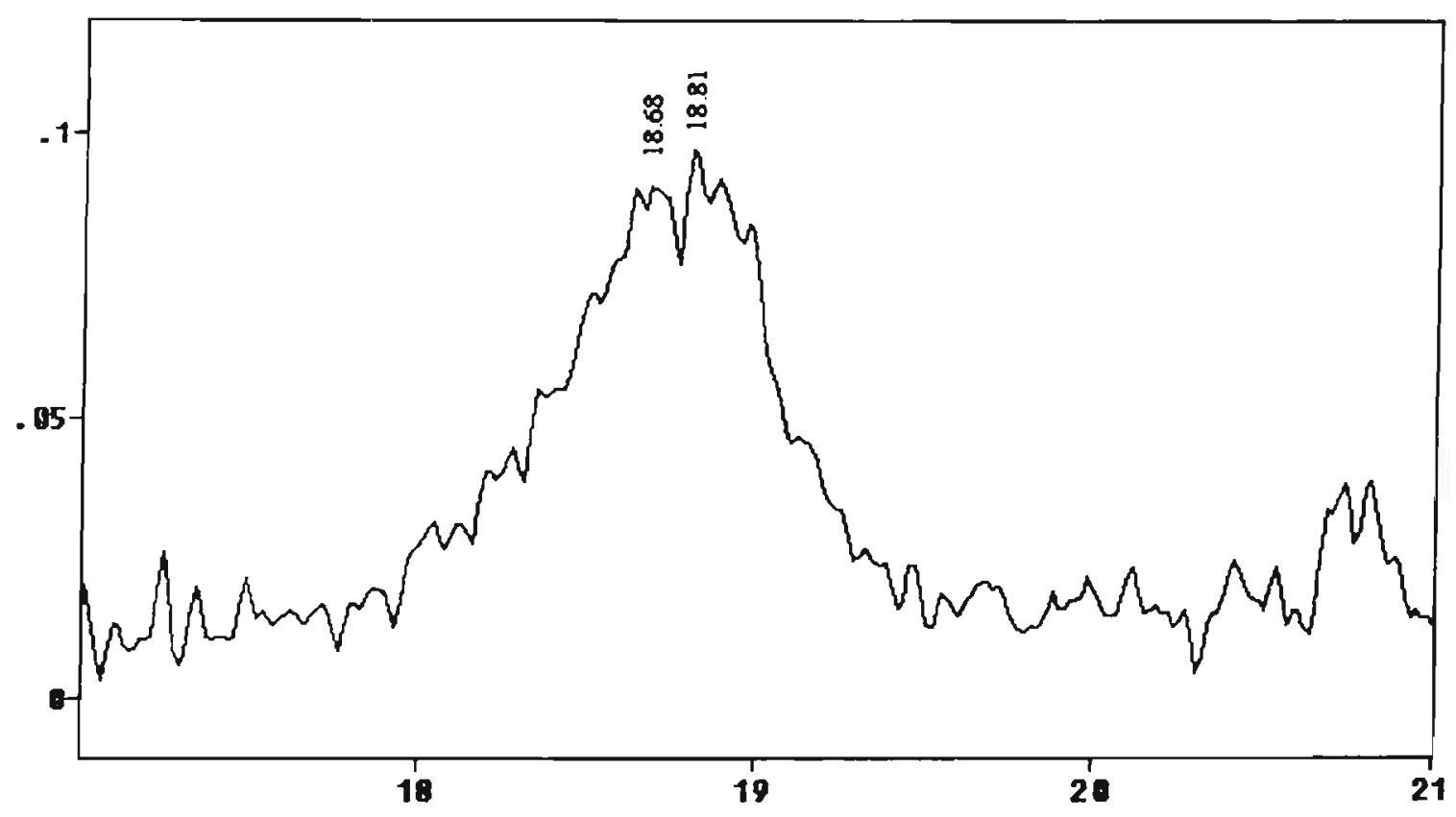

Figura 32: Difratograma de raios-X para o $P(V D F-T r F E)$ 60:40 irradiado por uma dose de $160 \mathrm{kGy}$. 


\section{2- Espectros Vibracionais na Região do Infravermeiho}

\subsection{1- Espectros Fotoacústicos na Região do Infravermelho}

Os espectros vibracionais na região do infravermelho foram obtidos por meio de detecção fotoacústica. uma vez que esta se mostra adequada à análise de filmes com a espessura estudada [75-77]. A região investigada encontra-se compreendida entre 4000 e $450 \mathrm{~cm}^{-1}$.

As atribuições tentativas foram realizadas com base nos dados existentes na literatura para o copolímero e para o PVDF, nas diversas formas cristalinas existentes [78-84].

A Figura 33 mostra o espectro fotoacústico para um filme de $\mathrm{P}(\mathrm{VDF}-\mathrm{TrFE})$ não irradiado. É possível observar a presença de uma banda fraca e larga centrada em $1739 \mathrm{~cm}^{-1}$, correspondente ao estiramento da carbonila, $v(\mathrm{C}=\mathrm{O})$, indício de oxidação prévia da amostra, provavelmente devido ao processo de fusão utilizada na preparação dos filmes.

Em 3011 e $2973 \mathrm{~cm}^{-1}$ ocorrem as bandas associadas aos estiramentos antissimétrico e simétrico, respectivamente, dos grupos metileno, $v\left(\mathrm{CH}_{2}\right)$.

É possível também visualizar nitidamente uma banda intensa em 1406 $\mathrm{cm}^{-1}$, acompanhada de bandas de menor intensidade em 1430 e $1453 \mathrm{~cm}^{-1}$. As duas primeiras foram anteriormente observadas para o PVDF e atribuídas por Kobayashi et al. [78] e Bachmann et al. [79], sendo aquela observada em $1406 \mathrm{~cm}^{-1}$ associada majoritariamente ao modo "wagging" do grupo metileno, $\omega\left(\mathrm{CH}_{2}\right)$, e aquela em $1430 \mathrm{~cm}^{-1}$. também majoritariamente, ao modo de deformação angular do grupo $\mathrm{CH}_{2}, \delta\left(\mathrm{CH}_{2}\right)$, como contribuição principal. É 
muito interessante notar, que tais atribuições coincidem com aquelas observadas para a fase- $\beta$ do PVDF [79].

Em $1345 \mathrm{~cm}^{-1}$ ocorre uma banda de intensidade média, a qual encontra como atribuição mais provável a composição dos modos de $\delta\left(\mathrm{CH}_{2}\right)$ e $\omega\left(\mathrm{CH}_{2}\right)$. Embora tal freqüência não tenha sido observada anteriormente para nenhuma forma cristalina do PVDF, Bachmann et al. [79] obtiveram o valor de freqüência $1356 \mathrm{~cm}^{-1}$ no cálculo do espectro vibracional da fase- $\gamma$ do PVDF. Possivelmente, a inserção do grupo TrFE (trifluoretileno) e conseqüente modificação de simetria e momento dipolar na cela unitária do copolímero, permite a atividade de tal banda no infravermelho.

Em $1293 \mathrm{~cm}^{-1}$ ocorre uma banda intensa que foi observada anteriormente, em $1294 \mathrm{~cm}^{-1}$, no espectro IV do PVDF em sua fase- $\alpha$ [79]. A atribuição tentativa feita pelos autores corresponde à composição dos modos de estiramento antissimétrico do grupo $\mathrm{CF}_{2}, v_{\mathrm{a}}\left(\mathrm{CF}_{2}\right)$, e "rocking" $\mathrm{CH}_{2}$, $\rho\left(\mathrm{CH}_{2}\right)$.

Se a banda em $1293 \mathrm{~cm}^{-1}$ é de fato, uma banda característica de uma fase ferroelétrica (fase-A, semelhante à fase $\alpha$ do PVDF), então, uma vez que as bandas em 1430 e $1406 \mathrm{~cm}^{-1}$ parecem caracterizar uma outra fase, $\beta$, o copolímero deve se encontrar com 2 fases cristalinas coexistentes. Tal hipótese é amplamente sustentada pelos dados de DSC para o copolímero não irradiado, que mostram dois pequenos picos endotérmicos abaixo da fusão, correspondentes à coexistência de 2 fases cristalinas [49].

Uma região de bandas intensas e sobrepostas, compreendida entre cerca de $1300 \mathrm{a} 1000 \mathrm{~cm}^{-1}$, é observada para o copolímero P(VDF-TrFE), de forma semelhante ao espectro do PVDF [10]. É possível observar bandas intensas nessa região, em 1196 e $1130 \mathrm{~cm}^{-1}$, que não são verificadas com tais valores para nenhuma das formas cristalinas do PVDF. Bandas em tal região 
estão associadas à composição de modos vibracionais de estiramento simétrico do grupo $\mathrm{CF}_{2}, v_{\mathrm{s}}\left(\mathrm{CF}_{2}\right)$, estiramentos antissimétricos de esqueletos carbônico, $v_{a}(\mathrm{C}-\mathrm{C})$, além de modos "wagging" e "twisting" metilênicos, $\omega$ $\left(\mathrm{CH}_{2}\right)$ e $\mathrm{t}\left(\mathrm{CH}_{2}\right)$ [79].

Foi observado anteriormente, para todas as formas cristalinas do PVDF, uma banda intensa em $1175 \mathrm{~cm}^{-1}$ a qual é associada à contribuição majoritária do estiramento antissimétrico $\mathrm{CF}_{2}, v_{\mathrm{a}}\left(\mathrm{CF}_{2}\right)$. Assim, a banda intensa observada em $1196 \mathrm{~cm}^{-1}$ para o copolímero, deslocada em cerca de $20 \mathrm{~cm}^{-1}$ do valor verificado no PVDF, parece corresponder a tal atribuição, considerados os efeitos da inserção do comonômero TrFE.

A presença de duas intensas bandas em 887 e $852 \mathrm{~cm}^{-1}$ é característica para o copolímero P(VDF-TrFE), e também para o PVDF. Bachmann et al. [79] observaram grande dependência de tais bandas com a radiação polarizada (// e $\perp$ ) no espectro de absorção no infravermelho, para o PVDF na fase- $\beta$. Desta forma, as bandas observadas em $884 \mathrm{e} 840 \mathrm{~cm}^{-1}$ são intensas quando o vetor elétrico é perpendicular à direção de estiramento do material, enquanto que, quando o vetor elétrico é paralelo à orientação do polímero, ocorre grande diminuição de intensidade das bandas, em especial daquela em $840 \mathrm{~cm}^{-1}$ que praticamente desaparece.

Resultado semelhante foi verificado por Kobayashi et al. [78], que mostram também o efeito causado no material fundido onde a banda em 840 $\mathrm{cm}^{-1}$ desaparece. Tais efeitos indicam que tal banda está associada à estrutura cristalina do material.

Os autores acima citados $[\mathbf{7 8 , 7 9}]$ atribuem, para o PVDF, a banda em $884 \mathrm{~cm}^{-1}$ a uma contribuição dos modos vibracionais $v_{\mathrm{S}}\left(\mathrm{CF}_{2}\right)$ e $v_{1}(\mathrm{C}-\mathrm{C})$ com contribuição principal do primeiro modo. A banda em $840 \mathrm{~cm}^{-1}$, também para 
o PVDF, é atribuída a combinação dos modos "rocking" metilênico, $\rho\left(\mathrm{CH}_{2}\right)$, e $v_{\mathrm{a}}\left(\mathrm{CF}_{2}\right)$ com participação majoritária de $\rho\left(\mathrm{CH}_{2}\right)$.

É possivel perceber a presença de uma banda de pequena intensidade locada em $780 \mathrm{~cm}^{-1}$. No caso do PVDF, é verificada uma banda em $775 \mathrm{~cm}^{-1}$ para a fase cristalina $\gamma$, que é atribuída a uma combinação dos modos $\rho$ $\left(\mathrm{CH}_{2}\right), v_{\mathrm{s}}\left(\mathrm{CF}_{2}\right)$ e $\omega\left(\mathrm{CF}_{2}\right)$ [79]. Além desta, pode ser observada também uma banda intensa em $511 \mathrm{~cm}^{-1}$, verificada na fase- $\beta$ do PVDF $[85,86]$ e atribuída à deformação angular do grupo $\mathrm{CF}_{2}, \delta\left(\mathrm{CF}_{2}\right)$, e em $530 \mathrm{~cm}^{-1}$, verificada na fase- $\alpha$ do PVDF com igual atribuição.

A Figura 34 mostra o espectro fotoacústico de um filme de P(VDFTrFE) irradiado por $1 \mathrm{~h}$, totalizando uma dose de $160 \mathrm{kGy}$. Poucas mudanças são detectáveis, destacando-se apenas a intensificação da banda correspondente a presença de carbonilas e pequenos deslocamentos dos modos $v_{\mathrm{a}}$ e $v_{\mathrm{s}}\left(\mathrm{CH}_{2}\right)$.

Após uma dose de $320 \mathrm{kGy}$ podem ser notados efeitos significativos nas intensidades relativas das bandas do copolímero, conforme mostra a Figura 35. Verifica-se assim, uma pequena diminuição das bandas correspondentes aos estiramentos $\mathrm{CH}_{2}$ em 3014 e $2977 \mathrm{~cm}^{-1}$, intensificação da banda em $1740 \mathrm{~cm}^{-1}$ e o aparecimento de uma banda em $1847 \mathrm{~cm}^{-1}$ atribuída tentativamente ao estiramento $v(\mathrm{C}=\mathrm{O})$ em ambiente eletronegativo $[80]$.

É notável a diminuição da intensidade relativa (em relação às bandas em 1406 e $1202 \mathrm{~cm}^{-1}$ ) das bandas 1425, 1282 e $1076 \mathrm{~cm}^{-1}$. Destaca-se ainda, a queda da intensidade da banda em $850 \mathrm{~cm}^{-1}$ em relação àquela em $888 \mathrm{~cm}^{-1}$. Uma vez que a banda em $850 \mathrm{~cm}^{-1}$ está associada à cristalinidade do material, tal evento indica, possivelmente, uma modificação da estrutura cristalina para uma forma menos ordenada do copolímero. 
A Figura 36 apresenta o espectro fotoacústico na região do infravermelho para um filme de P(VDF-TrFE) irradiado por $3 \mathrm{~h}$, totalizando uma dose de $480 \mathrm{kGy}$.

Os efeitos mais significativos em relação à dose anterior são, o desaparecimento da banda em $1282 \mathrm{~cm}^{-1}$, provavelmente associada à combinação entre $v_{\mathrm{a}}\left(\mathrm{CF}_{2}\right)$ e $\rho\left(\mathrm{CH}_{2}\right)$, e uma nova queda de intensidade da banda em cerca de $849 \mathrm{~cm}^{-1}$. Tais fatos parecem evidenciar a diminuição da cristalinidade do material ou uma mudança estrutural para uma forma menos ordenada.

Através da Figura 36 é possível notar o aparecimento de bandas fracas em 3860 e $3752 \mathrm{~cm}^{-1}$. Este comportamento parece se manter para doses de irradiação maiores, e não foi observado anteriormente nos espectros de absorção no infravermelho, o que leva a crer que seja um fenômeno de superfície que ocorra em pequena intensidade sobre o material, não sendo detectável por transmitância. A atribuição mais próxima e mais provável para tais bandas está relacionada à formação de grupos -OH em interação com os átomos de flúor das cadeias vizinhas [87]. Ligações de hidrogênio intermoleculares de grupos -OH com halogênios, $\mathrm{OH}^{\cdots} \mathrm{F}$ no caso, são conhecidas e resultam em absorçòes no infravermelho em cerca de $3600 \mathrm{~cm}^{-1}$ ou números de onda maiores [81]. A formação de grupos $-\mathrm{OH}$ ou $-\mathrm{O}-\mathrm{OH}$ no copolímero pode ter origem na desativação dos radicais formados durante o processo de irradiação, quando o material é exposto ao ar atmosférico (após a irradiação, que é feita a vácuo, $\sim 10^{-3} \mathrm{mmHg}$ ).

Uma outra hipótese para a observação destes altos números de onda é a possível dessorção de pequenas quantidades de gás HF no material irradiado da cela fotoacústica. Verifica-se para o $\mathrm{HF}$ na fase vapor uma freqüência de estiramento, $v(\mathrm{HF})$, de $3961 \mathrm{~cm}^{-1}$ [81]. A banda fraca observada 
em $3860 \mathrm{~cm}^{-1}$ poderia corresponder ao estiramento $\mathrm{HF}$, contudo, espectros na fase vapor apresentam estruturas finas rotacionais que neste caso se confundem com o nível de ruído.

Após uma dose de irradiação de $640 \mathrm{kGy}$ foi registrado o espectro fotoacústico do filme, que encontra-se representado na Figura 37.

São notáveis pequenas intensificações das bandas localizadas em 1127 e $847 \mathrm{~cm}^{-1}$, além de um aumento da banda de pequena intensidade em 774 $\mathrm{cm}^{-1}$ em relação ao material não irradiado. Tais intensificações, em especial da banda em $847 \mathrm{~cm}^{-1}$, podem estar relacionadas com um pequeno aumento no grau de cristalinidade do copolímero após exposição a esta dose de irradiação. Aumentos de cristalinidade desse tipo foram observados para o material examinado por difração de raios-X, irradiado pela mesma dose conforme o item $\mathbf{3 . 1}$ desta tese.

Após uma dose de $800 \mathrm{kGy}$ os efeitos da irradiação podem ser notados através da Figura 38. Nota-se a presença de bandas pouco intensas em 3860 e $3746 \mathrm{~cm}^{-1}$, acima discutidas. Observa-se que a posição das bandas relacionadas aos estiramentos $\mathrm{CH}_{2}, 3022$ e $2979 \mathrm{~cm}^{-1}$, encontram-se agora significativamente deslocados da posição no material não irradiado, $3011 \mathrm{e}$ $2973 \mathrm{~cm}^{-1}$. Tal fato é indicativo de uma modificação da estrutura molecular. Além destes eventos, é possível, ainda, notar uma diminuição das bandas em 888 e $849 \mathrm{~cm}^{-1}$.

Para a dose $960 \mathrm{kGy}$ os espectros fotoacústicos do material encontramse representados pela Figura 39. Para $1120 \mathrm{kGy}$ na Figura 40 e, finalmente, para a dose de 1280 kGy na Figura 41.

Em todos os casos acima, as tendências observadas anteriormente se repetem, indicando perda da cristalinidade do material e oxidação da superfície com formação de carbonilas e grupos $-\mathrm{OH}$ em interação com flúor. 


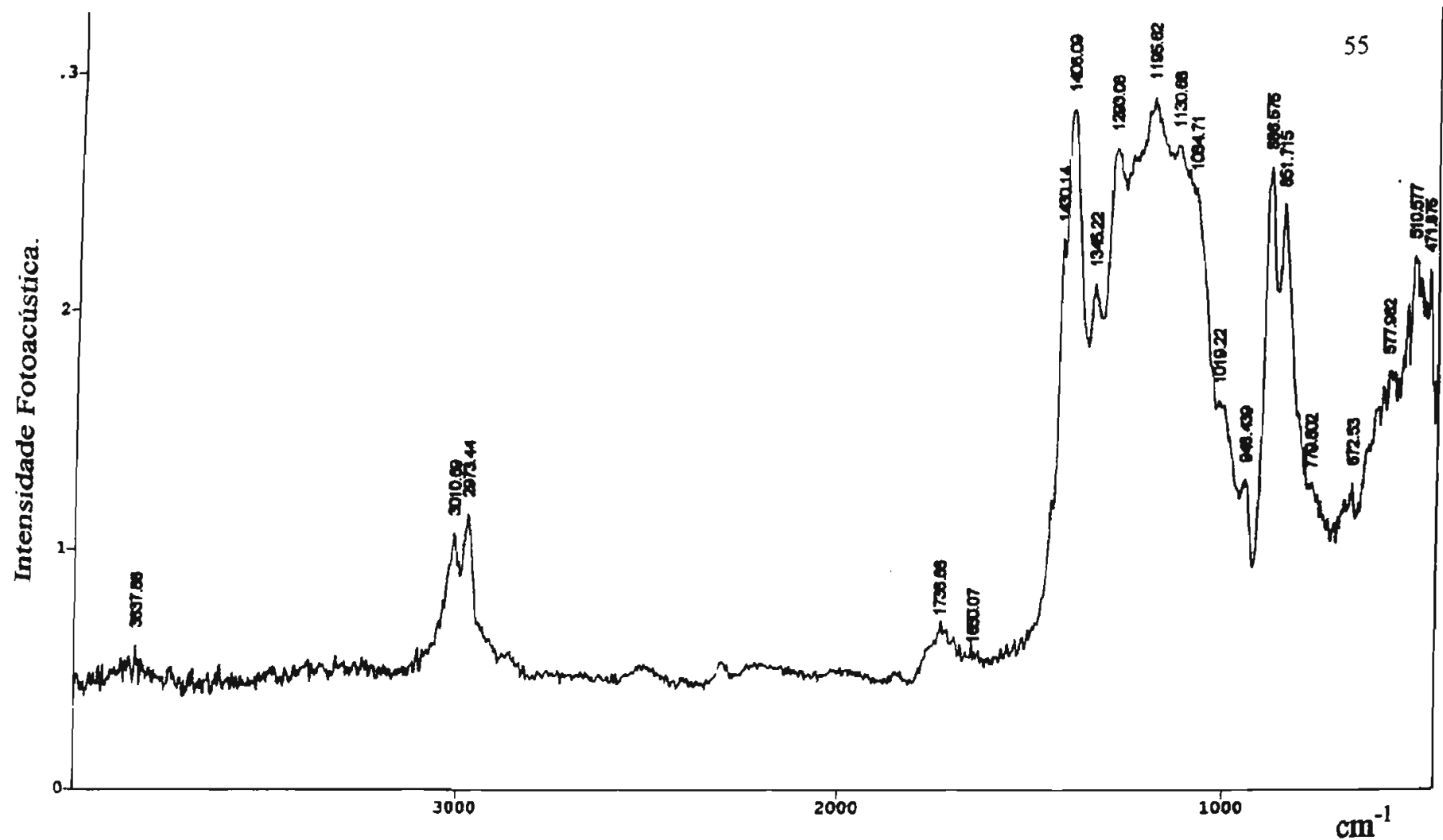

Figura 33: Espectro fotoacústico no infravermelho para uma amostra de

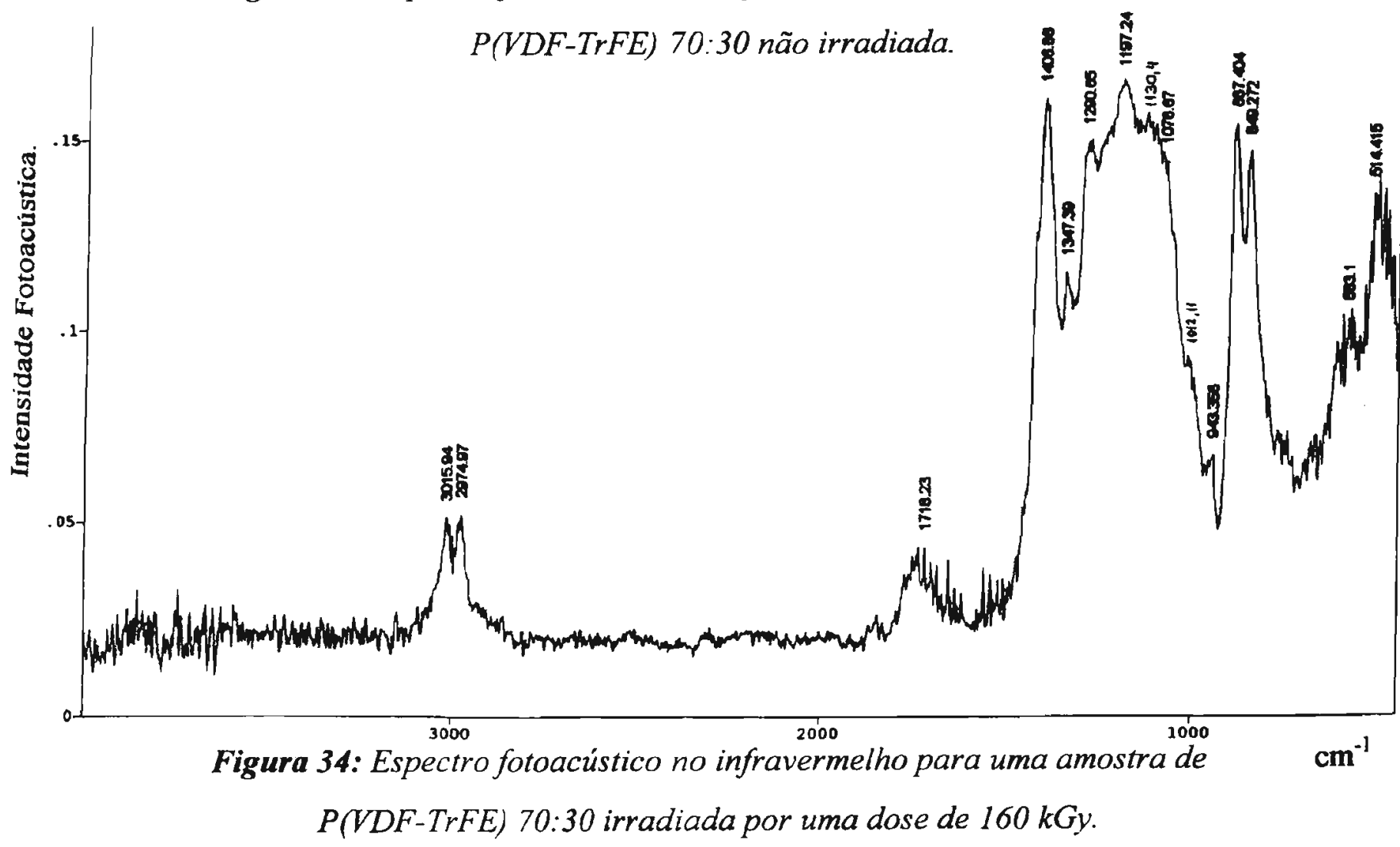




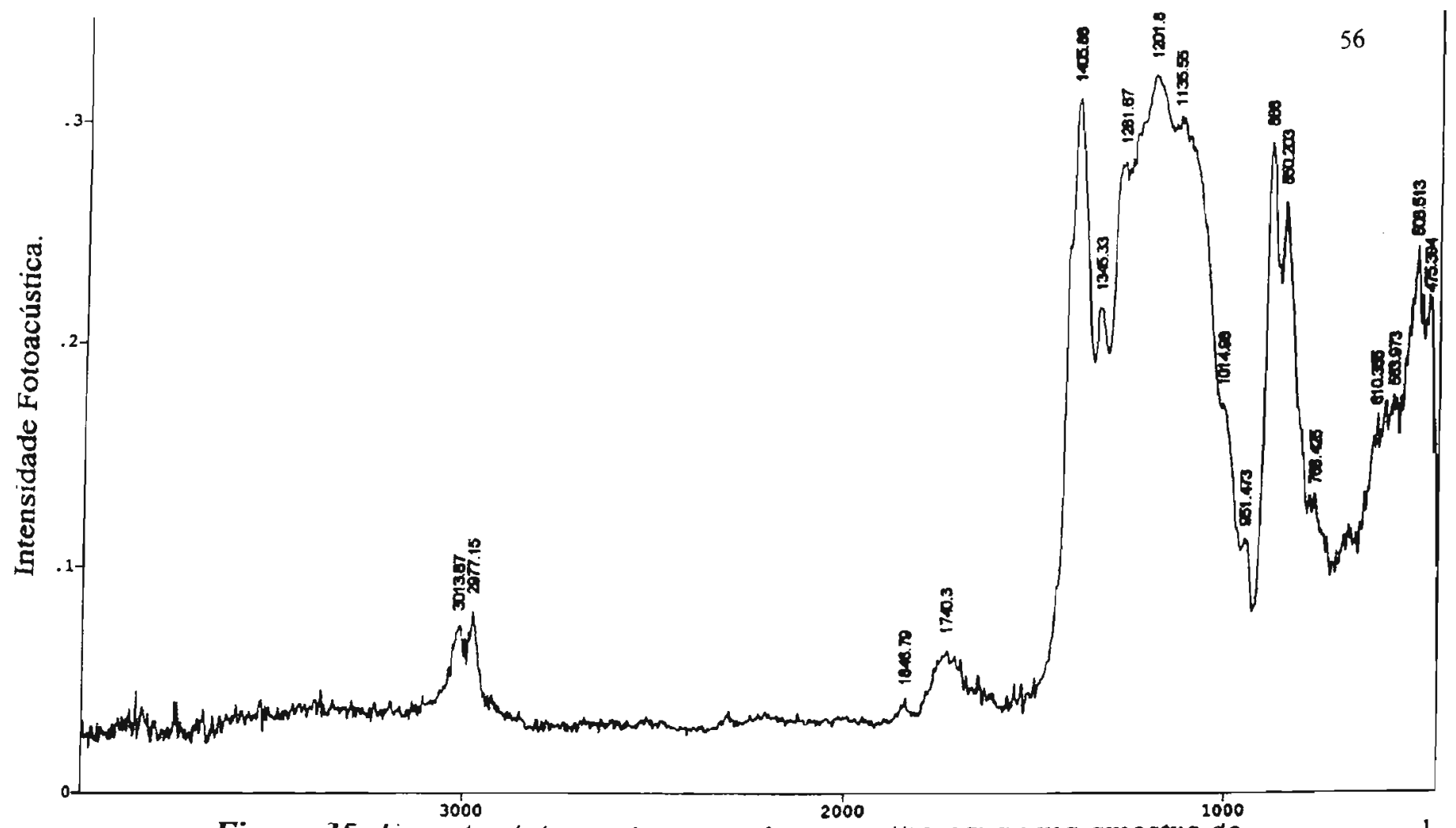

Figura 35: Espectro fotoacustlco no intraverme tho para uma amostra de $\mathrm{cm}^{-1}$ $P(V D F-T r F E) 70: 30$ irradiada por uma dose de $320 k G y$.

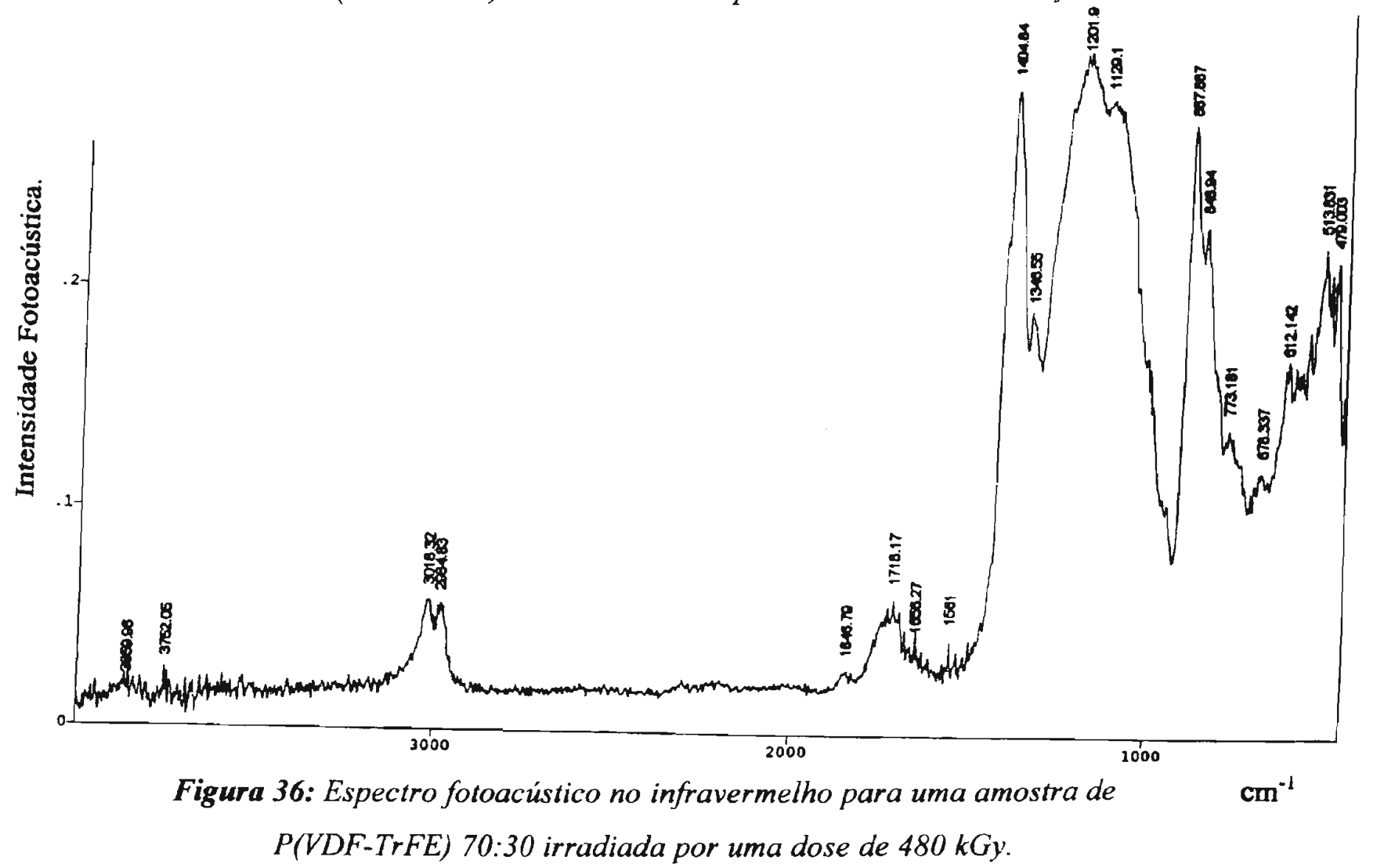



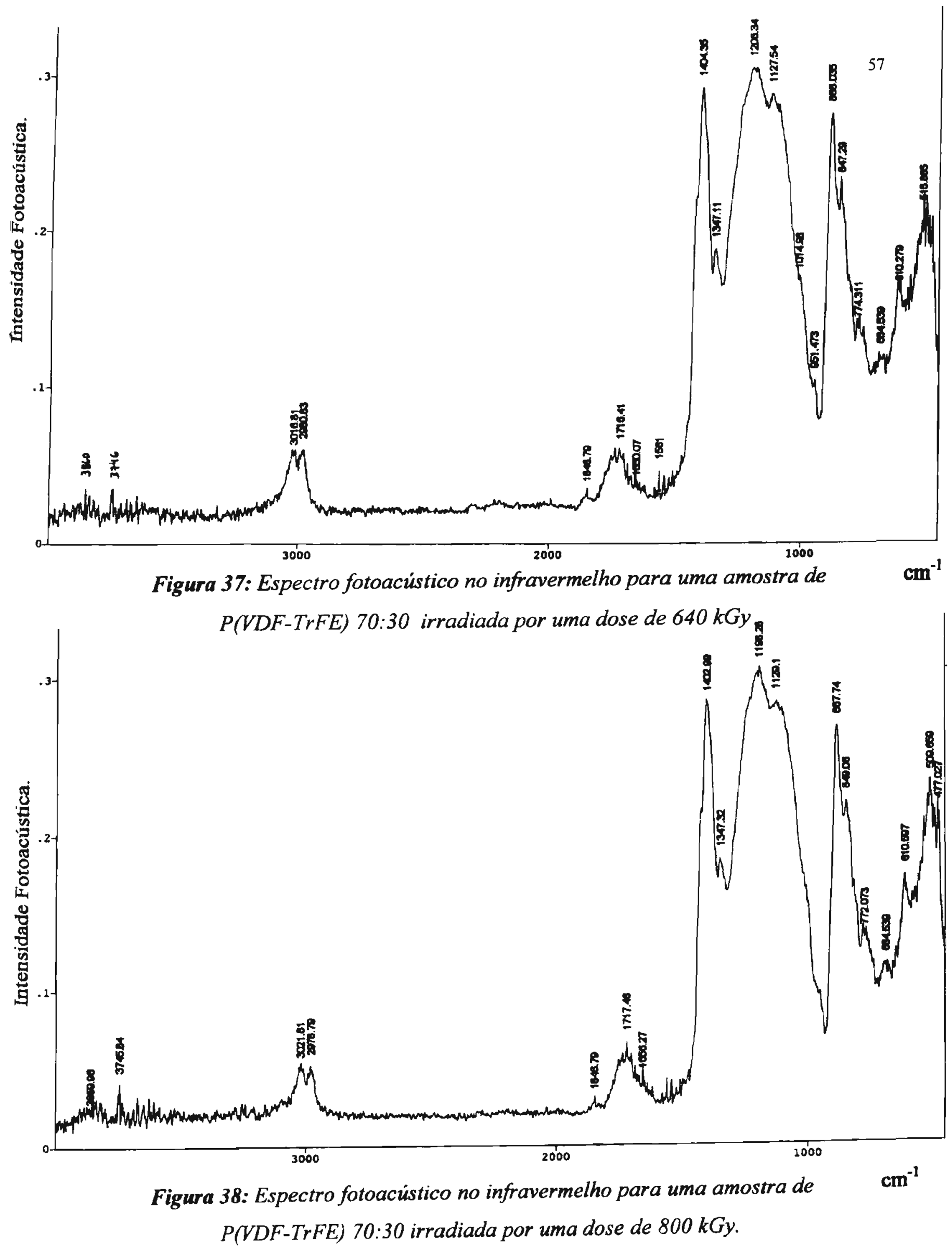


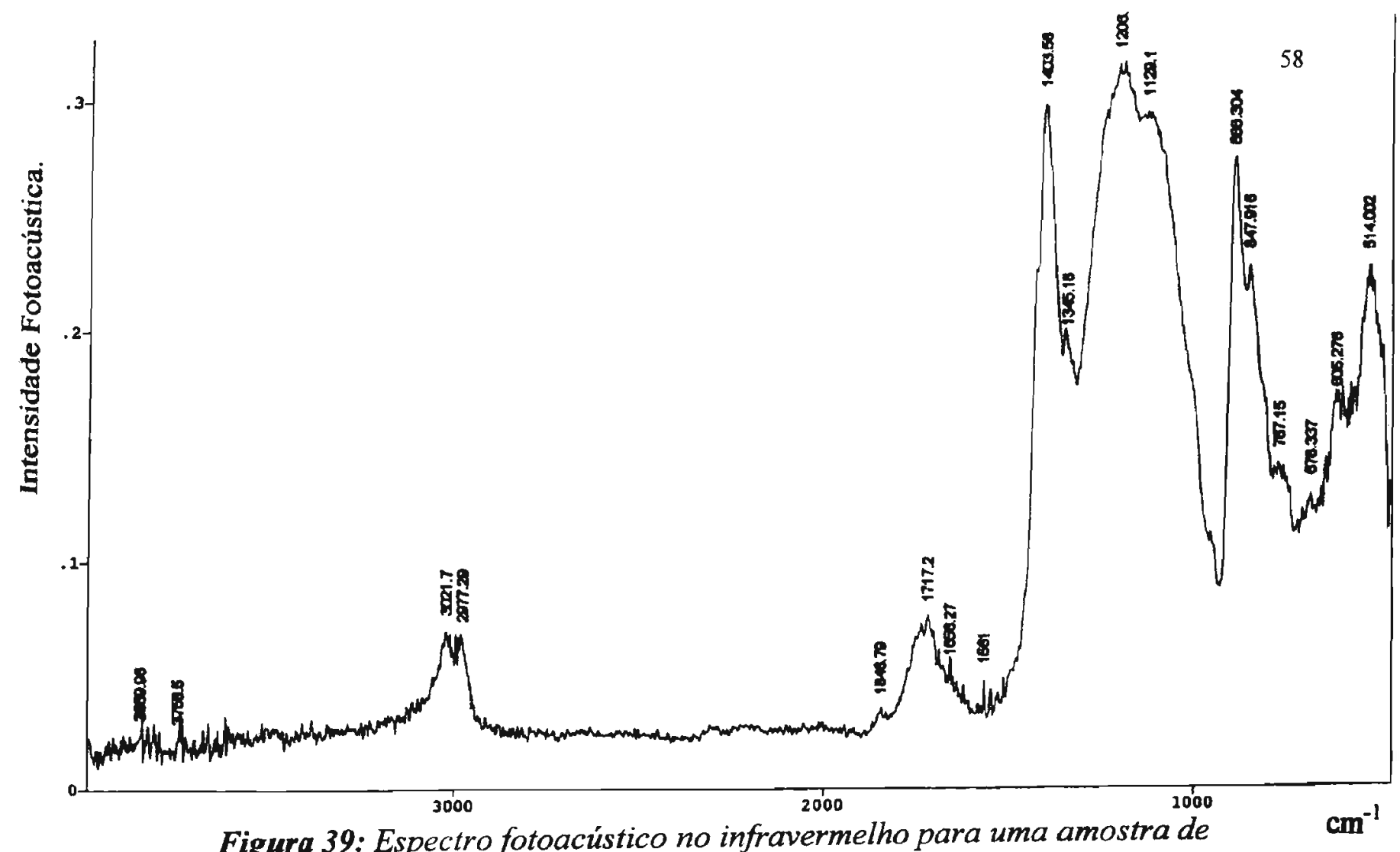

$P(V D F-T r F E) 70: 30$ irradiada por uma dose de $960 k G y$.

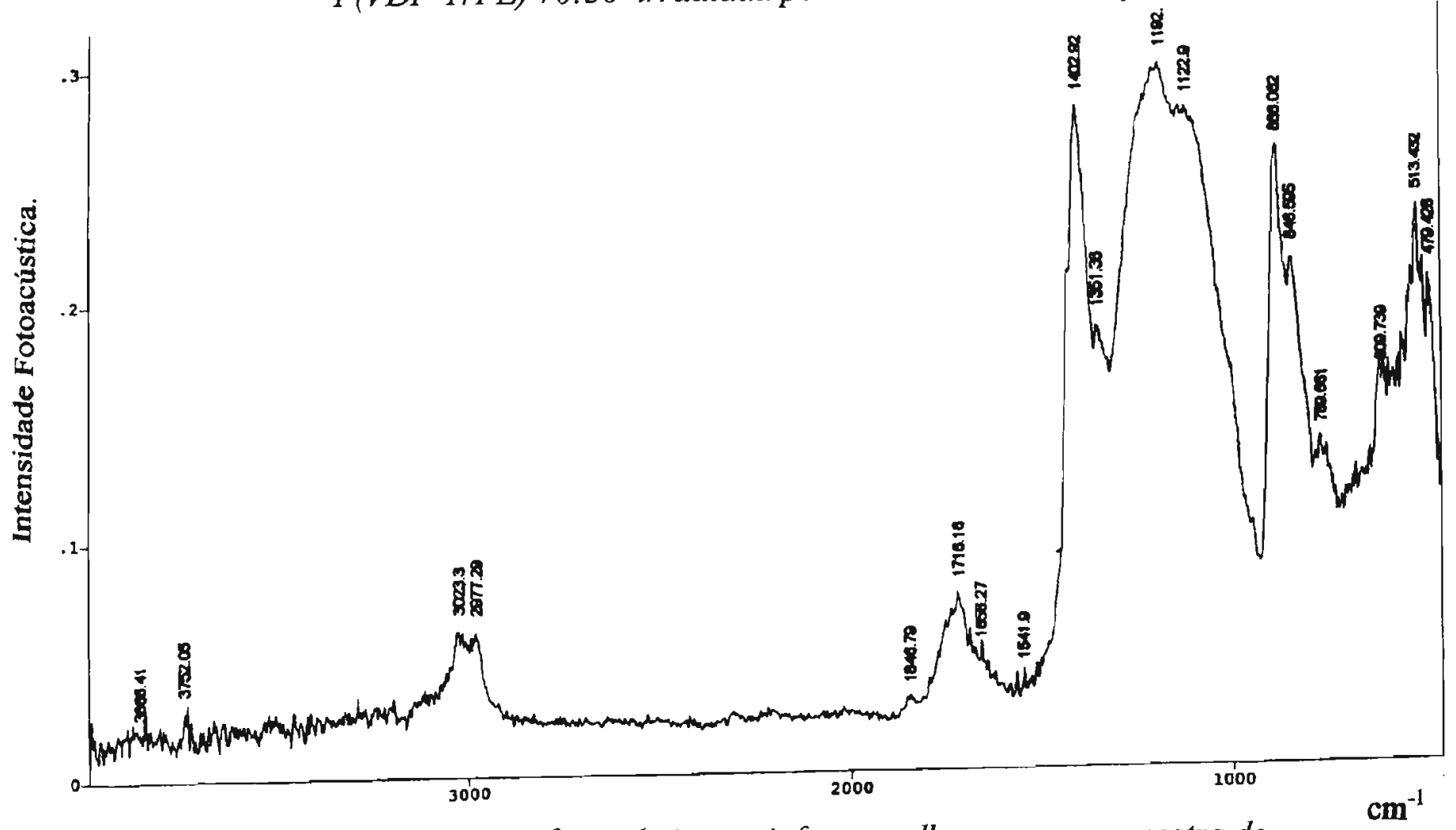

Figura 40: Espectro fotoacústico no infravermelho para uma amostra de $P(V D F-T r F E)$ 70:30 irradiada por uma dose de 1120 kGy. 


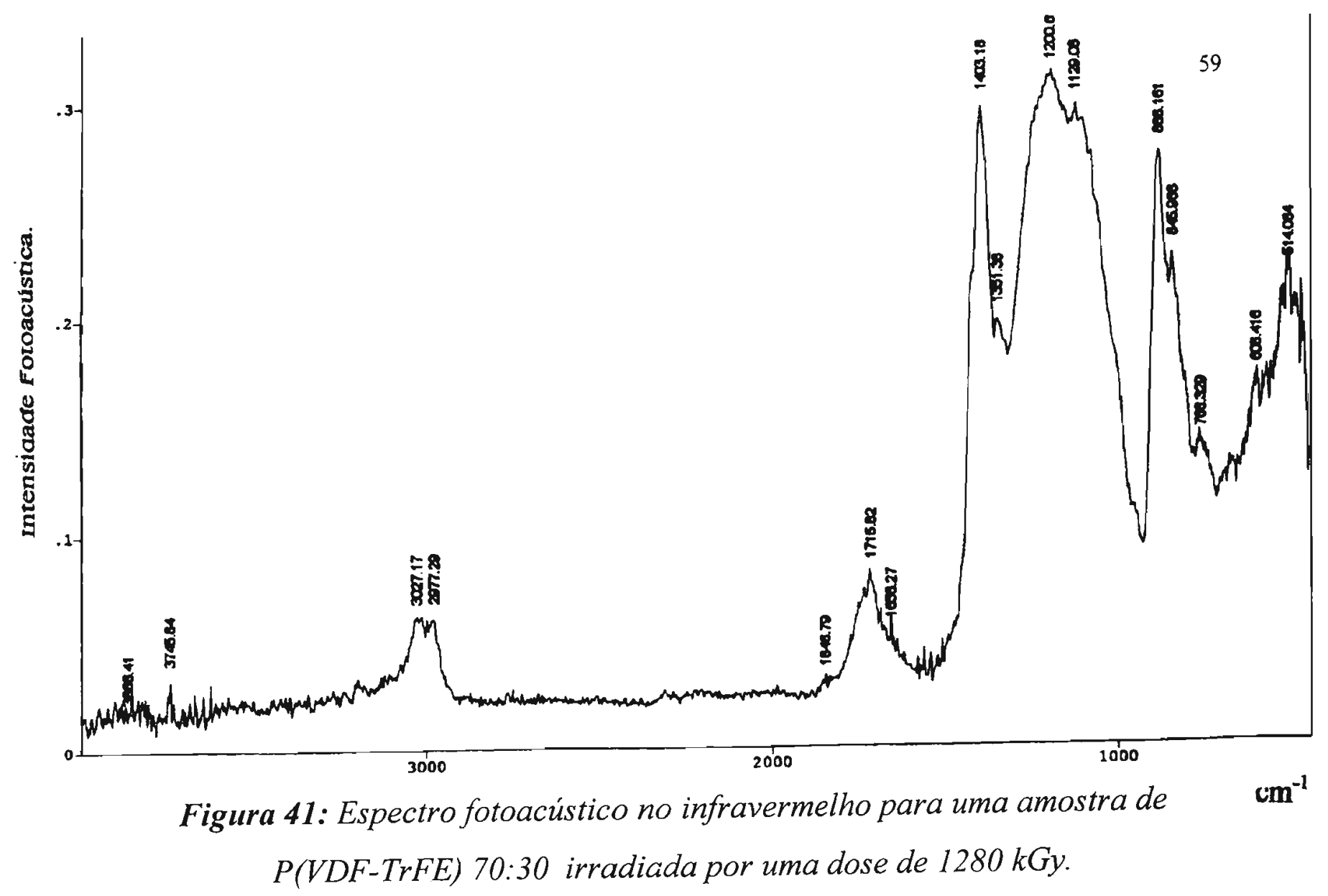




\subsection{2- Espectros de Transmitância na Região do Infravermelho}

A discussão sobre espectros de transmitância na região do infravermelho encontra-se limitada à região de números de onda compreendida entre 3500 e $1500 \mathrm{~cm}^{-1}$. Isso é devido ao fato de que os filmes utilizados, com cerca de $60 \mu \mathrm{m}$, apresentam elevada absorção na região abaixo de $1500 \mathrm{~cm}^{-1}$, sendo contudo mais adequados aos estudos de difração de raios-X, e mesmo à amostragem para o DSC.

A Figura 42 mostra o espectro IR para o copolímero P(VDF-TrFE) não irradiado. Destaca-se apenas a presença das absorções relacionadas aos modos vibracionais de estiramento simétrico $\left(2976 \mathrm{~cm}^{-1}\right)$ e antissimétrico $\left(3011 \mathrm{~cm}^{-1}\right)$ do grupo $-\mathrm{CH}_{2}$ da parcela de VDF do copolímero. Pequena absorção em torno de $1750 \mathrm{~cm}^{-1}(\nu \mathrm{C}=\mathrm{O})$ indica, provavelmente, algum grau de oxidação da amostra durante sua manufatura, conforme verificado no espectro fotoacústico.

$\mathrm{O}$ espectro IV do copolímero irradiado por $160 \mathrm{kGy}$ é apresentado na Figura 43. As únicas modificações significativas são a intensificação da banda larga ao redor de $1718 \mathrm{~cm}^{-1}$ e o aparecimento de uma nova banda em $1846 \mathrm{~cm}^{-1}$.

De forma semelhante ao que foi proposto para o PVDF irradiado [10], a banda em $1718 \mathrm{~cm}^{-1}$ pode corresponder à presença do grupo vinileno (-CH=CF-). Este tem origem na eliminação de $\mathrm{HF}$ devido ao rompimento das ligações $\mathrm{C}-\mathrm{H}$ e C-F pela radiação. Também, grupos terminais com origem no rompimento de cadeias, como $-\mathrm{CH}=\mathrm{CF}_{2}$, podem ser responsáveis por absorções à freqüências ligeiramente superiores devido ao ambiente eletronegativo. 
A nova banda observada inicialmente em $1846 \mathrm{~cm}^{-1}$ foi observada anteriormente durante a irradiação do PVDF na presença de ar, em cerca de $1850 \mathrm{~cm}^{-1}$ [82], e atribuida ao grupo carbonila em F-CO-F, podendo, no caso do copolímero, corresponder à formação de um haleto ácido, -COF [88]. Embora existam significativas discrepâncias quanto ao valor da freqüência do estiramento $\mathrm{C}=\mathrm{O}$ no referido composto [80], parece evidente tratar-se do estiramento do grupo carbonila em um ambiente eletronegativo.

Para a dose de 320 kGy o espectro IR representado pela Figura 44 mostra pequeno deslocamento dos modos de estiramento simétrico e antissimétrico, respectivamente para 2978 e $3015 \mathrm{~cm}^{-1}$. Além disso, ocorre pequena intensificação das bandas associadas aos estiramentos $\mathrm{C}=\mathrm{C}$ e $\mathrm{C}=\mathrm{O}$.

$\mathrm{O}$ deslocamento das bandas dos modos de estiramento do grupo $-\mathrm{CH}_{2}$ continua com o aumento da dose de radiação, como pode ser visto na Figura 45 (480 kGy). Tais freqüências parecem se estabilizar nos valores 2981 e $3020 \mathrm{~cm}^{-1}$, conforme pode ser visto para as amostras irradiadas a partir de 640 kGy até 1240 kGy (Figuras 46 a 50).

É interessante notar que os valores de freqüência para os estiramentos do grupo $-\mathrm{CH}_{2}$ encontram-se extremamente próximos àqueles observados para a fase $\alpha$ do PVDF [83]. Assim os dados vibracionais vão de encontro aos dados obtidos por DSC e difração de raios-X, admitindo que entre 3 e 4 horas de irradiação-X (480 e 640 kGy) ocorre a predominância de uma fase paraelétrica do $\mathrm{P}(\mathrm{VDF}-\mathrm{TrFE})$, semelhante à fase $\alpha$ do PVDF. 


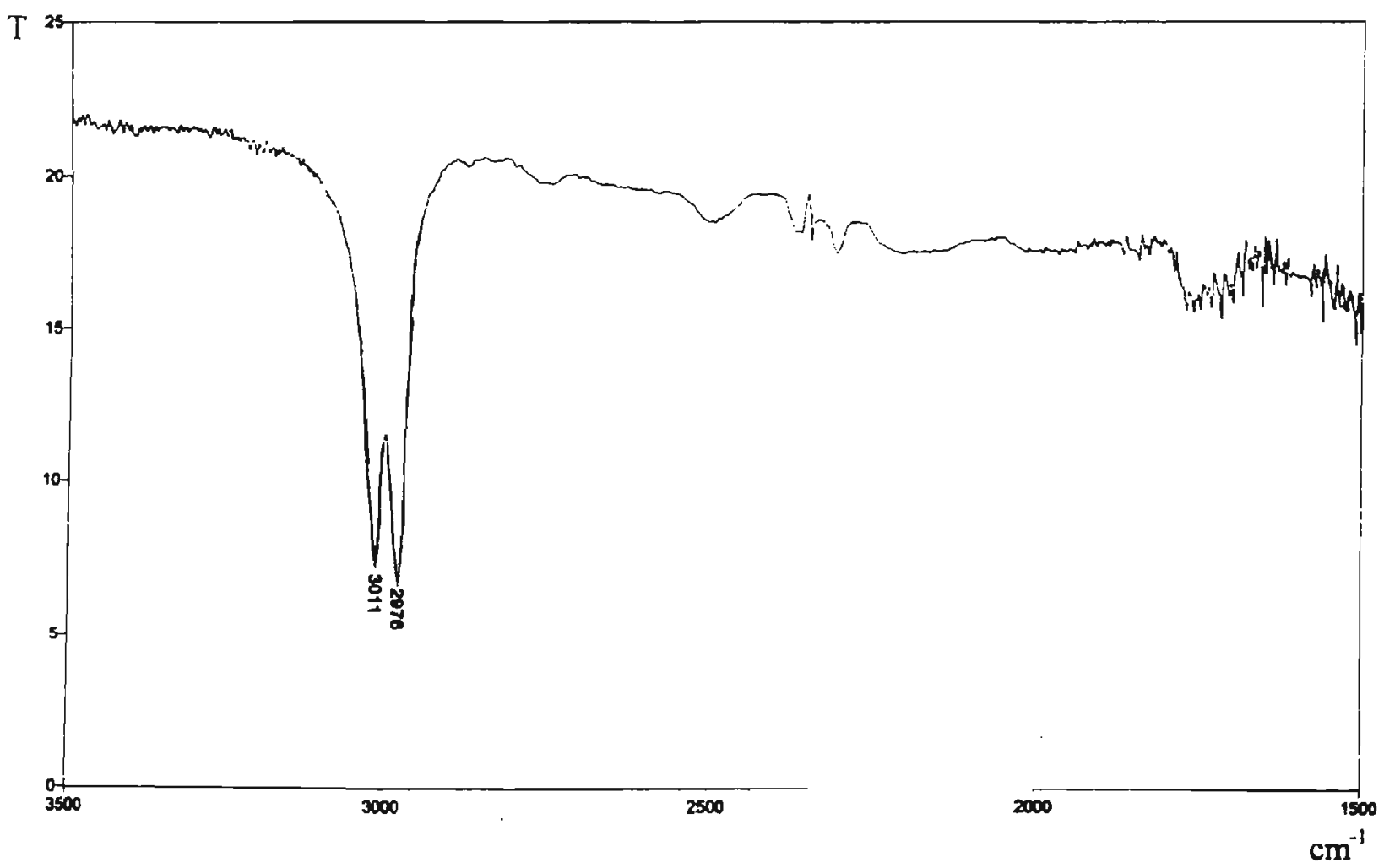

Figura 42: Espectro de absorção no infravermelho para o copolímero

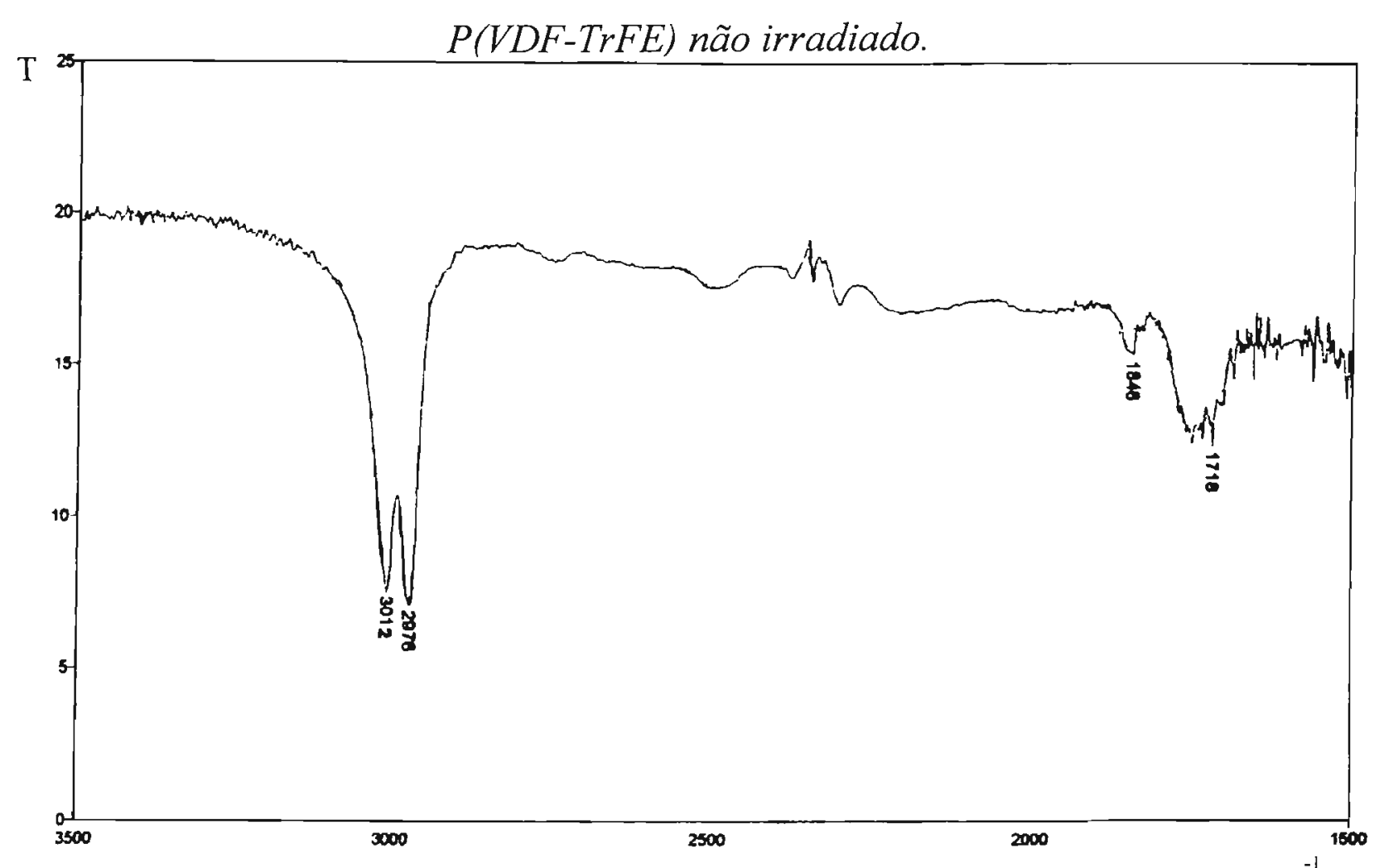

Figura 43: Espectro de absorção no infravermelho para o copolimero $\mathrm{cm}^{-1}$ $P(V D F-T r F E)$ irradiado por uma dose de $160 \mathrm{kGy}$. 


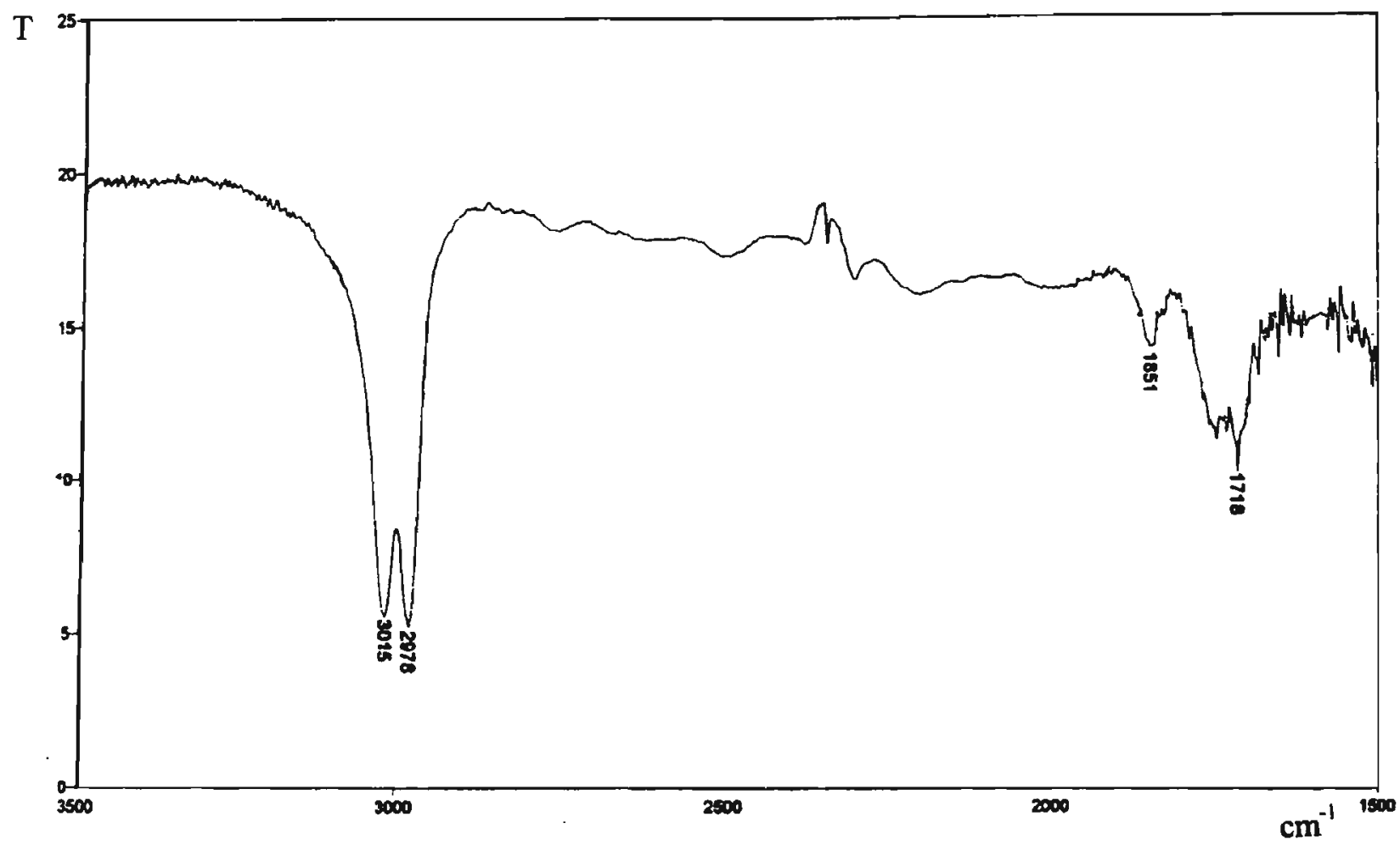

Figura 44: Espectro de absorção no infravermelho para o copolímero

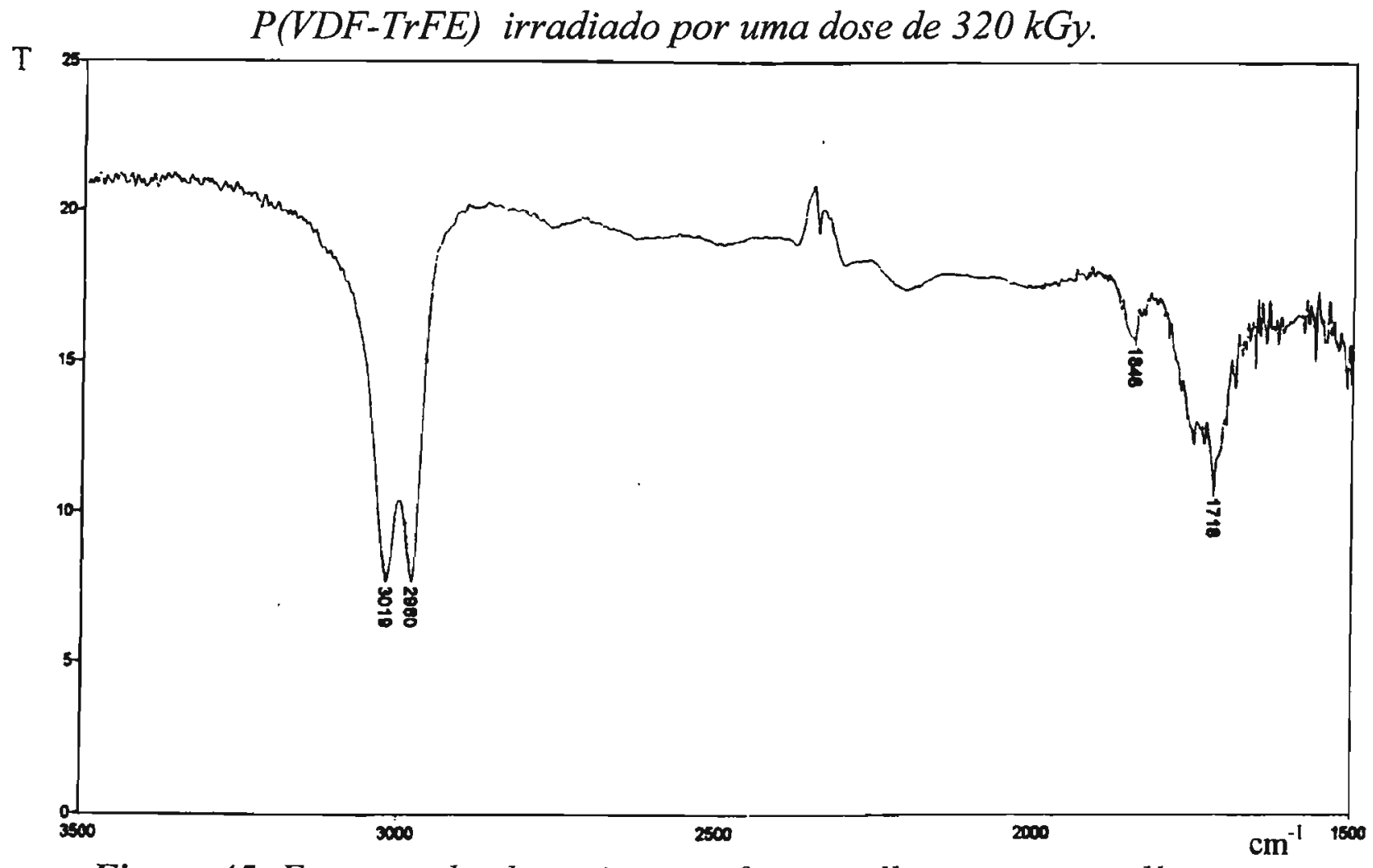

Figura 45: Espectro de absorção no infravermelho para o copolímero $P(V D F-T r F E)$ irradiado por uma dose de $480 k G y$. 


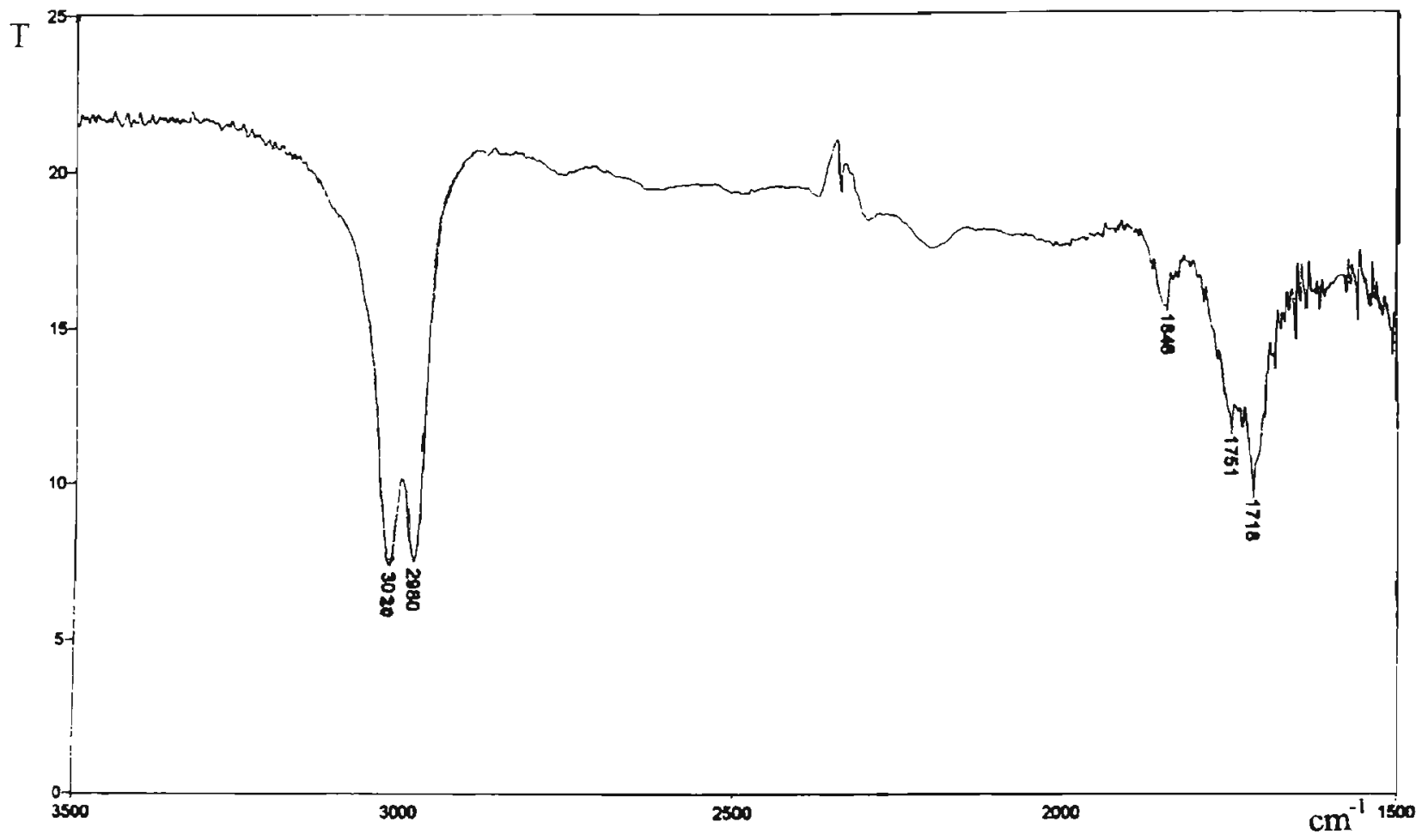

Figura 46: Espectro de absorção no infravermelho para o copolímero $P(V D F-T r F E)$ irradiado por uma dose de $640 k G y$.

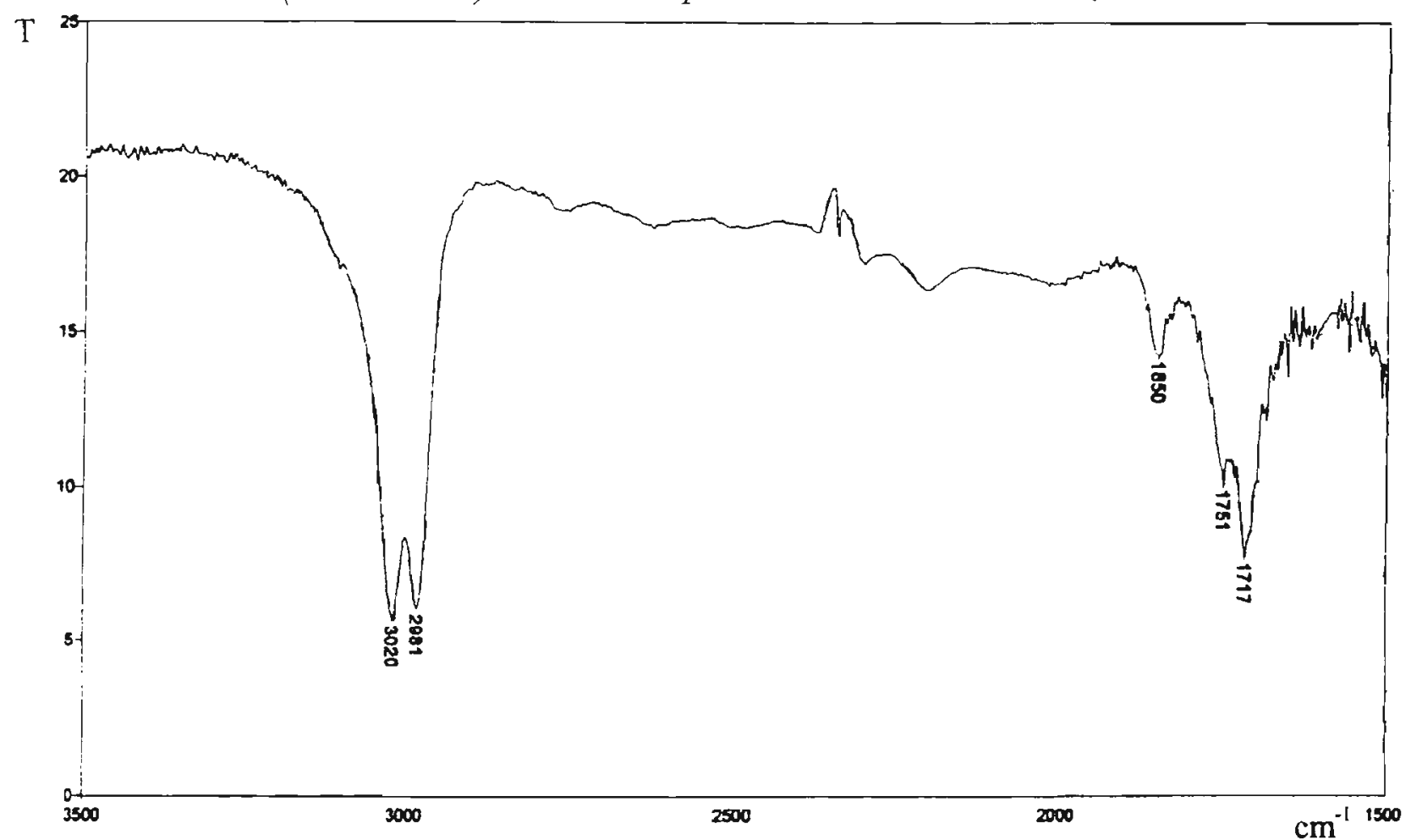

Figura 47: Espectro de absorção no infravermelho para o copolímero $P(V D F-T r F E)$ irradiado por uma dose de $800 k G y$. 


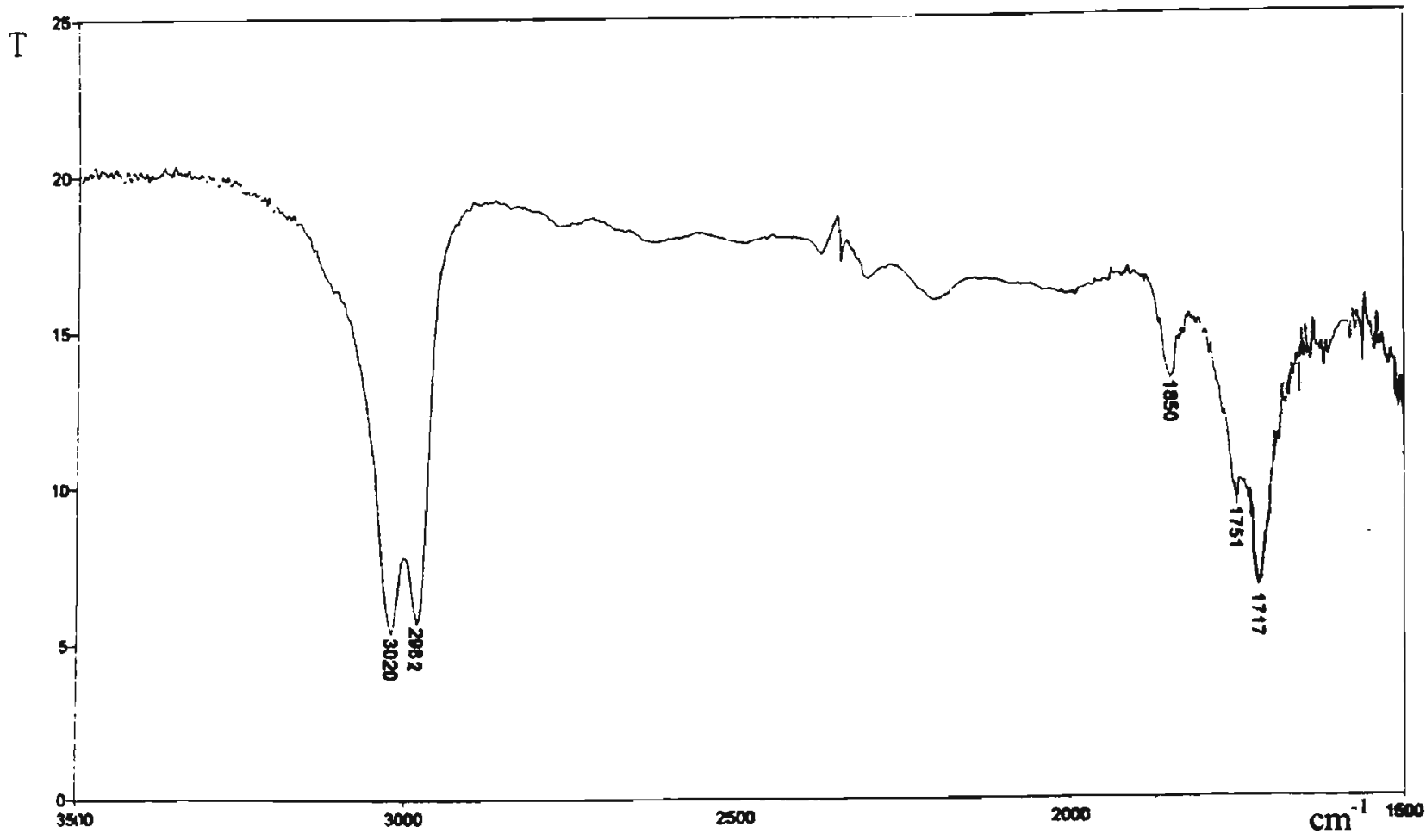

Figura 48: Espectro de absorção no infravermelho para o copolímero $P(V D F-T r F E)$ irradiado por uma dose de $960 k G y$.

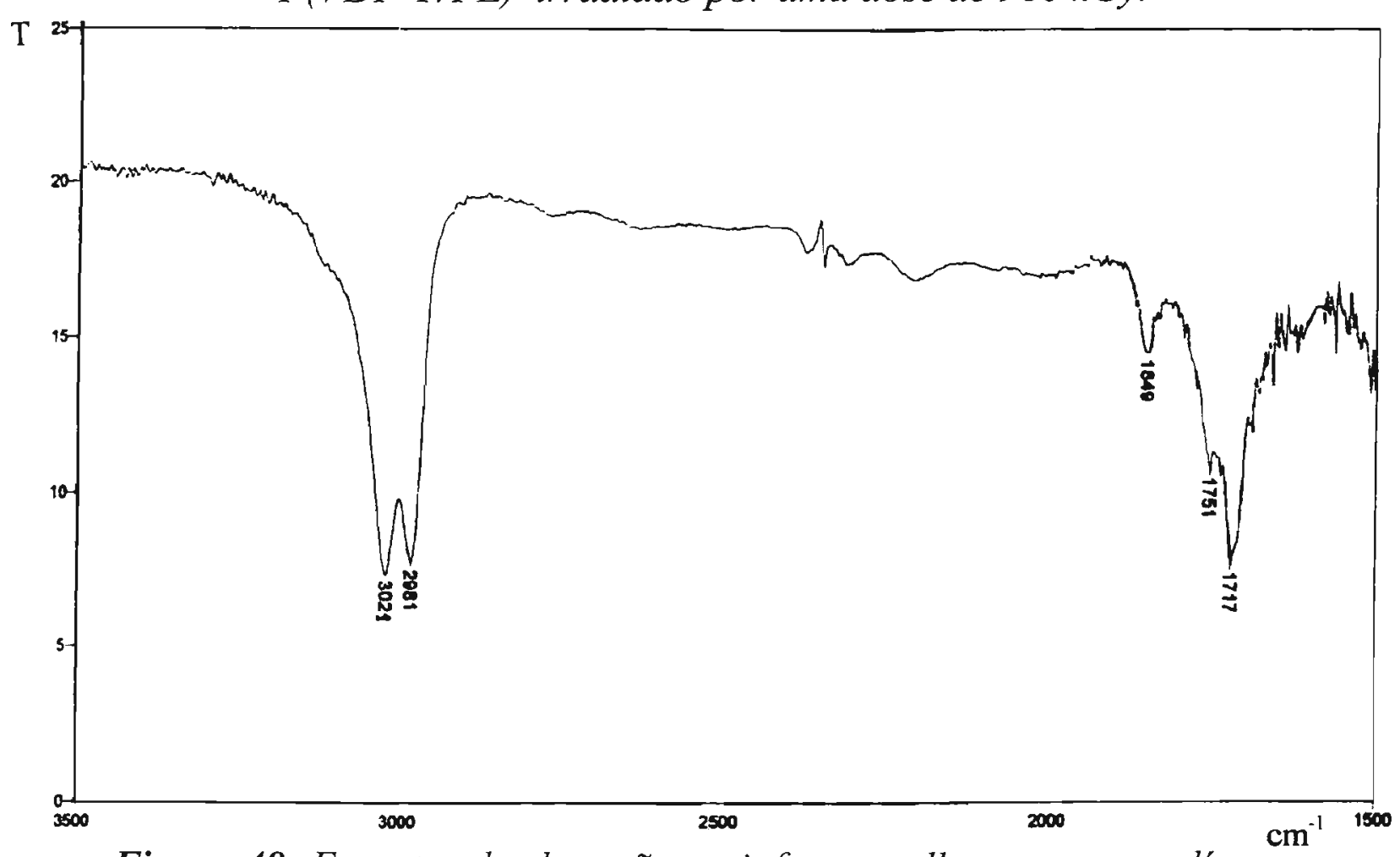

Figura 49: Espectro de absorção no infravermelho para o copolímero $P(V D F-T r F E)$ irradiado por uma dose de $1120 \mathrm{kGy}$. 


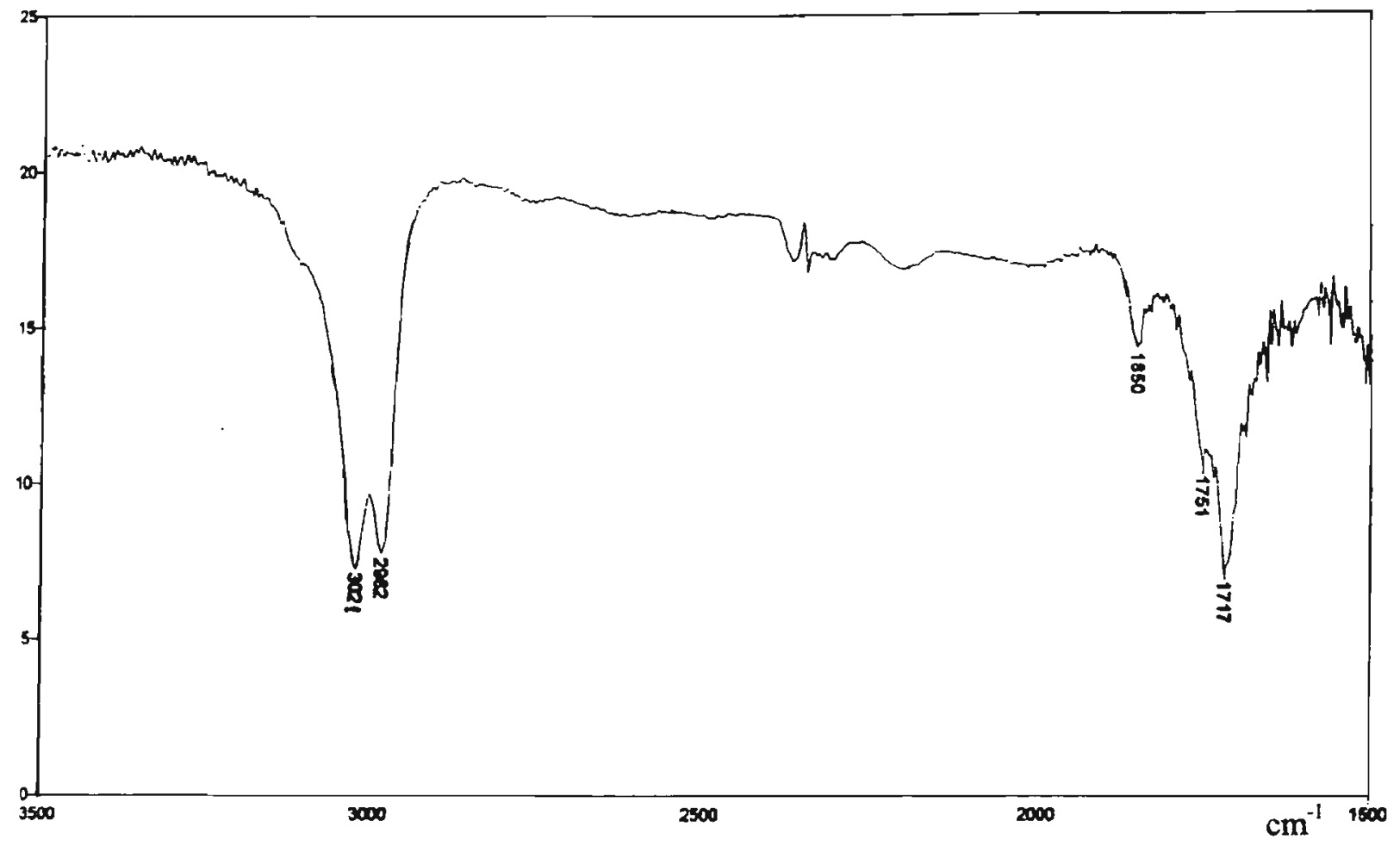

Figura 50: Espectro de absorção no infravermelho para o copolimero $P(V D F-T r F E)$ irradiado por uma dose de $1280 k G y$. 


\section{3- Espectros Vibracionais Raman}

Os espectros Raman foram obtidos através de um equipamento de microscopia Raman, descrito no item 2.2.4, para amostras de P(VDF-TrFE) na forma de filmes de $60 \mu \mathrm{m}$. As atribuições tentativas foram feitas com base nos dados vibracionais existentes na literatura para o PVDF [78-84,89] e na literatura pertinente aos efeitos envolvidos[90,91].

A Figura 51 apresenta o espectro de uma amostra de P(VDF-TrFE) não irradiada, na região de 100 a $1800 \mathrm{~cm}^{-1}$ (deslocamento Raman). É notável uma intensa banda devida à fluorescência do material em toda a região registrada, sobre a qual se sobrepõem as bandas Raman. Tal fato é comum a polímeros sintéticos, onde, aditivos, resíduos da reação de polimerização, de processos de oxidação e radicais, formados devido a processos degradativos, absorvem e reemitem a radiação laser incidente sobre a amostra, na forma de fluorescência. Os problemas resultantes da fluorescência da amostra, que geralmente se superpõe ao sinal Raman, podem ser resolvidos, muitas vezes, mudando-se a radiação do laser. Em nosso caso, a diminuição da fluorescência foi conseguida pela exposição da amostra ao laser por intervalo de 10 a 20 minutos antes da medida.

Observa-se na Figura 51 um conjunto de bandas pouco intensas compreendidas entre 268 e $640 \mathrm{~cm}^{-1}$, as quais, segundo Boerio e Koenig [84], correspondem a diversos modos vibracionais do grupo $\mathrm{CF}_{2}$. A seguir, ocorrem três bandas localizadas em 805 (média), 847 (intensa) e $882 \mathrm{~cm}^{-1}$ (média), em que as duas primeiras, segundo Rodríguez-Cabello et al. [89], estão claramente associadas com as fases $\alpha$ e $\beta$ do PVDF. Assim, a banda em 
$805 \mathrm{~cm}^{-1}$, atribuída principalmente a $v_{\mathrm{S}}\left(\mathrm{CF}_{2}\right)$, é característica da fase $\alpha \mathrm{e}$, a banda em $847 \mathrm{~cm}^{-1}$, associada a $v_{s}\left(C_{2}\right)$ e $v(C-C)$, correspondente à fase $\beta$.

No $\mathrm{P}(\mathrm{VDF}-\mathrm{TrFE})$ as fases $\alpha$ e $\beta$ do PVDF são equivalentes à fases paraelétrica e $\beta$ do copolímero, respectivamente. Sendo assim, seria possível monitorar uma transição da fase $\beta$, na qual o copolímero cristaliza naturalmente, para a fase paraelétrica (FP), através da variação das intensidades relativas de tais bandas. Esse tipo de monitoramento foi realizado por Rodríguez-Cabello et al. [89] em um estudo do efeito de estiramento do PVDF através da espectroscopia Raman, o qual evidenciou a transição da fase $\alpha$ para a fase $\beta$.

$\mathrm{Na}$ região compreendida entre 900 e $1500 \mathrm{~cm}^{-1}$ ocorrem bandas de intensidades variando entre fraca a média, as quais encontram atribuições idênticas àquelas observadas no infravermelho.

Os espectros Raman para as amostras irradiadas encontram-se representados na Figura-52, para a dose de $160 \mathrm{kGy}, \mathbf{5 3}$, para $320 \mathrm{kGy}, \mathbf{5 4}$, para $480 \mathrm{kGy}, \mathbf{5 5}$, para $640 \mathrm{kGy}, \mathbf{5 6}$, para $800 \mathrm{kGy}, \mathbf{5 7}$, para $960 \mathrm{kGy}, \mathbf{5 8}$, para 1120 kGy e 59, para 1280 kGy. Percebe-se com clareza pelo acompanhamento dos espectros, a diminuição de intensidade da banda em $847 \mathrm{~cm}^{-1}$, juntamente com o quase total desaparecimento das bandas de menor intensidade após altas doses de irradiação. Nota-se também significativo aumento na banda de fluorescência ao longo de toda região espectral, que tem origem, muito provavelmente, na formação e aprisionamento de radicais livres no interior do material, conforme será discutido no item 3.4 .

A Figura 60 apresenta uma montagem de todos os espectros Raman obtidos, na região compreendida entre 200 e $1200 \mathrm{~cm}^{-1}$, de forma a permitir a comparação. Destaca-se em especial o conjunto de bandas localizadas 
inicialmente em 805,847 e $882 \mathrm{~cm}^{-1}$, para as quais foi feito um monitoramento semelhante àquele realizado por Rodríguez-Cabello et al. [89]. Fez-se assim a medida da intensidade relativa das três bandas através das razões: $I_{805} / I_{882}, I_{805} / I_{847}$ e $I_{882} / I_{847}$, escolhendo-se para tanto uma linha base adequada entre 650 e $1000 \mathrm{~cm}^{-1}$ e então tomando-se as medidas de cada banda.

A Figura 61 mostra a variação das intensidades relativas em função da dose de irradiação. Pode-se observar que todas as intensidades relativas mostram uma tendência inicial ao aumento e, a partir da dose de $800 \mathrm{kGy}$ permanecem estáveis. É nítido o ponto de máximo observado para $\mathrm{I}_{805} / \mathrm{I}_{882} \mathrm{e}$ $\mathrm{I}_{805} / \mathrm{I}_{847}$ na dose de $640 \mathrm{kGy}$, ponto em que, após uma mudança da estrutura cristalina de uma fase $\beta$ (ferroelétrica) para a fase $P$ (paraelétrica), ocorre um aumento da cristalinidade do material. Exatamente a esta dose foi observado por difração de raios-X um aumento de cristalinidade após uma mudança de estrutura (item 3.1). Rodríguez-Cabello et al. [89] observaram o comportamento inverso, por estiramento, daquele que aqui verificamos, com um perfil espectral idêntico ao da Figura 60. Seus gráficos de intensidade relativa das bandas $I_{840} / I_{800}$ em função da porcentagem de estiramento tem perfil sigmoidal como os da Figura 61, porém sem picos de máximo. 

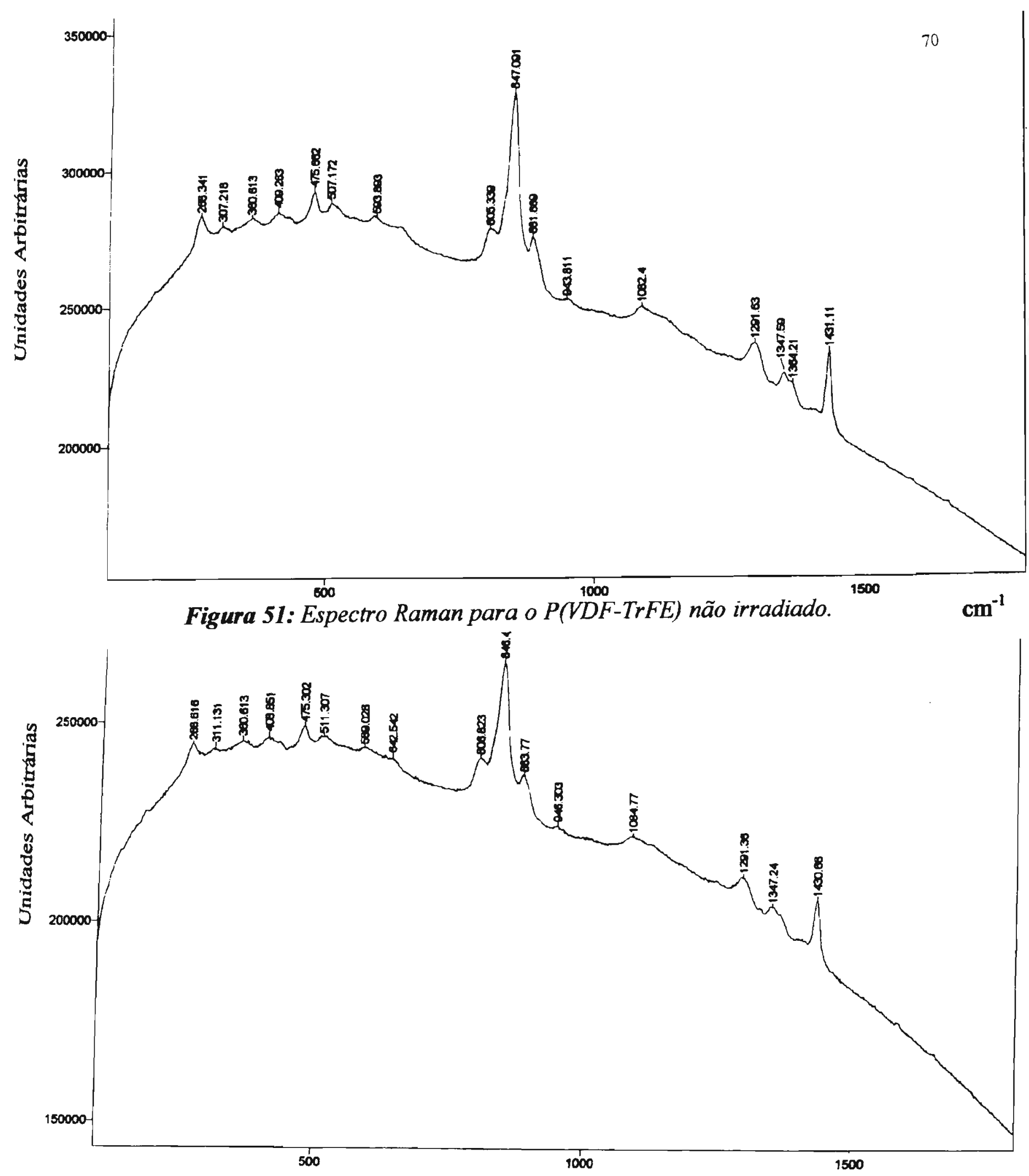

Figura 52: Espectro Raman para o $P(V D F-T r F E)$ irradiado por uma dose $\quad \mathrm{cm}^{-1}$ de $160 k G y$. 


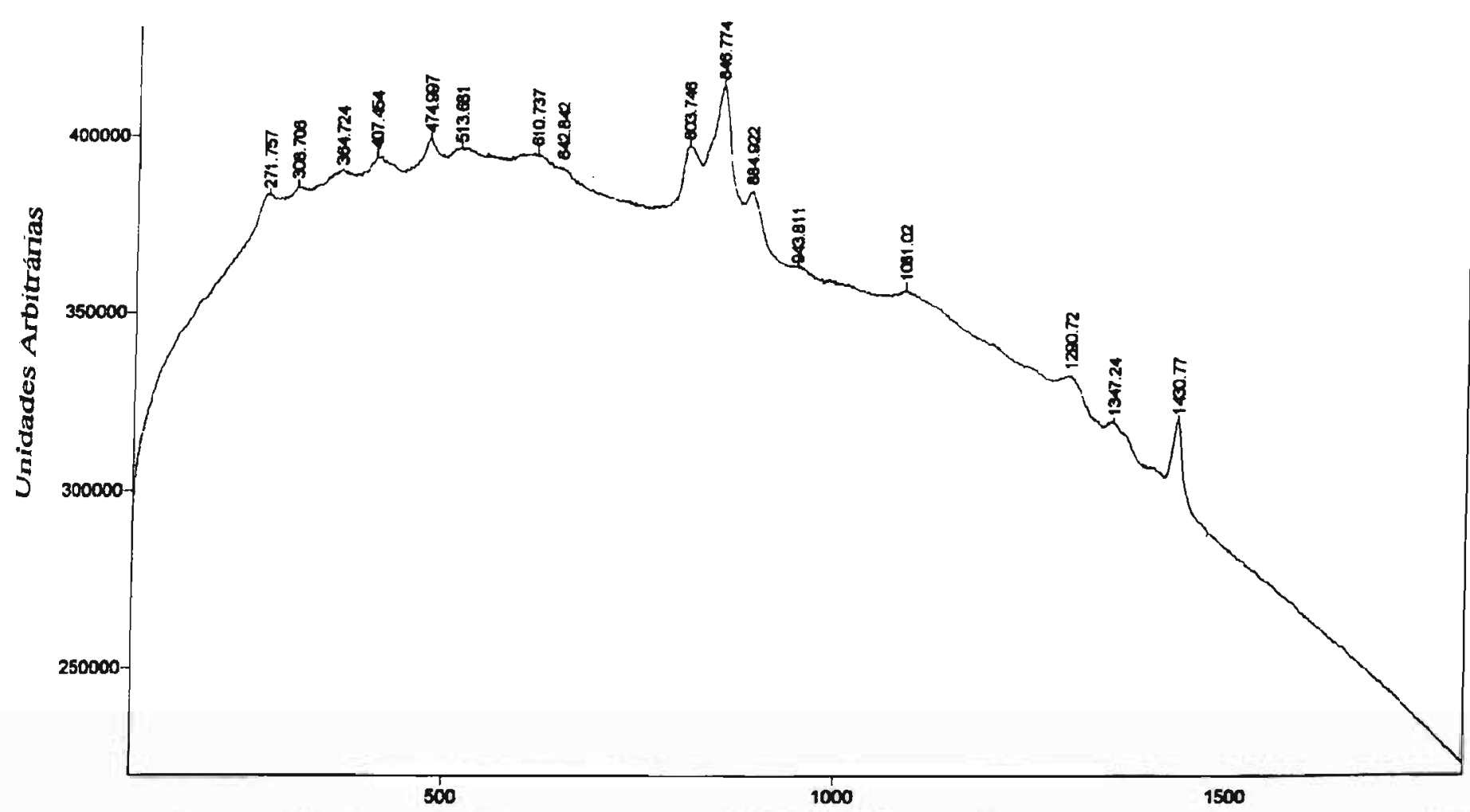

Figura 53: Espectro Raman para o $P(V D F-T r F E)$ irradiado por uma dose

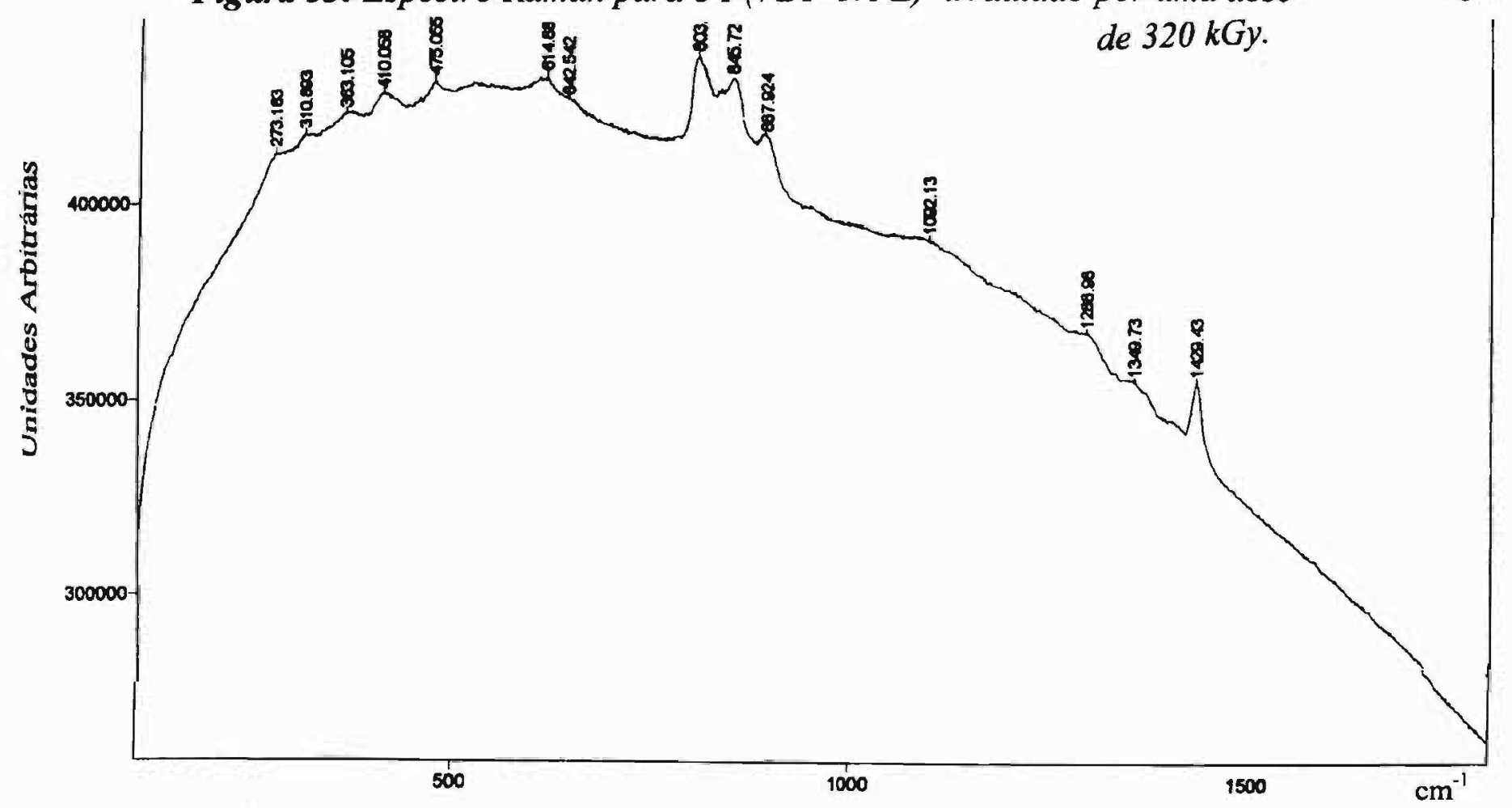

Figura 54: Espectro Raman para o $P(V D F-T r F E)$ irradiado por uma dose de $480 k G y$. 


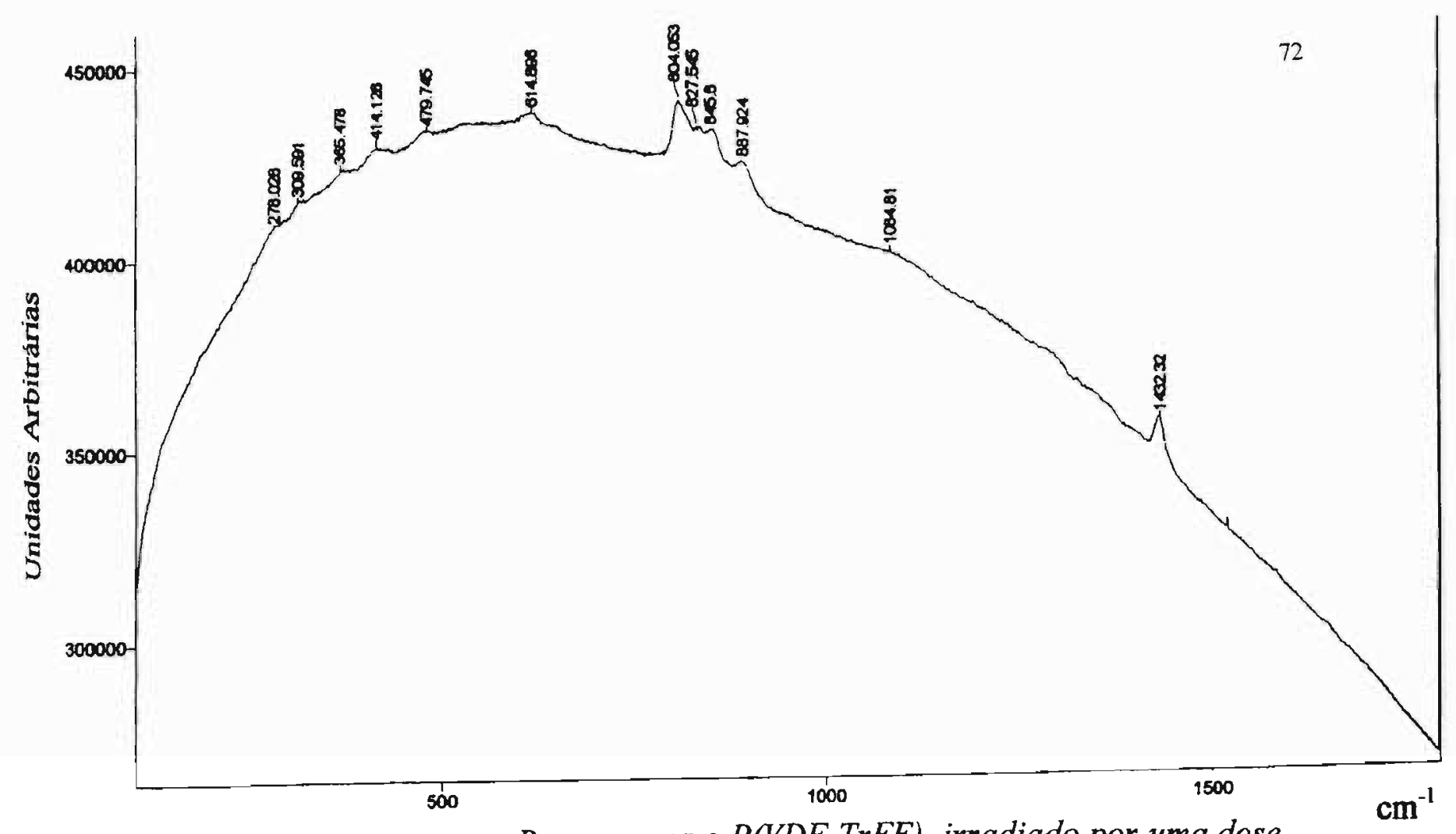

Figura 55: Espectro Raman para o P(VDF-TrFE) irradiado por uma dose

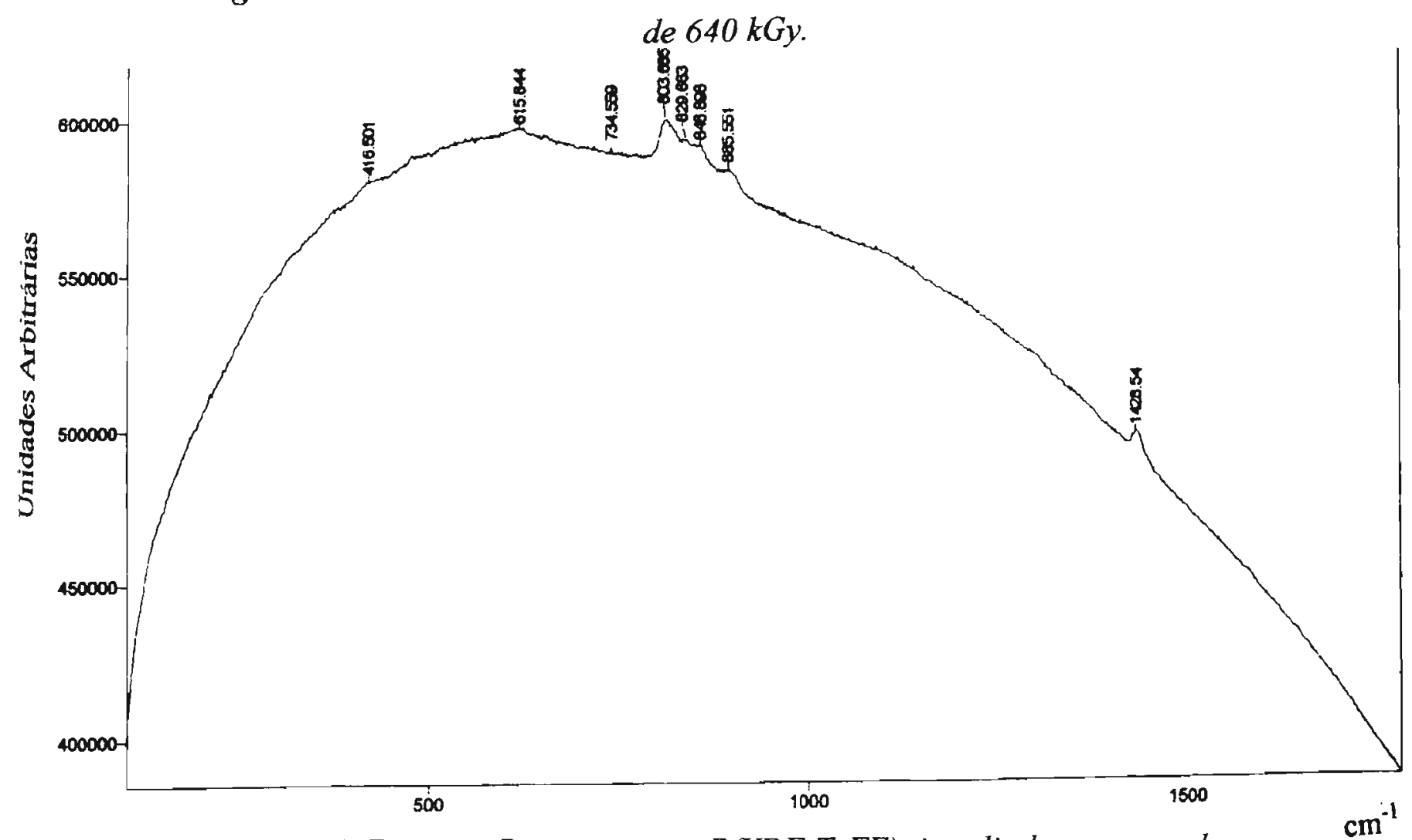

Figura 56: Espectro Raman para o P(VDF-TrFE) irradiado por uma dose de $800 k G y$ 


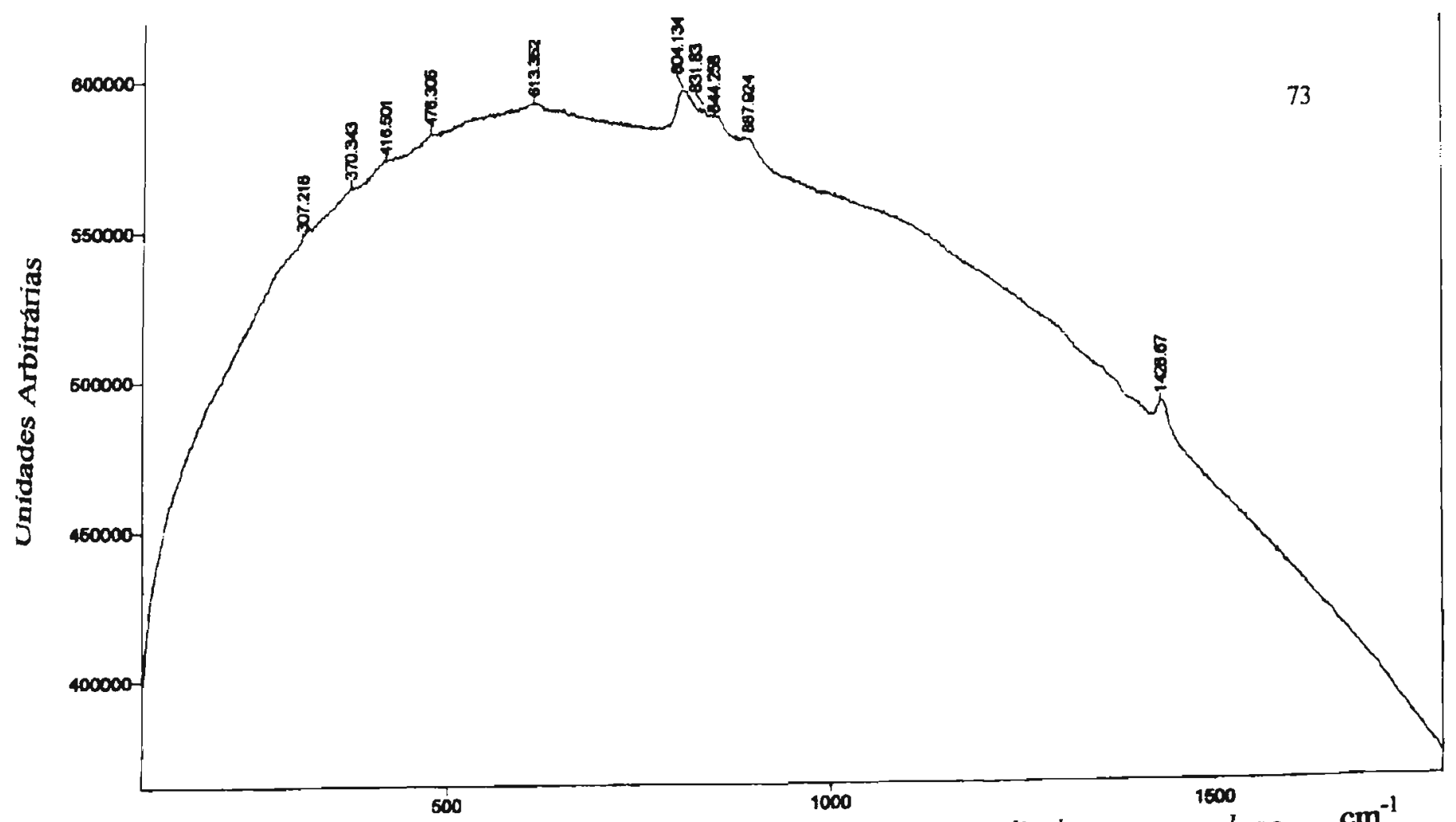

Figura 57: Espectro Raman para o P(VDF-TrFE) irradiado por uma dose $\mathrm{cm}^{-1}$ de $960 k G y$.

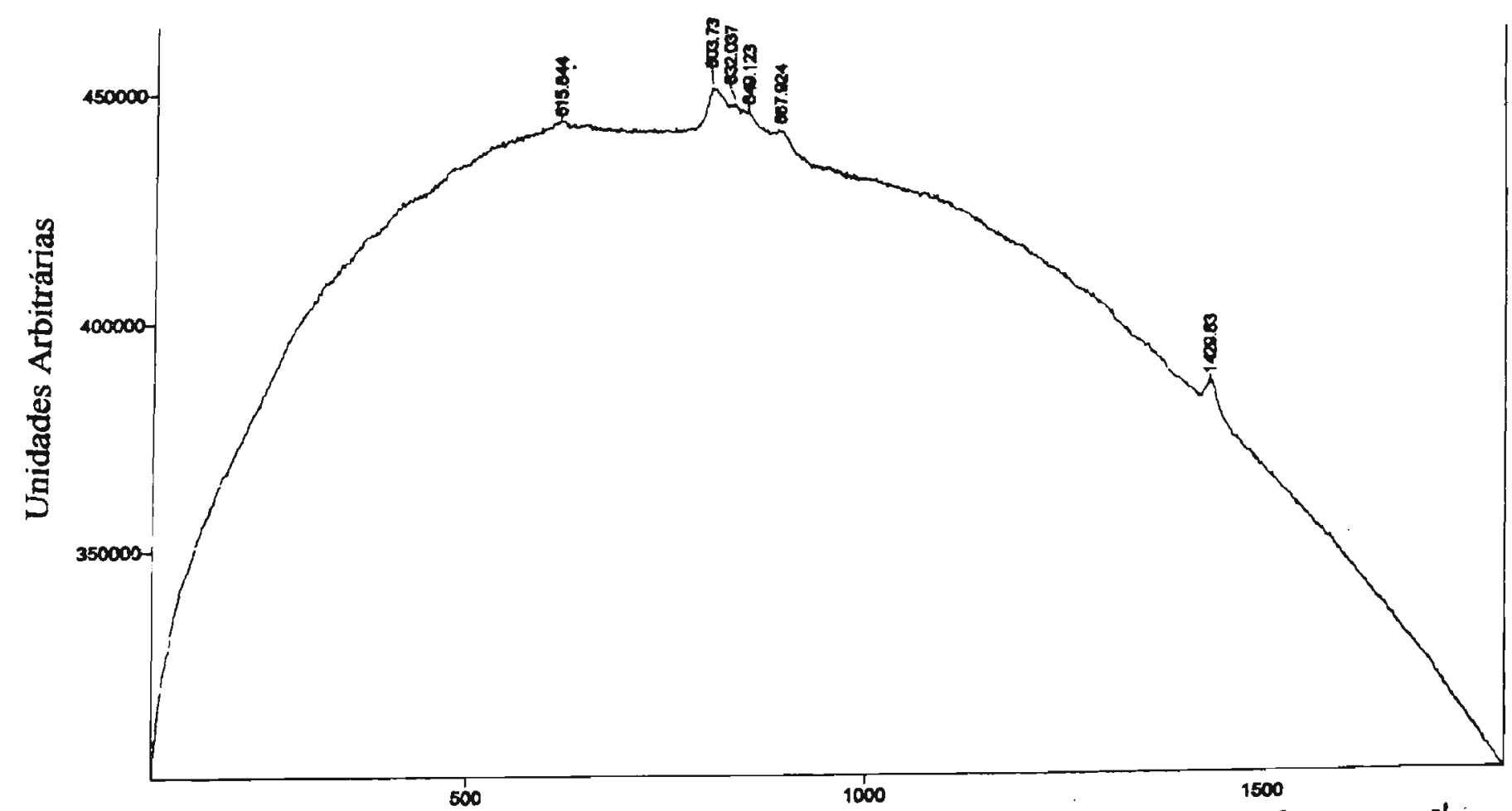

Figura 58: Espectro Raman para o $P(V D F-\operatorname{Tr} F E)$ irradiado por uma dose $\mathrm{cm}^{-1}$ de $1120 k G y$ 


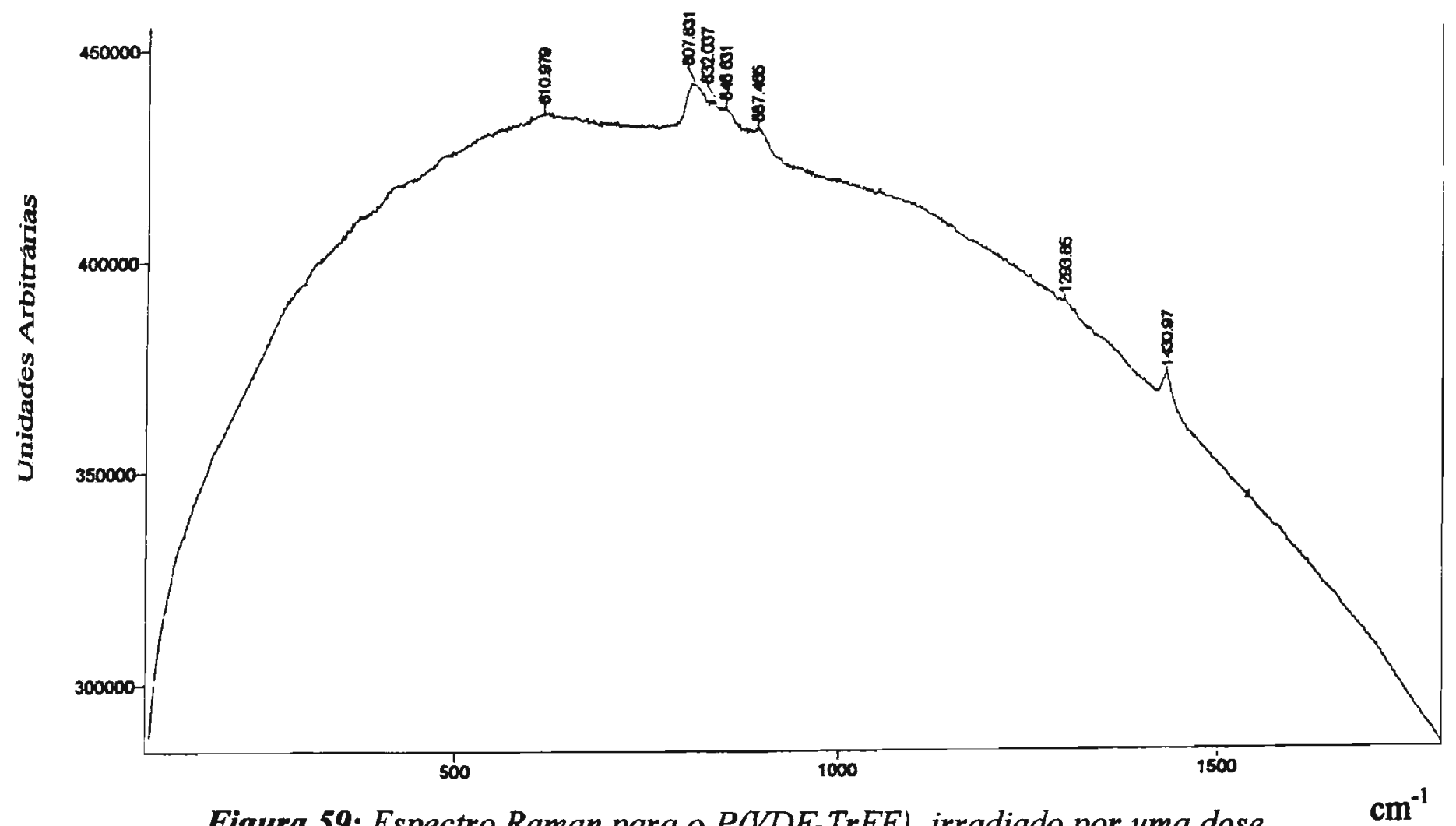

Figura 59: Espectro Raman para o P(VDF-TrFE) irradiado por uma dose $\mathrm{cm}^{-1}$ de $1280 k G y$. 


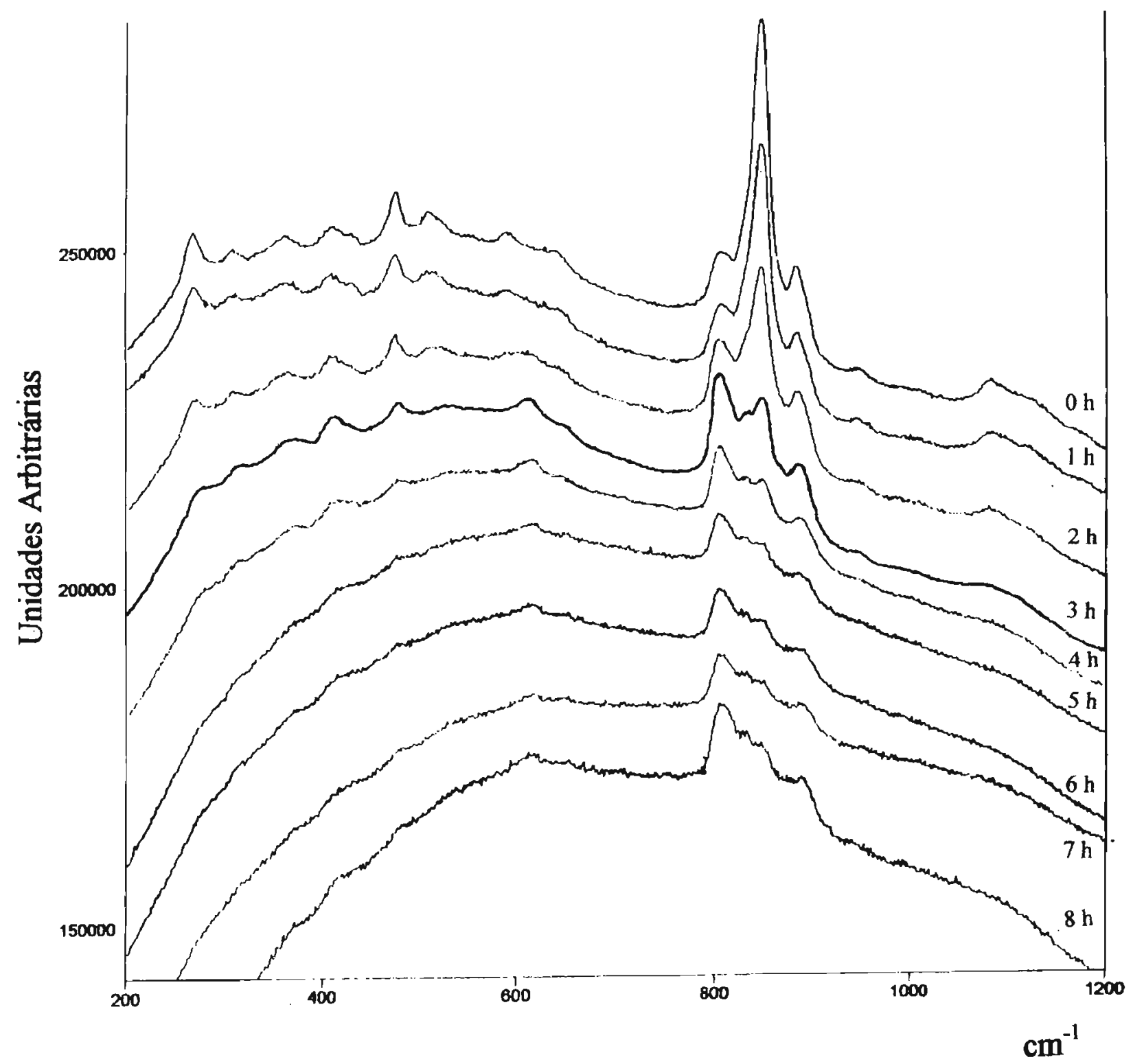

Figura 60: Espectros Raman para o P(VDF-TrFE) não irradiado e irradiado a diversas doses 


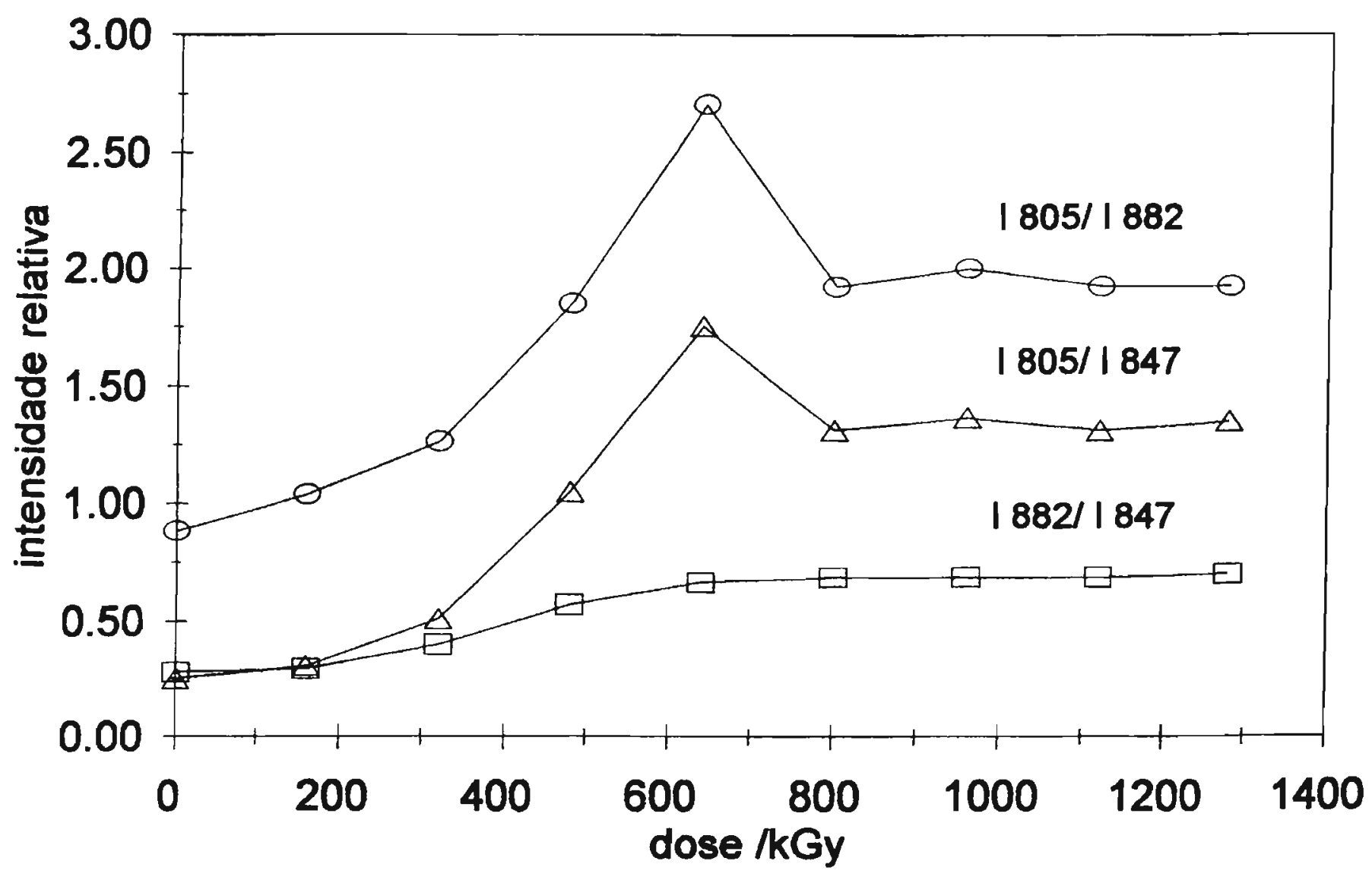

Figura 61: Intensidade relativa das bandas Raman em função da dose de irradiação para o P(VDF-TrFE) 70:30. 


\section{4- Espectroscopia de Absorção Eletrônica}

Os espectros de absorção na região do ultravioleta-visível para os filmes do copolímero $\mathrm{P}(\mathrm{VDF}-\mathrm{TrFE})$, não modificado e irradiados, são aqui apresentados entre comprimentos de onda $190 \mathrm{~nm}$ e $500 \mathrm{~nm}$.

Para cada amostra irradiada foi realizado um acompanhamento das variações espectrais por cerca de 30 dias após a irradiação, ou até estabilização do espectro. Tal acompanhamento foi realizado de forma a fornecer alguma informação sobre os radicais formados durante a irradiação, seu tempo de vida e forma de desativação, com a formação de ligações cruzadas, duplas, grupos peróxidos, carbonila e outros.

A radiação de alta energia é conhecida por promover a formação de radicais sobre polímeros fluorados $[\mathbf{2 , 8 7 , 2 8}$. No caso do $\mathrm{P}(\mathrm{VDF}-\mathrm{TrFE})$ a presença de significativo conteúdo de hidrogênio o faz distinto do politetrafluoretileno, e a presença de átomos de $\mathrm{F}$ e $\mathrm{H}$ impede o rearranjo vicinal para a formação de radicais mais estáveis, devido a ausência de orbitais desocupados, ao contrário dos polímeros clorados [92]. Segundo Rosenberg et al.[2], a presença de átomos de $\mathrm{H}$ parece facilitar a formação de insaturações e ligações cruzadas, acompanhadas pela formação de $\mathrm{H}_{2}$ e $\mathrm{HF}$. Além disso a formação de radicais secundários deve ser favorecida em relação aos radicais primários, devido a sua estabilidade.

A Figura 62 mostra os espectros UV-Vis para a amostra do copolímero não irradiado, irradiado por 5 min. (13,3 kGy), $10 \mathrm{~min}$. (26,6 kGy) e 20 min.(53,2 kGy), e após envelhecimento por 1 mês. 
O filme não irradiado apresenta um espectro com uma banda de absorção em 192 nm, e uma curva decrescente com o aumento do comprimento de onda.

Filmes irradiados por 5 minutos apresentam bandas de absorção em aproximadamente 192, 222 e $272 \mathrm{~nm}$. Os filmes irradiados por 10 minutos mostram bandas de absorção em 195, 222, 272, 342 e 364 nm. Aqueles irradiados por 20 minutos apresentam bandas em 200,222, 272, 342 e 364 nm. O aumento da intensidade das bandas em 192 e 222 nm é mais pronunciado do que o aumento das demais bandas.

A intensidade das bandas em 222, 272, 342 e $364 \mathrm{~nm}$ diminuem acentuadamente com o envelhecimento.

A absorção da banda em $192 \mathrm{~nm}$ é geralmente atribuída a duplas ligações isoladas. Esta banda mostra um deslocamento para comprimentos de onda maiores com o aumento do tempo de irradiação, possivelmente devido a um aumento de concentração de grupos $-\mathrm{CF}=\mathrm{CF}$ - comparado à concentração de grupos $-\mathrm{CH}=\mathrm{CF}$-. Esta mesma banda, nos filmes irradiados, apresenta também um deslocamento para comprimentos de onda maiores com o tempo de envelhecimento, devido a reorganização/relaxação molecular após as reações de rompimento de cadeia [11].

A presença das bandas em 222 e $272 \mathrm{~nm}$ pode indicar, como visto anteriormente para o PVDF [10], a formação de duplas ligações conjugados [88], respectivamente, dienos e trienos. É nítida, contudo, a diminuição da banda centrada em $222 \mathrm{~nm}$ até a estabilização, após 30 dias da irradiação. Efeitos desse tipo foram verificados anteriormente [74]. Isso pode indicar a existência de radicais aprisionados no filme que absorvem nessa região e são desativados rompendo as duplas ligações formadas durante ou imediatamente após a irradiação. 
As bandas em 342 e $364 \mathrm{~nm}$ podem ser atribuídas aos cromóforos de radicais que são gerados pela irradiação com raio-X [74].

De acordo com Weir [93] a reação entre os radicais gerados pela degradação do material e o próprio polímero, não depende unicamente do mecanismo de formação de tais radicais, mas também do escape destes das "gaiolas" onde são inicialmente formados. Também o coeficiente de difusão e o volume livre no polímero determinarão o tempo de desativação do radical em um sítio reativo do material.

Efeitos semelhantes foram observados por Daudin et al. [94]. 


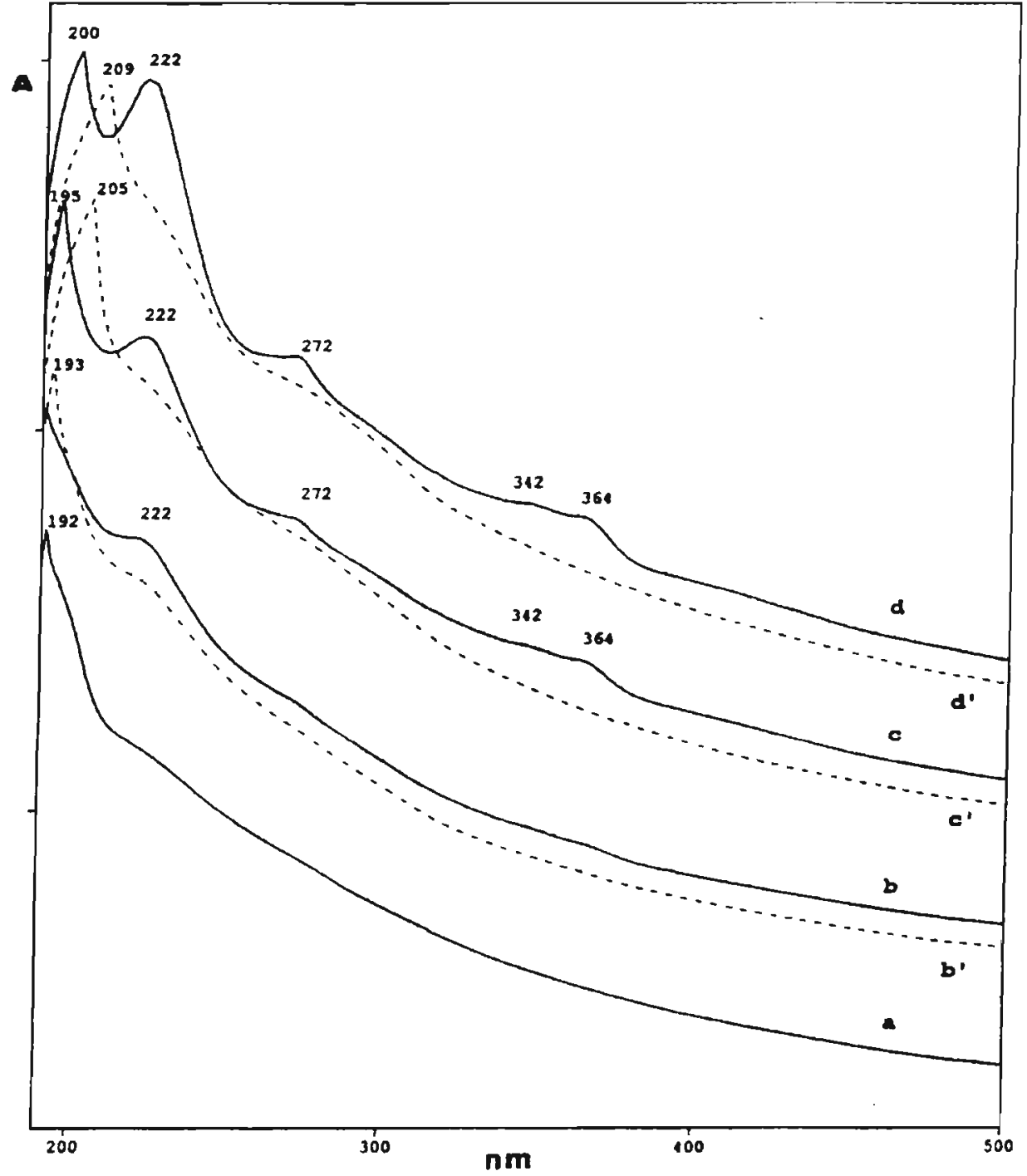

Figura 62: Espectros de absorção UV/visivel de filmes de P(VDF-TrFE) $70: 30$ (a) não irradiado, (b) irradiado por 5 min., (c) 10 min., (d) 20 min., $e$ após envelhecimento por um mês (linha tracejada): (b') 5 min., (c') 10 min., (d') $20 \mathrm{~min}$. 


\section{5- Calorimetria Exploratória Diferencial (DSC)}

As Figuras 63 e 64 registram, respectivamente, as curvas DSC para a $1^{\underline{a}}$ e $2^{\underline{a}}$ rampa de aquecimento do $\mathrm{P}(\mathrm{VDF}-\mathrm{TrFE})$ 70:30 não modificado e submetido às doses de 160 (1 h), 480 (3 h), 640 (4 h), 960 (6 h) e 1280 kGy $(8 \mathrm{~h})$, as quais se mostraram mais significativa para essa discussão.

A Tabela 1 sumariza, em sua totalidade, os dados obtidos através da curvas de DSC.

Tabela 1: Temperaturas on set $\left.{ }^{\rho} \mathrm{C}\right)$ referentes à fusão $\left(T_{m}\right)$ e Curie $\left(T_{C}\right)$, entalpias $\left(\Delta H_{m}\right)(\mathrm{J} / \mathrm{g})$ e entropias $\left(\Delta S_{m}\right)\left(x 10^{-2} \mathrm{~J} / \mathrm{K} . \mathrm{g}\right)$ para o P(VDF-TrFE)

70:30, não irradiado e irradiado por vários intervalos de tempo (h).

\begin{tabular}{|ccccccccc|}
\hline Tempo & \multicolumn{3}{c}{ Primeiro aquecimento } & \multicolumn{3}{c|}{ Segundo aquecimento } \\
& $\mathrm{T}_{\mathrm{C}}$ & $\mathrm{T}_{\mathrm{m}}$ & $\Delta \mathrm{H}_{\mathrm{m}}$ & $\Delta \mathrm{S}_{\mathrm{m}}$ & $\mathrm{T}_{\mathrm{C}}$ & $\mathrm{T}_{\mathrm{m}}$ & $\Delta \mathrm{H}_{\mathrm{m}}$ & $\Delta \mathrm{S}_{\mathrm{m}}$ \\
\hline 0 & 69 & 150 & 27,3 & 6,45 & 66 & 152 & 30,7 & 7,22 \\
1 & 46 & 140 & 24,3 & 5,88 & 59 & 126 & 19,1 & 4,78 \\
2 & 36 & 140 & 23,2 & 5,62 & 47 & 111 & 17,3 & 4,50 \\
3 & 38 & 130 & 16,4 & 4,07 & 33 & 96 & 11,8 & 3,20 \\
4 & & 117 & 12,3 & 3,15 & 31 & 90 & 8,6 & 2,37 \\
5 & & 102 & 11,1 & 2,96 & & 87 & 7,9 & 2,19 \\
6 & & 83 & 6,8 & 1,91 & & 77 & 5,8 & 1,66 \\
7 & & 80 & 5,0 & 1,42 & & 75 & 6,0 & 1,72 \\
8 & & 72 & 4,2 & 1,22 & & 55 & 8,0 & 1,83 \\
\hline
\end{tabular}




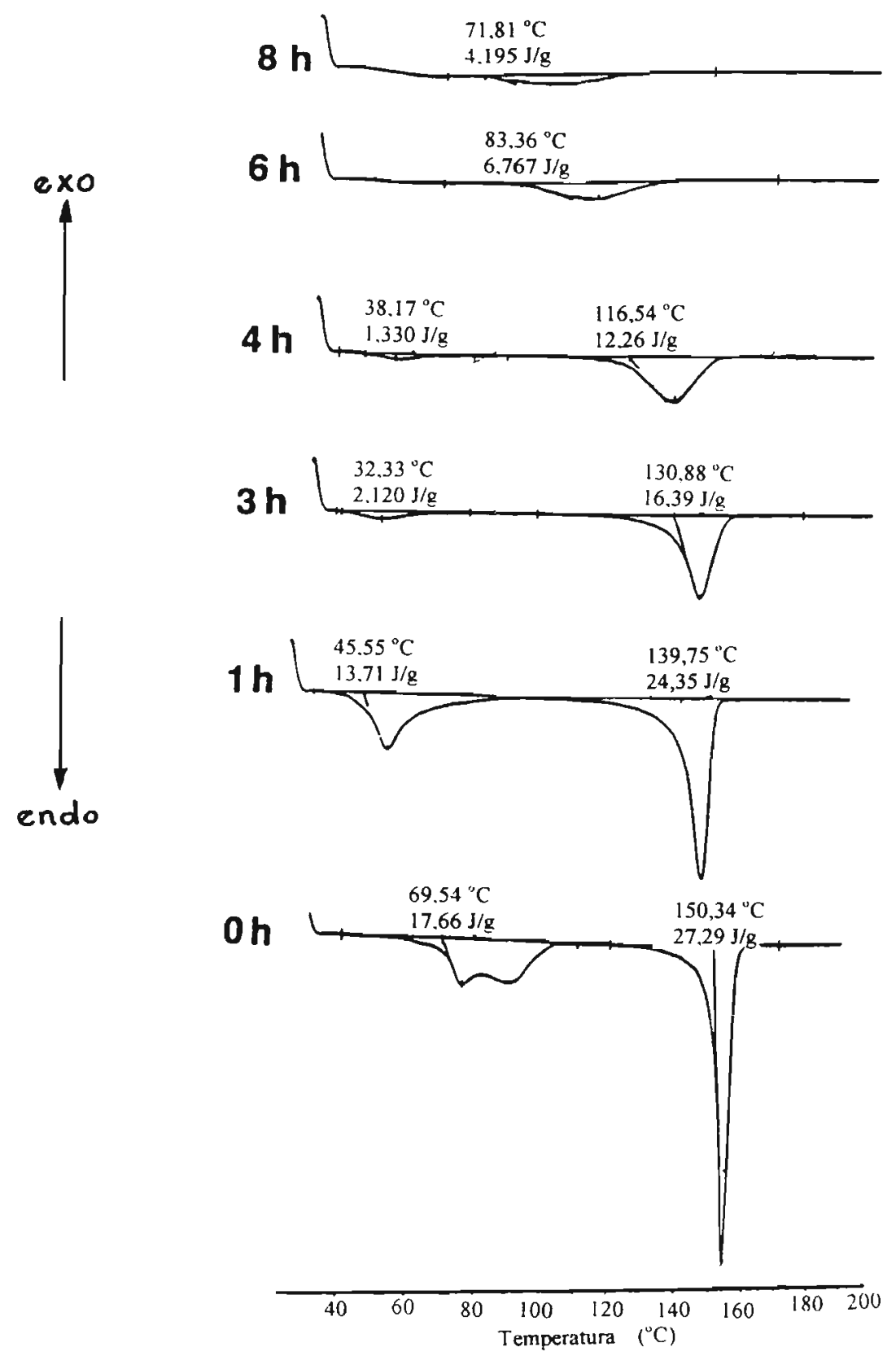

Figura 63: Curvas de DSC sob atmosfera dinâmica de $\mathrm{N}_{2}$ e razão de aquecimento de $10^{\circ} \mathrm{C} / \mathrm{min}$, para do $P(V D F-T r F E) 70: 30$ não irradiado e irradiado por 1, 3, 4, 6 e 8 horas. Primeiro aquecimento. 

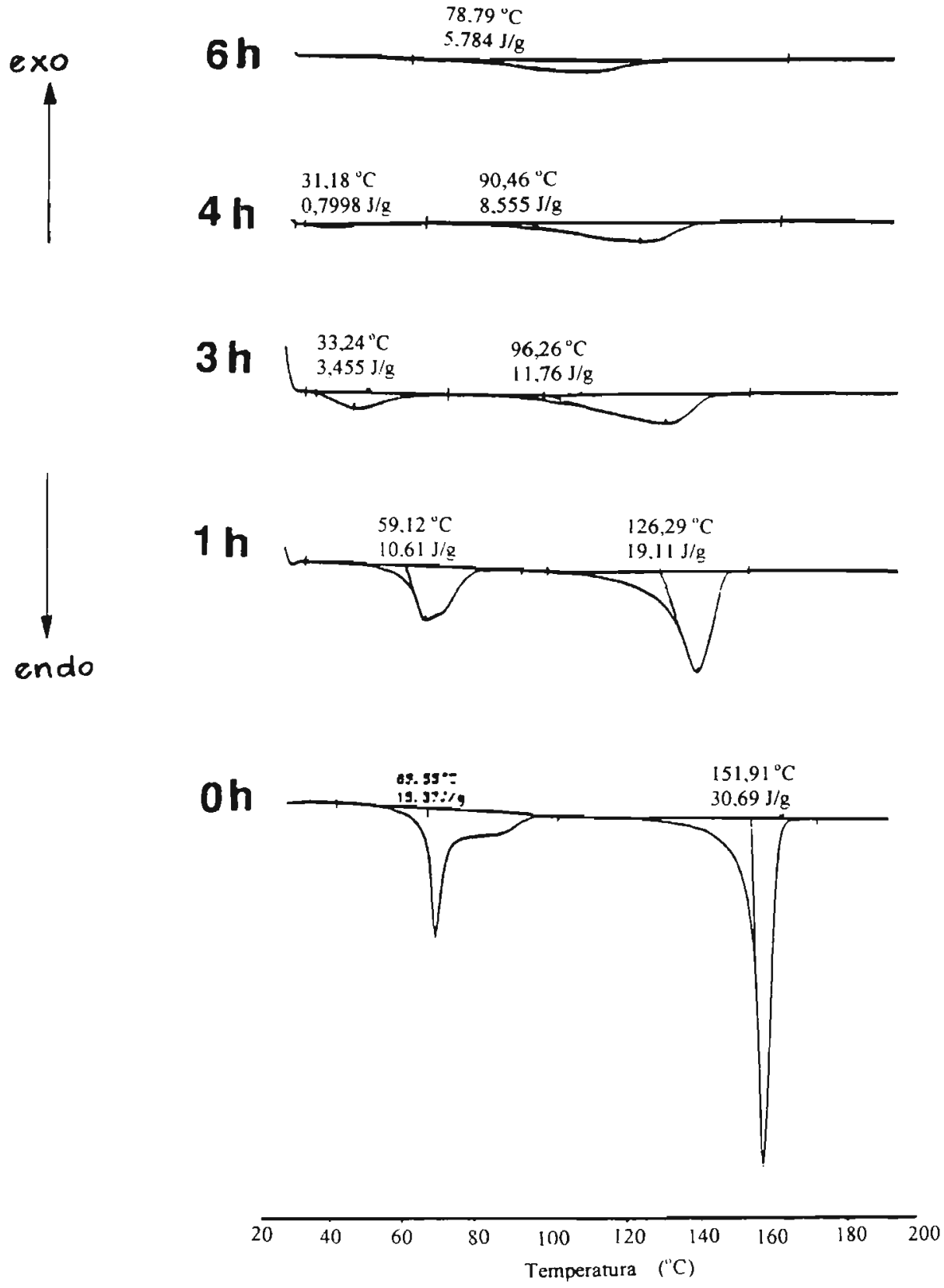

Figura 64: Curvas de DSC sob atmosfera dinâmica de $N_{2}$ e razão de aquecimento de $10^{\circ} \mathrm{C} / \mathrm{min}$, para o $P(V D F-\operatorname{TrFE}) 70: 30$ não irradiado e irradiado por 1, 3, 4, 6 e 8 horas. Segundo aquecimento. 
Em geral, no $1^{\underline{0}}$ aquecimento tem a função de eliminar a história térmica do material, sendo efetivamente consideradas apenas as rampas de resfriamento (cristalização) e $2^{\underline{\underline{o}}}$ aquecimento. Contudo, foram aqui consideradas na interpretação dos resultados, tanto a $1^{\underline{a}}$ quanto a $2^{\underline{\underline{a}}}$ rampa de aquecimento, uma vez que se deseja verificar as eventuais transições térmicas induzidas pela radiação, e admite-se que tal informação é registrada durante a $1^{\underline{\underline{a}}}$ rampa de aquecimento. De fato, sendo o P(VDF-TrFE) de natureza polimórfica, o processo de cristalização do material irá conduzi-lo, possivelmente, a fases cristalinas distintas.

Observa-se para o material não irradiado na Figura 63 a existência de duas regiões distintas, a primeira compreendida entre $60^{\circ}$ e $100^{\circ} \mathrm{C}$, evidenciada por picos endotérmicos sobrepostos, com um $\Delta H_{m}$ total correspondente a $17,7 \mathrm{~J} / \mathrm{g}$, e a segunda caracterizada por um único pico endotérmico em $154,2^{\circ} \mathrm{C}$ com $\Delta \mathrm{H}=27,3 \mathrm{~J} / \mathrm{g}$.

Yagi et al. [49], observaram dois picos endotérmicos nas curvas DSC de copolímeros com porcentagem molar de VDF variando de 54 a $90 \%$, aos quais denominaram temperatura de fusão $T_{m}$, maior $\Delta H$, e $\left(T_{m}{ }^{\prime}\right)$, de menor $د$ H. Não relataram, contudo, qualquer sobreposição de eventos de $T_{m}$ ', conforme observado para o filme não irradiado na região de $60^{\circ}$ a $100^{\circ} \mathrm{C}$ da Figura 63. $O$ valor de $T_{m}$ observado pelos referidos autores para um copolímero de teor de VDF semelhante (cerca de $70 \%$ ) coincide com aquele aqui observado. Os autores verificaram que $T_{m}$ e $T_{m}$ ' são independentes da taxa de aquecimento ou processo térmico ao qual a amostra tenha sido submetida anteriormente. Assim, concluem que o pico $\mathrm{T}_{\mathrm{m}}$ ' é característico da natureza do material, como uma transição térmica de estado sólido, fusão parcial da fase cristalina ou fusão de uma determinada fase cristalina do material coexistente com uma segunda fase. 
Os dados obtidos por Higashihata et al. [61], essencialmente, corroboram àqueles obtidos por Yagi et al. [49].

$\mathrm{O}$ material não irradiado foi submetido à $2^{\mathrm{a}}$ rampa de aquecimento, conforme a Figura 64, onde é possível observar duas regiões distintas. De forma semelhante à curva DSC do primeiro aquecimento, a região compreendida entre $50^{\circ}$ e $90^{\circ} \mathrm{C}$ apresenta picos sobrepostos, o primeiro bem definido e localizado em $68,3^{\circ} \mathrm{C}$, e na segunda região, um pico intenso e bem definido na temperatura de $156,6^{\circ} \mathrm{C}$. Pode-se atribuir a intensificação de um dos picos da primeira região $\left(\mathrm{T}_{\mathrm{m}}\right)$ à predominância de uma fase cristalina após o processo de resfriamento. É possível notar, também, um pequeno deslocamento, para valores maiores, da temperatura de fusão $\left(T_{m}\right)$ da $2^{\underline{a}}$ rampa em relação à $1^{\underline{a}}$, além de uma diminuição do valor de $\Delta H$ associado a $\mathrm{T}_{\mathrm{m}}$ ' para $15,4 \mathrm{~J} / \mathrm{g}$ e aumento do $\Delta \mathrm{H}$ correspondente a $\mathrm{T}_{\mathrm{m}}$ para $30,7 \mathrm{~J} / \mathrm{g}$. Tais fatos deixam evidente a modificação de estrutura cristalina quando ocorre a cristalização a partir do material fundido.

Teyssedre et al. [52] observaram a região compreendida entre $75^{\circ} \mathrm{e}$ $125^{\circ} \mathrm{C}$, para um copolímero $\mathrm{P}(\mathrm{VDF}-\mathrm{TrFE})$ na razão molar 65/35 (VDF/TrFE), desdobrada em dois componentes. Associaram tal região à temperatura de Curie, correspondente à transição da fase ferroelétrica para a fase paraelétrica, característica dos materiais ferroelétricos.

Em um trabalho anterior, Teyssedre et al. [95] haviam investigado a temperatura de Curie para o PVDF, não encontrando a transição ferroparaelética (fase $\beta \rightarrow$ fase $\alpha$ ) durante a curva de aquecimento, e nem mesmo a transição reversa (fase $\alpha \rightarrow$ fase $\beta$ ), pois o PVDF cristaliza espontaneamente na fase $\alpha$ (paraelétrica). Uma vez que o seu copolímero com TrFE cristaliza diretamente na fase ferroelétrica [36] a sobreposição 
observada deve corresponder, provavelmente a duas fases ferroelétricas distintas.

Duas hipóteses concorrem na explicação do desdobramento verificado na temperatura de Curie. Tashiro et al. [96] atribuem tal fato à existência de uma fase transiente entre as fases ferroelétrica e paraelétrica, a qual denominaram "fase resfriada". Moreira et al. [97] consideram a existência de dois tipos de fases ferroelétricas a baixa temperatura, diferindo na perfeição cristalina. Sugere-se assim, que a fase menos ordenada se transforme em fase paraelétrica a uma temperatura mais baixa do que a fase mais ordenada $[52,97]$. A segunda hipótese tem encontrado maior respaldo experimental na explicação da dupla transição (transição de Curie), observada no P(VDFTrFE) 70/30 não modificado [52].

Em vista da discussão acima, admitindo-se portanto a coexistência de duas fases ferroelétricas, é possível atribuir o primeiro evento térmico do copolímero não irradiado no $1^{\underline{0}}$ e $2^{\underline{Q}}$ aquecimentos (Figuras 63 e 64) a uma transição da fase ferroelétrica menos ordenada (fase A) para a fase paraelétrica (fase $\mathrm{P}$ ), e o segundo evento à transição da fase ferroelétrica mais ordenada (fase $\beta$ ) para a fase paraelétrica (fase $\mathrm{P}$ ). $\mathrm{O}$ terceiro evento corresponde à fusão da fase paraelétrica.

Observa-se também, pela comparação das Figuras 63 (não irradiado) e 64 (não irradiado), que durante o processo de resfriamento ocorre a predominante cristalização da fase ferroelétrica menos ordenada em detrimento daquela mais ordenada.

Durante a primeira rampa de aquecimento para o do $\mathrm{P}(\mathrm{VDF}-\mathrm{TrFE})$ submetido à dose de $160 \mathrm{kGy}$ (Figura-63), observa-se apenas dois picos endotérmicos sem a presença de qualquer desdobramento. A primeira transição, provavelmente a transição de Curie, ocorre em $52,7^{\circ} \mathrm{C}$ associada a 
um valor de $\Delta \mathrm{H}$ de $13,7 \mathrm{~J} / \mathrm{g}$, enquanto o segundo evento, fusão, ocorre em $146,2^{\circ} \mathrm{C}$ com $\Delta \mathrm{H}=24,35 \mathrm{~J} / \mathrm{g}$. Assim, a comparação desta curva com aquela do material não irradiado evidencia a diminuição das temperaturas de transição com a irradiação.

$\mathrm{O}$ abaixamento da temperatura de transição ferro-paraelétrica tem sido associada à diminuição dos cristalitos da fase ferroelétrica [52]. Tal fato pode estar relacionado à incorporação de defeitos na cadeia (cabeça-cabeça e cauda-cauda), entre as unidades de VDF ou TrFE.

Após o processo de cristalização observa-se um novo aumento da temperatura de Curie, associado a um novo desdobramento dessa transição, conforme a $2^{\text {a }}$ rampa de aquecimento (Figura 64). Ao mesmo tempo, o pico de fusão principal sofre um deslocamento para menor temperatura, atingindo $136,5^{\circ} \mathrm{C}$. Os valores de $\Delta \mathrm{H}$ associados a ambos os eventos são menores do que aqueles observados na $1^{\underline{a}}$ rampa de aquecimento, estando associados também ao grau de defeitos na cadeia.

$\mathrm{O}$ aumento e desdobramento da temperatura de Curie acima observado, indica ainda a coexistência de duas fases ferroelétricas, enquanto que a diminuição da temperatura de fusão pode estar associada a algum grau de modificação da fase cristalina predominante ou mesmo modificação química provocada pela radiação.

Com doses superiores de radiação, os resultados de DSC mostram a diminuição da área correspondente ao pico de fusão. Nota-se também o abaixamento da temperatura de transição $\left(T_{c}\right)$, perda da fase ferroelétrica, diminuição de $T_{m}$ e do grau de cristalinidade.

A coexistência de duas fases ferroelétricas abaixo da temperatura de Curie para o copolímero $\mathrm{P}(\mathrm{VDF}-\mathrm{TrFE})$ 70:30 foi anteriormente observada $[55,98,99,59]$ no aquecimento do material. 
Com base nos dados de difração de raios-X, Tashiro e Kobayashi [98] e Tanaka et al. [55] sugerem a coexistência de duas fases ferroeléticas abaixo da temperatura de Curie. Isso parece ocorrer somente para as composições 70:30 e 75:25, enquanto que as razões molares 60:40 e 80:20 apresentam uma única temperatura de transição $[99,100]$. 


\section{6- Análise Termogravimétrica (TGA)}

A figura 65 mostra as curvas $T G$ do $P(V D F-T r F E) ~ 70: 30$, não irradiado e irradiado por 5 e 8 horas. A amostra não irradiada apresenta uma curva TG com apenas uma transição de perda de massa ( $92 \%$ ) com uma temperatura inicial de decomposição de $486{ }^{\circ} \mathrm{C}$ e um resíduo de aproximadamente $8 \%$.

A amostra irradiada por 5 horas mostra uma curva TG com uma perda de massa de $\sim 82 \%$, temperatura inicial de decomposição de $447{ }^{\circ} \mathrm{C}$ e um resíduo de $18 \%$.

Com 8 horas de irradiação a amostra apresenta uma curva TG com aproximadamente $68 \%$, temperatura de decomposição igual a $419{ }^{\circ} \mathrm{C}$ e um resíduo de $\sim 32 \%$.

A dimuição da temperatura de decomposição pode estar relacionada à cisões das cadeias do polímero, e o aumento da quantidade de resíduo pode estar associado com a formação de ligações cruzadas entre as cadeias poliméricas [11].

A partir de medidas de massa molar do copolímero 60:40, da Cunha et al. [74] verificaram uma diminuição da massa molar e um aumento da fração insolúvel com o aumento da dose de irradiação, que estão associados com as cisões de cadeia e ligações cruzadas intermoleculares, respectivamente. 


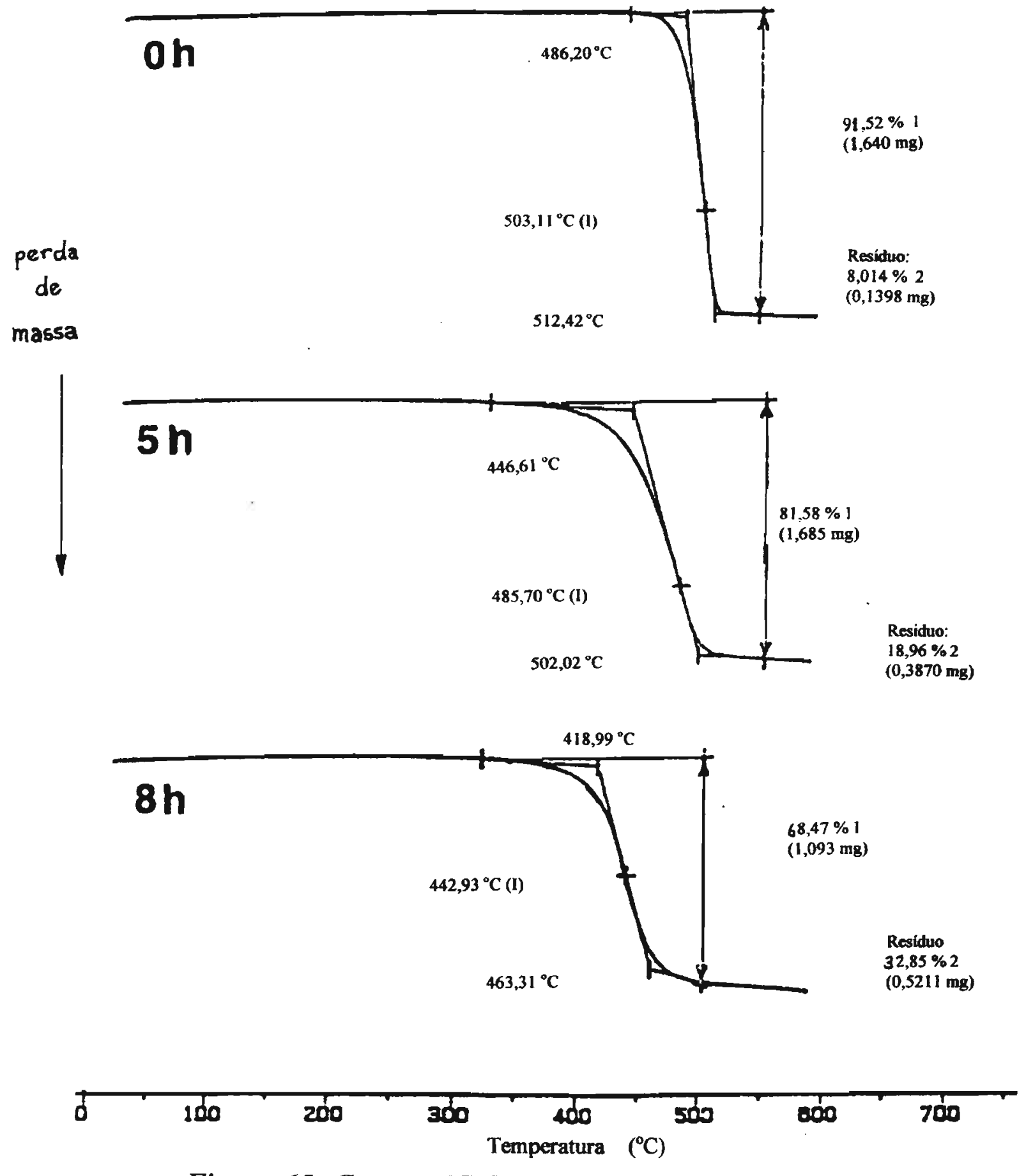

Figura 65: Curvas TG do P(VDF-TrFE) 70:30 não irradiado e irradiado por 5 e 8 horas, obtidos sob atmosfera dinâmica de $N_{2}$ e razão de aquecimento de $20^{\circ} \mathrm{C} / \mathrm{min}$. 


\section{Conclusões}

Os resultados de difração de raios-X mostram diminuição de intensidade do pico associado à fase cristalina $\beta$ com a dose de irradiação. $O$ mesmo se observa em relação ao alargamento desse pico. Os dados de raio-X mostram também aumento nas distâncias interplanares (diminuição do ângulo de Bragg) para os filmes irradiados a uma dose de $640 \mathrm{kGy}$. Esses resultados indicam uma transição da fase cristalina $\beta$ (ferroelétrica) para a fase paraelétrica induzida pela radiação-X. É importante notar que entre as doses de 480 e 640 kGy é visível a intensificação do único pico de difração, correspondente a fase paraelétrica. Isso representa um aumento dessa fase cristalina devido, provavelmente, ao reparo de defeitos dos cristalitos.

Os resultados de DSC mostram a diminuição da temperatura de Curie e da temperatura de fusão com o aumento da dose de irradiação. A diminuição dos valores de $\Delta H_{m}$ com a irradiação refletem a diminuição do grau de cristalinidade. A transição ferro-paraelétrica ocorre aproximadamente após 4 horas de irradiação (640 kGy). O copolímero não irradiado, a temperatura ambiente, mostra a coexistência de duas fases ferroelétricas (FA e Fß), que coalescem após uma hora de irradiação. As curvas da segunda corrida DSC mostram um aumento de intensidade do pico da fase ferroelétrica de temperatura mais baixa, provavelmente a fase A menos ordenada, devido à fusão e subsequente resfriamento da amostra.

Os resultados de TGA apresentam evidências do aumento de cisões de cadeia e ligações cruzadas intermoleculares com o tempo de irradiação.

Os espectros no infravermelho apresentam evidências de oxidação da amostra posterior a irradiação, através da formação de grupos carbonila. 
Apresenta também diminuição da intensidade de bandas associadas à conformação totalmente trans (fase $\beta$ ) que é uma evidência das mudanças conformacionais induzidas pelas radiações- $X$.

Os espectros Raman mostram um aumento na fluorescência com o aumento das doses de irradiação, provavelmente devido à formação de radicais livres gerados pela radiação-X. As duas bandas características da fase cristalina $\beta$ mostram drásticas mudanças de intensidade relativa com a dose de irradiação. Essas mudanças de intensidade alcançam um máximo a uma dose de $640 \mathrm{kGy}$, conforme o observado na difração de raios-X.

Os espectros UV-visível mostram a formação de duplas ligações no copolímero com aumento do tempo de irradiação, e evidências da formação de dienos e trienos ao longo das cadeias poliméricas. Mostram também a formação de cromóforos a partir dos radicais criados pela interação dos raiosX com o copolímero.

Um dos modelos que podem ser propostos para os efeitos da interação da radiação de alta energia com o copolímero, admite como principal evento a deidrofluoração e a conseqüente formação de duplas ligações (devido à formação de radicais secundários na cadeia) [70]. Dessa forma, a redução das interações intercadeia, resultante da eliminação de um elemento muito eletronegativo, permitiria a expansão do retículo cristalino (aumento da distância interplanar verificada na difração de raios-X), além das mudanças conformacionais introduzidas pela inserção de insaturações na cadeia. Tal fato encontra-se de acordo com a transição de fases proposta. Após a expansão do retículo, o aumento do volume livre na região cristalina permitiria então a difusão e recombinação de fragmentos da cadeia originários dos rompimentos provocados pela radiação (radicais primários), que após 
uma determinada dose levariam a um máximo grau de reparos de defeitos nas regiões cristalinas, aumentando assim a cristalinidade do material. A etapa seguinte, aumentando-se a dose de radiação, levaria à formação de ligações cruzadas e resultaria, finalmente, na obtenção de uma estrutura amorfa, como verificada anteriormente para outros polímeros fluorados [101].

Abrem-se aqui algumas possíveis vertentes para a investigação deste copolímero. Assim, no aspecto estrutural, uma melhor elucidação do modelo de transição de fases poderia ser fornecida por um monitoramento, pré e pós irradiação, dos eventos ocorridos via AFM (microscopia de força atômica) ou STM (microscopia de tunelamento por varredura).

Os efeitos conformacionais da cadeia previstos no modelo, poderiam ser investigados através da ressonância magnética nuclear de ${ }^{13} \mathrm{C},{ }^{1} \mathrm{H}$ ou ${ }^{19} \mathrm{~F}$.

De forma auxiliar, a espectroscopia EPR permitiria a deteç̧ão mais segura das espécies formadas, contribuindo à elucidação do mecanismo.

Finalmente, um interessante estudo vibracional, através da microscopia Raman em função da temperatura, e mesmo da dose de irradiação, poderia ser realizado. Neste estudo, a correlação entre as bandas Raman e as fases cristalinas poderia se tornar bastante evidente, além da possibilidade de verificação de histerese com o efeito de temperatura.

Este trabalho procura mostrar a complementariedade entre as informaçoes obtidas por diferentes técnicas fisico-químicas, para um melhor entendimento da interação da radiação de alta energia e do copolímero P(VDF-TrFE) 70:30. 

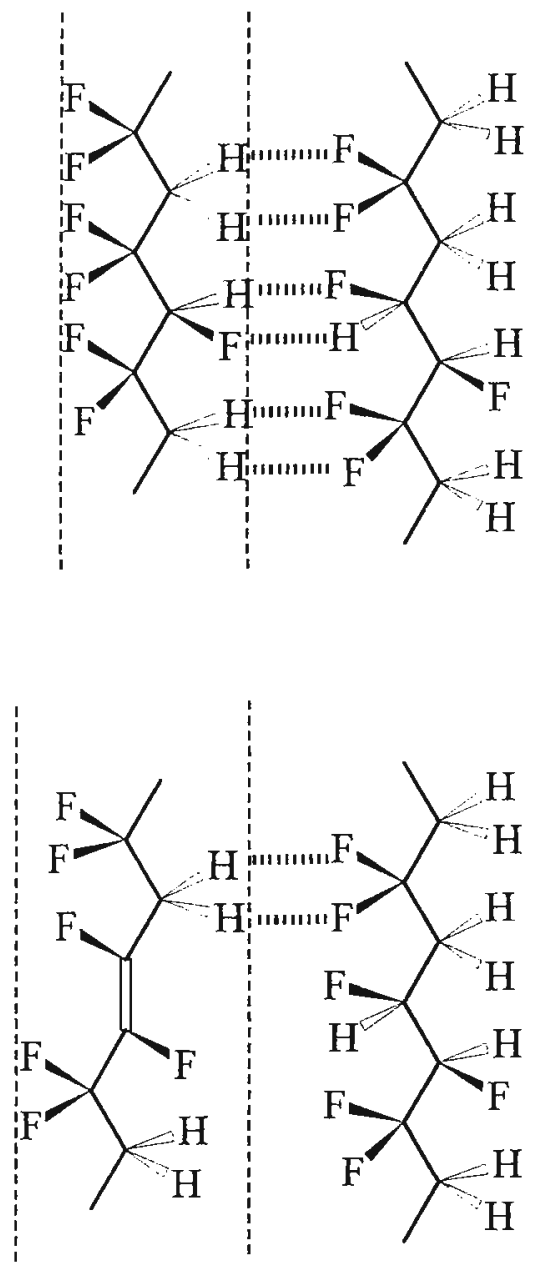

Figura 66: Expansão do retículo devido à formação de insaturações nas cadeias poliméricas. 


\section{Bibliografia}

1. H. Staudinger, Berichte, 1073 (1920).

2. Y. Rosenberg, A. Siegmann, M. Narkis e S. Shkolnik, J. Appl. Polym. Sci., 45, 783 (1992).

3. W. Bürger, K. Lunkwitz, G. Pompe, A. Petr e D. Jehnichen, J. Appl. Polym. Sci., 48, 1973 (1993).

4. K. Murakami in "Aspects of Degradation and Stabilization of Polymers", H. H. G. Jellinek (editor), Elsevier Scientific Publishing Company (1978).

5. E. Reichmanis e J. H. O'Donnell, “The Effects of Radiation on High Technology Polymers". In J. H. O'Donnell (editor) ACS Symp. Ser., 381 (1989).

6. W. Schnabel, "Polymer Degradation - Principles and Practical Applications". Hanser, München (1981).

7. N. H. Takata, "Caracterização das Modificações Estruturais Induzidas por Raios X em Politetrafuoretileno (PTFE)", Dissertação de Mestrado, Instituto de Química - USP, São Paulo (1995).

8. L.G.C. dos Santos, "Degradação de Poliacrilonitrila por Raios-X", Dissertação de Mestrado, Instituto de Química - USP, São Paulo (1992).

9. M. E. Sbampato, "Degradação de Poli(cloreto de vinila) por Raios-X”, Dissertação de Mestrado, Instituto de Química - USP, São Paulo (1984).

10. Y. Kawano e S. Soares, Polym. Degr. Stab., 35, 99 (1992).

11. H. A. C. Gil, R. M. Faria e Y. Kawano, Polym. Degr. Stab., in press (1998). 
12. F. W. Billmeyer, Jr., "Textbook of Polymer Science", $3^{\text {rd }}$ edition, John Wiley \& Sons, Inc., New York (1984).

13. W. D. Callister, Jr., "Materials Science and Engineering - An Introdution", $3^{\text {rd }}$ edition, John Wiley \& Sons, Inc., New York (1994).

14. A. A. A. de Queiróz, E. R. Barrak, H. A. C. Gil e O. Z. Higa, J. Biomater. Sci. Polym. Edn., 8 (9), 667 (1997).

15. A. A. A. de Queiroz, "Obtenção de Copolímeros de Enxerto Via Radiação Ionizante, Caracterização e Estudo de suas Propriedades Hemocompatíveis". Tese de Doutoramento, IPEN - CENEN - SP, São Paulo (1993).

16. F. D. Egitto, Pure Appl. Chem., 62 (9), 1699 (1990).

17. Giroux e Cooper, J. Appl. Polym. Sci., 43 (1), 145 (1991).

18. F. Arefi, P. Montazer-Rahmati, V. Andre e J. Amouroux, J. Appl. Polym. Sci.: Appl. Polym. Symposiuum, 46, 33 (1990).

19. Y. Homose, T. Ohaku, H. Chuma, S. Okazaki, T. Saruta, M. Masui e M. Takeuchi, J. Appl. Polym. Sci.: Appl. Polym. Symposium, 46, 153 (1990).

20. N. Inagaki, S. Tasaka e K. Hibi, J. Polym. Sci. Part A: Polym. Chem., 30 (7), 1425 (1992).

21. N. Inagaki, S. Tasaka e M. Imai, J. Appl. Polym. Sci., 48, 1963 (1993).

22. N. Inagaki, S. Tasaka, J. Ohkubo e H. Kawai, J. Appl. Polym. Sci.: Appl. Polym. Symposium, 46, 399 (1990).

23. D. C. Schram, G. M. W. Kroesen e J. J. Beulens, J. Appl. Polym. Sci.: Appl. Polym. Symposium, 46, 1 (1990).

24. J. Wang, D. Feng, H. Wang, M. Rembold e F. Thommen, J. Appl. Polym. Sci., 50, 585 (1993). 
25. B. B. Baker e D. J. Kasprzak, Polym. Degr. Stab., 42, 181 (1993).

26. J. L. Koenig, "Spectroscopy of Polymers", ACS Professional Reference Book, New York (1992).

27. D. O. Hummel (editor), "Proceedings of the $5^{\text {th }}$ European Symposium on Polymer Spectroscopy", Verlag Chemie, New York (1979).

28. F. Rånby e J. F. Rabek, “ESR Spectroscopy in Polymer Research”, Springer-Verlag, Berlin (1977).

29. J. L. Koenig, "Chemical Microstructure of Polymer Chains", John Wiley \& Sons, Inc., New York (1980).

30. H. W. Siesler e K. Holland-Moritz, "Infrared and Raman Spectroscopy of Polymers", Marcell Dekker, New York (1980).

31. H. Ishida (editor), "Symposium on Fourier Transform Infrared Characterization of Polymers", Plenum Press, New York (1987).

32. O. Sala, "Fundamentos da Espectroscopia Raman e no Infravermelho", Editora da Universidade Estadual Paulista, São Paulo (1996).

33. H. G. M. Edwards, A. F. Johnson e I. R. Lewis, J. Raman Spectr., 24, 475 (1993).

34. D. I. Bower e W. F. Maddams, "The Vibrational Spectroscopy of Polymers", Cambridge University Press, Cambridge (1989).

35. P. W. Atkins, "Physical Chemistry", 5" ed., Oxford University Press, Oxford (1994).

36. J. A. Day, E. L. V. Lewis e G. R. Davies, Polymer, 33 (8), 1571 (1992).

37. J. K. Krüger, M. Prechtl, J. L. Wittmann, S. Meyer, J. F. Legrand e G. D’Asseza, J. Polym. Sci. Part B: Polym. Phys., 31 (5), 505 (1993).

38. C. Herkt-Maetzky, K. Moser e J. Gessner, J. Appl. Polym. Sci.: Appl. Polym. Symposium, 48, 417 (1991). 
39. A. E. Feiring, J. F. Imbalzano e D. L. Kerbow, Trends in Polym. Sci., 2 (1), 26 (1994).

40. A. J. Lovinger, Science 220 (4602), 1115 (1983).

41. H. Kawai, Jpn. J. Appl. Phys., 8, 975 (1969).

42. G. R. S. Slemon, "Equipamentos Magnetoelétricos: Transdutores, Transformadores e Máquinas", Rio de Janeiro, Livros Técnicos e Científicos; São Paulo, Ed. da Universidade de São Paulo (1974).

43. M. M. Costa e J. A. Giacometti, Appl. Phys. Lett., 62 (10), 1091 (1993).

44. A. J. Lovinger, "Developments in Crystalline Polymers-1", D. C. Basset (editor), Applied Science Publishers, London (1982).

45. T. Hattori, M. Kanaoka e H. Ohigashi, J. Appl. Phys., 79 (4), 2016 (1996).

46. L. Jie, C. Baur, B. Koslowski e K. Dransfeld, Physica B, 204 (4), 318 (1995).

47. J. Su, Z, Y. Ma, J. I. Scheinbeim e B. A. Newman, , J. Polym. Sci.: Part B: Polym. Phys., 33, 85 (1995).

48. A. C. Jayasuriya, S. Tasaka, M. Ohtani e N. Inagaki, J. Appl. Phys., 79 (2), 1017 (1996).

49. T. Yagi, M. Tatemoto e J. Sako, Polymer J., 12 (4), 209 (1980).

50. Y. Tajitsu, H. Ogura, A. Chiba e T. Furukawa, Jap. J. Appl. Phys., 26 (4), 554 (1987).

51. H. Mizuno e Y. Nagano, J. Chem. Phys., 96 (4), 3234 (1992).

52. G. Teyssedre, A. Bernes e C. Lacabane, J. Polym. Sci. Part B: Polym. Phys., 33, 879 (1995).

53. A. Bune, S. Ducharme, V. Fridkin, , L. Blinov, S. Palto, N. Petukhova e S Yudin, Appl. Phys. Lett., 67 (26), 3975 (1995). 
54. N. Alves, "Estudo da Polarização Ferroelétrica no Copolímero P(VDFTrFE)" Tese de Doutorado, Instituto de Física e Química de São Carlos USP, São Carlos (1992).

55. H. Tanaka, H. Yukawa e T. Nishi, Macromolecules, 21, 2469 (1988).

56. S. Ikeda e H. Suda, Phys. Rev. E, 56 (3), 3231 (1997).

57. J. Choi, P. A. Dowben, S. Pebley, A. V. Bune, S. Ducharme, V. M. Fridkin, S. P. Palto e N. Petukhova, Phys. Rev. Lett., 80 (6), 1328 (1998).

58. A. V. Bune, V. M. Fridkin, S. Ducharme, L. M. Blinov, S. P. Palto, A. V. Sorokin, S. G. Yudin e A. Zlatkin, Nature, 391, 874 (1998).

59. R. Gregorio Jr., M. M. Botta, , J. Polym. Sci.: Part B: Polym. Phys., 36, 403 (1998).

60. M. C. Christie, J. I. Scheinbeim e B. A. Newman, J. Polym. Sci.: Part B: Polym. Phys., 35, 2671 (1997).

61. H. Higashihata, J. Sako e T. Yagi, Ferroelectrics, 32, 85 (1981).

62. K. Koga e H. Ohigashi, Jap. J. Appl. Phys., 59 (6), 2142 (1986).

63. K. Omote, H. Ohigashi e K, Koga, J. Appl. Phys., 81 (6), 2760 (1997).

64. P. Bauer, L. Audaire, J. J. Simonne e F. Bauer, J. Physique III, 7, 1209 (1997).

65. A. Logarezzi, "Degradação de Membranas de Celulose Regenerada por Irradiação de Raios-X”, Tese de Doutorado, Instituto de Química - USP, São Paulo (1991).

66. J. C. D. Lopes, P. R. Olivato, P. A. M. Vasquez e Y. Hase, Anais da Associação Brasileira de Química, 41, 87 (1992).

67. ASTM - norma D 3417 - 83. 
68. C. Fischer, J. K. Krüger, K. P. Bohn, U. Vogt, J. Schreiber, R. Jiménez, D. Wolf, J. F. Legrand, P. Alnot e B. Servet, J. Polym. Sci.: Part B: Polym. Phys., 33, 237 (1995).

69. F. Macchi e B Daudin, Nucl. Instr. and Meth., B 46, 324 (1990).

70. D. Schlößer e A. Le Moël, Nucl. Instr. and Meth., B 107, 313 (1996).

71. A. Odajima, Y. Takase, T. Ishibashi e K. Yuasa, Proc. $5^{\text {th }}$ Intern. Symp. Electrets, 642, Heidelberg (1985).

72. J. Ohwaki, H. Yamazaki e T. Kitayama, J. Appl. Phys., 52 (11), 6856 (1981).

73. E. Petersohn, N. Betz e A. Le Moël, Nucl. Instr. and Meth., B 105, 267 (1995).

74. H. N. da Cunha, L. H. C. Mattoso e R. M. Faria, J. Polym. Sci. Part B: Polym. Phys., 35 (8), 1201 (1997).

75. H. H Perkampus, Encyclopedia of Physical Science and Technology, 10, 355 (1987).

76. C. Q. Yang, R. R. Bresee e W. G. Fateley, Appl. Spectr., 41 (5), 889 (1987).

77. C. Q. Yang, Appl. Spectr., 45 (1) 102 (1991)

78. M. Kobayashi, K. Tashiro e H. Tadokoro, Macromolecules, 8 (2), 158 (1975).

79. M. A. Bachmann e J. L. Koenig, J. Chem. Phys., 74 (10), 5896 (1981).

80. A. H. Nielsen, T. G. Burke, P. J. H. Woltz e E. A. Jones, J. Chem. Phys., 20, 596 (1952).

81. L. J. Bellamy, "The Infrared Spectra of Complex Molecules", $3^{\underline{a}}$ edição, Chapman and Hall, London (1975). 
82. M. Hagiwara, G. Ellinghorst e D. O. Hummel, Makromol. Chem.,178, 2913 (1977).

83. G. Cortili e G. Zerbi, Spectroc. Acta, 23 A, 285 (1967).

84. F. J. Boerio e J. L Koenig, J. Polym. Sci Part A-2, 7, 1489 (1969).

85. G. Xue, Y. Wang, S. Liu, Y. T. Liao, Macromolecules, 28, 3476 (1995).

86. K. Hayashi, H. Tsubakihara e U. Kubo, Jpn. J. Appl. Phys., 36, 1176 (1997).

87. A. V. Prasad e R. P. Singh, Pure Appl. Chem., A33 (1) 91 (1996).

88. R. M. Silverstein, G. C. Bassler e T. C. Morril, "Identificação Espectrométrica de Compostos Orgânicos", 3ª edição, Ed. Guanabara, Rio de Janeiro, 1979.

89. J. C. Rodríguez-Cabello, J. C. Merino, J. M. Pastor, U. Hoffmann, S. Okretic, H. W. Siesler, Macromol. Chem. Phys., 196, 815 (1995).

90. C. Castiglioni, M. Del Zoppo e G. Zerbi, J. Raman Spectrosc., 24, 485 (1993).

91. Z. Iqbal e E. Weidekamm, in "Vibrational Spectroscopy of Phase Transitions", Z. Iqbal e F. J. Owens (editores), Academic Press, Inc., Orlando (1984).

92. P. Sykes, "Guia de Mecanismos da Química Orgânica", Universidade Nova de Lisboa, Lisboa (1989).

93. N. A. Weir em "Developments in Polymer Degradation", Editor: N. Grassie, Elsevier Applied Science, 7, 193 (1987).

94. B. Daudin, M. Dubus e J. F. Legrand, J. Appl. Phys., 62, 994 (1987).

95. G. Teyssedre, A. Bernes e C. Lacabanne, J. Thermal Analysis, 40, 711 (1993). 
96. K. Tashiro, K. Takano, M. Kobayashi, Y. Chatani e H. Tadokoro, Ferroelectrics, 57, 297 (1984).

97. R. L. Moreira, P. Saint Gregorie, M. Lopez e M. Latour, J. Polym. Sci.: Polym. Phys. Ed., 27, 709 (1989).

98. K. Tashiro e M. Kobayashi, Japan J. Appl. Phys., 24, 873 (1985).

99. R. M. Faria, J. M. G. Neto e O. N. Oliveira, J. Phys. D: Appl. Phys., 27, 611 (1994).

100.J. S. Green, B. L. Farmer e J. F. Rabolt, , J. Appl. Phys., 77 (8), 3766 (1995).

101. P. Musumeci, L. Calcagno, R. Percolla e G. Foti, J. Appl. Phys., 77 (8), 3766 (1995). 